Ethics, Law and Social Justice Kiyoung Kim

Professor of Law and Governance

The Research Institute

Chosun University 


\section{Ethics and Responsibility}

\section{Introduction}

Ethics and responsibility would be a vexing or awesome topic that the contemporary citizen more likely wishes to avoid to giving his or her views or opinions. That is perhaps because the society transforms rapidly and turns to become more diverse from the past decades. These concepts, on the other, comes not in the ancient or middle era classics, but from the near modern context in $18^{\text {th }}$ England and French (Cooper, T., 2012). In dealing with the nature and relationship between the two concepts, another notion of morality also comes into a comparative context. Morality, if often interchangeably used with the ethics, could be seen in some differences that ethics is a dimension one step removed from action. So we used to preach our dependents or subjects to conform their conduct to the kind of moral demand, "Exert your best to the interest of nations or society," "Practice a love and humiliation with brothers, sisters and neighbors," "Never be drunken while driving," "Do not commit an adultery or do not steal other's property," and the likes. Law, then, would be a minimal of morality which prescribes a prohibited conduct and corresponding criminal sanctions proportionally with the gravity of culpability or social harms (2012). Those concepts might share a common element in a great extent, but could be made distinguished in some of subtleties.

\section{US Government on Review}

One organization comes readily into my mind since it is now engaged in serious problems involving the international human rights, morality, war and politics. The US government facing an issue of Syria tragedy and use of fatal chemical weapons is illustrative. The middle east nations have long been a region of world attention with a political instability, terrorism, antipathy and confrontation and occasional carnage of wars. Most recently Saddam Hussein was held a war criminal to be executed from his unlawful invasion of Kuwait, and Bin Laden also perished from the American justice about his terrorism. Kaddafi also was driven to disappear for his dictatorship and undemocratic cruelty, and many others including an Egyptian consequence of turmoil and radical transformation in 2013. Syria has been charted notorious to perpetrate a years of genocide and persecution which, in years through, awakened the global minds of peace and humanity. The organization, US government, is largely considered a quasi-police regime for the international peace and human rights, which constitute two sublime ideals that the current international community upholds. It operates basically within the US constitution and international laws, but the nature of business possesses a high extent of international politics and diplomacy. Notably, they have to legitimate their sanction or war of alleged justice from UN or other ground of international laws. As the US acts in some ultimate supremacy of UN Security Council in this area of controversy, the right to veto entertained by five major permanent member states in the Council is generally determinative although some grey occasions of legitimacy could be raised and disputed by scholars. Domestically, the issue has ambiguities also involving a constitutional authority waging a war between the Congress and President. It most always tends to avoid a judicial review in its substance and merits since the judiciary often abstains on the ground of political question doctrine. Most practically, the organization has to focus on the attitudes or collaboration of key allies, seriousness of problem, and international atmosphere, risks involved, and the post-war consequences. 


\section{Ethics and Responsibility with the Neighboring Concepts}

Across the four concepts mentioned above, i.e., ethics, responsibility, morality and law, we can verify instantly that those share a common ingredient, to say, public value or humanity, religious and traditional beliefs, social custom, exposure and common experience, shared passion, standard of reason in the prevailing context of society and some of learned interplay or receipt among the gross base of people or organizational members. If we consider a morality were to be prime to penetrate the whole of four, we may have a basic dichotomy between the deontological and teleological paradigms of moral assertion (2012). The deontological version of morality would possess a more quality of absolutism on a desired human conduct and behavior. That likely defines a context of each individual in the face of God or prevailing custom, and meditates through the flesh and spiritual ideals. The deontological approach, thus, often induces one unavoidable solution and prefers a consummation of ideals without alternatives or options. This less likely allows the circumstances or relativistic nature of moral issues to operate in guiding the conduct of individual or organization. It would, in general sense, only be possible in a limited scope of inalienable values, more likely be pertinent with an individual than organization, more religious than social in apprehension, less likely to compromise and so on. The teleological frame of morality often presupposes a utilitarian concept, hence, more likely relativistic, circumstantial, interactive or communicative, reciprocal, evolutionary, and etc. It pursues a greatest good in the greatest number, and has quality to compromise and improve (2012). Then, this dichotomy, in some sense, could be seen to correspond with two perceptions of J.S. Mill on liberty, to say, hedonic nature of pleasure and higher pleasure. In the context of organization and public administration, the teleological concept of morality contributed profoundly to the ethics of bureaucracy and responsibility of public employees.

An exploration of ethics would be in two ways, which are descriptive of the process how the individual or organization applies their ethical concept to their conduct and organizational decision making (2012). The other would be normative so that the leaders or decision makers are compelled or practically demanded to abide by and uphold a certain set of values, job requirement, organizational culture and workplace democracy.

\section{Some Thoughts on Their Relationships}

From the above, we can derive several points of relationship between the ethics and responsibility.

First, the ethics are presumed on some of societal or organizational context while the responsibility is affiliated with a role, discipline, or sanction and particularized form of realized ethics (Laureate Education Inc., 2013). Without the concept of role or responsibility, the ethics would be practically small thing to be only instructive and inculcating. The ethics are generated and continue or evolve in interplay with the system, process, culture, intelligence and rationale or reason, which, if in a specific context, would be prevailing and governing if some lesser extent of coercion and compulsion than law. Hence they are more objective and persistent on the given society and organizations, but can conflict among each other if deviated from a specific sphere. For example, the ethics between the interested nations about a Syrian incident would not be same or even conflict about the phenomenon and governing ethics. On other case, we may see a 
conflict of ethics between the justice department and Mafia organization. Given that a Huntington's forecast on the clash of culture denotes as a most factor in the contemporary world politics, the conflict of ethics would be more bureaucratic or organizational in connotation and mid-colored between the law and culture. This implies that the ethics could be more specific, more organized and tangible in recognition and apprehension of the concerned, more operationalized in action, convincing, and substantial or comprehensive, which is other than culture, but might be lesser than law. This implies that the ethics would be more readily applied to the concept of responsibility, and offers the basis to pursue a responsibility other than culture (The Internet Encyclopedia of Philosophy: Ethics, 2013). Given this attribute, the US government would be more properly conceived in view of ethics and as one of organization rather than the nation or state, which lacks the kind of absolute legitimacy unlike the domestic politics (2013). If we say culture, that would mean a kind of retreat or high of conceptual drawback because of its rigidities and irreconcilable nature at basics. On the other hand, more formalistic approach from the normative nature or international law, that would lack an agility or strategic aspect to secure a peace or human rights. This conception would be practically less wrong if we guess on a more likelihood that President Obama and his national security council would consume much of his time on, inter alia, strategic slides or projections, action or time plan, involved stakeholders than the books describing the cultural differences or historical antipathy as well as than the UN chapter, constitution or statutes.

\section{Conclusion: Application of the Concepts}

Then, the ethics US government has to identify and respect would not be new in a vast context of established sensibilities or understanding. As a quasi-police role state in the world, we could be conventional and less skeptical of what decision US government has to make and act. Perhaps I would not be incorrect to label the US a quasi-police role state if bipolarity or multi-polarity would be respectfully suggested by the scholarly circle of international politics. That would be dissimilar with the late 1990's and early millennium years, that the ethics or responsibility from a war and the military operation, in its process, could also not be the same. Obviously, the President and his council members would assume a divergent and complicated context of cooperation and collaboration if Russia vetoed a military operation. UK, traditionally a key ally in the international peace keeping operation, denied a ready collaboration unless any sufficient evidence are to be gathered to support the legitimacy of action by further steps of UN. Then the ethical nature of this issue might turn to be more likely a morality dispute which would be less organized and requires a solitude of basic beliefs (Laureate Education, Inc., 2008). This aspect shows a dynamism or more circumstantial nature of ethics than law or morality, which would be organizational or bureaucratic than the state or religion. The responsibility may be viewed in two spheres, i.e., objective and subjective (Cooper, T., 2012). The ethical administrators have a deep awareness of values, beliefs, traditions, norms and standards, and specific context of organizational goals and democratic virtues. They are conforming to the ethics of organization and do not breach it, which flavors in any given or objective context of system and interaction on ethics. When we consider the subjective responsibility on ethics, we often require them to exercise his best wisdom and inner process to reach some specific decision in the belief to uphold the ethics. Hence, responsibility seeks to unravel the specific application of ethics and can be viewed as enhanced and particularized form of ethics to ensure a process reengineering and vitality 
or morality of organizational performance. Given its political nature of issue, the responsibility of President and his cabinet or council members also largely are political. Hence, unethical decision, which would perhaps be to undermine the set of values or democratic virtues, realistic lesson from the past, general conviction of American people, and amicability of international community, might bring a loss of next election, domestic reaction in an acid criticism and international disrepute of American prestige.

\section{References}

Laureate Education Inc. (2013). Course Preview and Course Introduction :Ethics and Social Justice.

Cooper, T. (2012). The Responsible Administrator. San Francisco, CA: John Wiley \& Sons.

Laureate Education, Inc. (2008). Ethics and social justice. Baltimore: Author.

"Philosophical Roots" with Amanda Baker (approximately 11 minutes).

The Internet Encyclopedia of Philosophy: Ethics. Retrieved Sep. 2, 2013 from http://www.iep.utm.edu/ethics/.

The Internet Encyclopedia of Philosophy: Responsibility. Retrieved Sep. 2, 2013 from http://www.iep.utm.edu/responsi/. 


\section{Some Thoughts on the Morality and Ethics}

\section{The Concepts, their Quality and Connection}

Morality is generally defined as a code of conduct as the guide for an action or conduct, which would be formed, upheld, and testified by any particular society or social groups (Stanford Encyclopedia of Philosophy: Morality, 2013). In comparison, ethics is often discussed about the ways of desired state for an agent or being where he or it could thrive or rest in pleasure, philia, good character and good will (Stanford Encyclopedia of Philosophy: Ethics, 2013). Ethics, therefore, may be approached in our usual contact, say, friendship. Ethical conduct or behavior often leads to a friendship in which an individual would consider the factors, say, usefulness, good moral character or pleasure in making a friend. For Aristotle's, a friend could not be many, but small in number since the true friendship could only be possible by protraction of lived experiences and sharing. Hence, the ethics often can be more friendly engrafted with the discourse of leadership and organization. Morality often is said of a minimal of law, and this description also could be true between the ethics and morality. Hence, morality offers a basic ingredient of ethics that the immoral leaders would never be received as an ethical leader. Ethics, however, generally requires something more in addition to the moral requirements (2013). Morality would repudiate an organicism generally that the reason, religion, tradition and social custom are a principal source to found the elements of morality. Ethics, therefore, concerns a relationship, interactive dimension, and constructive pleasure in sharing and existence. Morality would pursue a human aspect leading to some of inviolable code of conduct, and often be conceived to cover a general base of people within the society.

That leads to the difference that morality would be more friendly with the politics and citizenry while the ethics would be more linked with the bureaucracy and various forms of organization. This would bring that the scope of influence would differ. Morality would be seen as more plenary and influence in a larger scope as in the case of Kantian universalism or J.S. Mill's essence of civilized liberty. However, the conflict, at least a differing perception about the morality, is some of usual phenomenon as we see in the Oriental and Occidental virtues. For example, Good Samaritan law dictates the moral obligation, later developed into the principle of case law, that nobody betrays the nature of order, hence morality in our concern, even if we does not offer a rescue effort for the person in predicament. Once he is involved in the rescue activities, the duty is created to tender any best reasonable way to save him or her from the danger and perils. Oriental morality, as propounded by the Saint as named Mencius, goes otherwise that one is intuitively driven and morally demanded to rescue a drowning child. Other illustrations about a different concept of morality would span widely with the Muslim, Christian, Quakers, homosexuals, Buddhist adherents, and even between the socialists and liberalists (Stanford Encyclopedia of Philosophy: Morality, 2013). In this purview of subtlety about the unversalization and sectarianization, morality could not be said definitely to enjoy a larger scope of respect than the ethics. A morality often phases in the dimension, which is fundamental and basic, and that possesses the quality to expand and even coerce. The typical contrast as perceived by Roman rulers between the citizens of Rome and barbarians of periphery may presuppose a superiority of their morality, civilization, system and tradition. One historian also comments on the nature of western imperialism as a moral conquest and westerners' lesson against the Orient or uncultivated barbarianism. Kantian universalism, and his protégé, Hegel's thesis d'état raison perhaps would work as a prelude 
for a Hitler's excessive or abusive expansionism of Germanian sanctity or superiority against the exterior morality. So the morality possesses a character of ultimacy and inviolability, hence, fairly religious, but on reason, custom and tradition which would be a relative factor to intercourse with other group or society of different morality. This relativism would require a tolerance more than the ethics since the moral conviction is fundamental and easily embedded in any irreconcilable beliefs. It also can be made keenly affiliated with the politics on campaign and organization that a dissidence or sectarianism is a matter of course to shape the federal constitutionalism in the American continent in $18^{\text {th }}$ century. Ethics, on the other, is formed relatively and interactively to reach some of pleasant state. Hence, it entails the quality of human condition and eclectic nature depending on the circumstances. Hence, the word can be dealt with the concept of social justice as seen in the title of this course (Laureate Education Inc., 2013).

The concern of social justice or welfare, in the earlier of 20th century, plainly reveals an evolution of circumstances from the orthodoxy in belief between the liberalism and quest for a political dominance in the mid of $19^{\text {th }}$ century. If the latter assimilates an operation of morality through the basics of capitalist society, the turn of $20^{\text {th }}$ century to see the social justice would come possible as the kind of ethics from a general base of improved wealth, a market failure and polarization of society, increased representation and extended role of the elected officials, and so on. As Aristotle postulated, the ethics can be facilitated by the paradigm of virtuous agent, which would be mutatis mutandis a proactive nature of character in the contemporary equation. Hence, it is positive and proactive while the morality would largely be defensive and conservative on the tradition or basic disposition of each person or agent. His three companion idols, say, contient, incontinent, and evils, is simple but facile to show the contrast involving the four types of character (Stanford Encyclopedia of Philosophy: Ethics, 2013). Contient is a knoweldged person, but stern to keep staying with the counter-pressure. Incontientis ignorant, and did not appreciate the nature, condition, necessary things and events. This, of course, leads to any vulnerability and weaknesses in responding to the counter-pressure. Evils are out of merits to obfuscate and confuse the nature of challenges or undermine the existing conditions to harm an agent or organization. The virtuous agents, in comparison, would be a most idealistic quality as a leader or governor, but this does not necessarily means these persons are best lived nor always bring an affirmative consequence to improve and cultivate. For the Aristotle's case, the good character and good will come into play to construct an understanding of ethics (2013). One other important focus was drawn from the intelligent or knowledge dimension of human condition, what he called philia (2013). So the concept likely represents a modern dualism about an inner human dimension which cover a consciousness or cognizance and intent. As Duke William conquered the Great Britain in 1076, an agent acts on his intent and will, who would perhaps operate their firms or enterprises on good will.As Sir. Coke and Blackstone spelt on the principles of common law, the leaders of organization are some knowledgeable person to guide the followers in any kind of blackletter rules, often implicitly, however, in his dimension of philia. Aristotle viewed a priori existence of political community or polity before an agent or person. This implies that the ethics and virtue of leadership are one of central qualities although he saw a happiest life in philosophers or their ways of living. These ingredients to compound into the whole of ethics simply show a major difference from the morality. To say, the morality is orienteered dominantly toward an inner dimension of humanity, but the ethics often is expressed in the apparent way, and is interchanged interactively and relationally. Morality often pursues a self- perfection, consistency with the 
code of conduct in fulfilling a satisfaction of self, as well as avoidance of self collapse. That nature would be dominant even if we occasionally encounter an agent or entrepreneurs morally condemned in the newspaper stories or others. We can see that the knowledge or intent comes to serve relationally and enables a beginning point to interact and lead. A theory of appreciative inquiry would show this in a fashion. The leaders or strategy finders begin his job by inquiring, hence knowledge, in the intent, hence will, to encourage their target organizations. Ethics would require a course of journey to create a pleasant condition of humans and organizations while the morality often is given by an exterior authority as a code of conduct. Hence, a friendship illustration in the discourse of ethics is fairly apposite to reveal the context of differences for two thesis (2013). Let me say some more about recent chores.

\section{Reflections from My Recent Experience}

I have experienced some of displeasure in conducting my lecture series. I have borrowed a specially equipped lecture room for videotaping in this fall term. The videotaping failed once in time last week to display without an audio effect. It also failed again to overlap the two lectures into one piece or might be hacked or stolen, which removed, in no way, a half of class from two hours content. The failure involves an incomprehensible technical difficulties about the computer device and attendant facilities that lay professors could not handle. The paid staffs, who often are graduates of college, were available, but they hardly penetrated the core of technical issues. Their advice is meeker, and most profoundly, other principals in charge are very negative about the use of special room. They are fairly defensive and like to be loyal to the original purpose of that room as a matter of school policy. Actually, however, the policy seems flexible and the hard nature of my course has a good justification for videotaping at the aim of post-school studies for the students. This negative stance of college administrators and less will of theirs seem to create an atmosphere to influence the technical staffs. Their skills and knowledge also seem imperfect to perform their role and service. I got infuriated with the two times failure in sequence. I do not even like to speak of any rule consequetialiam or act consequentialism in this case. However, the ethics are only way to explain this displeasure. The school administrators and technical staffs never are immoral and I could not tell any specific point in violation of any code of conduct. They stay peacefully to be satisfied and look likely to keep with a good moral character. The only way to explain my anger would be from their inaction, as likely contientor incontient. They are never immoral, but merely neither virtuous nor proactive against the counter-pressure. They hang around half of hours for one hour class by reserving any definite advice about the use of special mike. They are never immoral, but we can hardly find any friendship, a useful equivalent with ethics in analogy. Ethics, then, would be an enhanced concept for the desired human or organizational condition (2013).

\section{Reference}

Laureate Education Inc. (2013). Ethics and Social Justice

"Fundamental Concepts" with Amanda Baker (approximately 16 minutes). 
Stanford Encyclopedia of Philosophy: The Definition of Morality. Retrieved Sep. 7, 2013 from http://plato.stanford.edu/entries/morality-definition/.

Stanford Encyclopedia of Philosophy: Aristotle's Ethics (parts 1-4). Retrieved Sep. 7, 2013 from http://plato.stanford.edu/entries/aristotle-ethics/. 


\section{A Comparative Understanding of Liberalism and Libertarianism}

\section{The Main Profile of Two Thoughts}

Liberalism and Libertarianism are close concepts, but distinguished in the basis and its present effect on the community.

A libertarianism begins with the self full- ownership and penetrate the kind of property or physics origin of metaphor through the discourse (Stanford Encyclopedia of Philosophy: Libertarianism, 2013). It provides the ways to understand a personal autonomy, and its relations with the community and governance. Its contemporary evolution would be less extensive and took the nature of countervailing theme against the paradigm of welfare state or egalitarian liberalism. It tends to seek some of strengthened or defensive logic concerning a lesser intervention, more enhanced conception of personal autonomy from the social justice, as well as an emphasis on distinction between the society and polity or government. Hence, the ideas of libertarian adherents may go into an anarchy or requires a stern justification about the intervention, any scheme of administration on justice or new community ideals. Its tradition, in due course, can be traced back to Lockean ideas and its contemporary leading theorist would be Nozick (2013; R. Nozick, 1977).

A liberalism would begin to perceive one as an agent more than the libertarianism that it spans widely thorough the human nature and interaction within the polity or political community (Stanford Encyclopedia of Philosophy: Liberalism, 2013). This ideal generally is considered to play a foundational role in the evolution of western democracy through 18 and $19^{\text {th }}$ centuries in UK and US. Its origin should get more extended, but its significance as an ideal was framed in the moment as a new social idea in the $16-19^{\text {th }}$ century western community. It is the kind of rebellious understanding from the prevailing purview of those times from the feudal subjectivity and later a divinity of monarch. One or agent is not autonomous or self-willed to be liberal, and current form of freedom or liberty would only be attributed to the limited scope of people. This perception had broken at first with the struggle between the King, a representation of new nationalism in Europe and Pope, and resolved in the Westphalia peace regime. A next phase would be the contention between the wealthier class and ancien regime as represented by the feudal system and monarchy. In this phase, the contractarian theory offered the ground to liberalize the class of commercial merchants, industrialists, and local agrarians, and other class of bourgeois. It reshaped a dominant version of nobility, divinity and feudal ethics into a new paradigm and ways of understanding. Hobbes, Locke and Rousseau are considered as leading three originators of this ideal, who had, nonetheless, subtle differences in proposing their social contract in theory and basics (2013). From this social contract frame, a limited government could be enabled and the abuse of power may be checked or kept in balance in its structure and function. That means that the people turned to become qualified to enjoy their inalienable rights, such as rights to life and liberty as well as property right. The divinity of monarch was said of illusion to be replaced by a new hypothesis of social contract while Hobbes did not advance to this extent. The ideal of liberalism made a profound impact on the basic structure of democratic rule in the late of $18^{\text {th }}$, notably on the constitutionalism in US and universalism of human rights in France. This ideal, philosophically enriched by the work of J.S. Mills, served as a dominant perspective to rule the conquered lands and countries by the British power in the Victorian age. 
From the idea of J.S. Mills on liberty, we can learn much of human condition, the duty and responsibility of agent, ethics, and ways of interplay to implant or inculcate himself and neighbors (J.S. Mill, 2002). In his conception, therefore, the liberty is not restrictive to the negative concept from coercion or compulsion. Beyond this basic liberty, he evangelized many intrinsic in his philosophical deliberation to substantiate the views of liberty or liberalism to bridge toward the positive concept of liberty. For example, he saw that the context of individual to grow and learn is essential to ensure the liberalism. He also distinguished the doctrine of free trade from the principle of individual liberty, and taught that the justification of personal and economic liberty was distinct (2002). He diversified the true nature of one or agent, and enabled to explicate the unraveled dimension of humanity if just philosophically or as unsupported by the contemporary science on humanity or psychology. Mill's perfectionism and his conception about the two ways of pleasure, hedonic and higher ones has likely echoed in consonance with the modern views on the Maslow's hierarchy of human needs. He is also available in contrast with the Marxism provided that Marx is purely mercantile and economic in viewing the society on its basics. Millian concept might be received as a false consciousness from the communist adherents in one way, and may bring a structural distaste for the scholars of colonial experience. In his words, we can read, "Despotism is a legitimate form of government in dealing with barbarians, provided the end be their improvement..." (Stanford Encyclopedia of Philosophy: Liberalism, 2013). This view yet would likely be disfavored by Koreans in the context of Japanese imperial rule or US in the context of British rule. I consider, however, his idea is pioneering to flourish a reasonable pluralism and also interesting as if he whispered the Victorian glory of larger opportunities and ample space to fill the civilization errand in the ruled lands. That comes, for example, by mentioning about developing individuality and cultivating capacities. $\mathrm{He}$ therefore saw the barbarians not be qualified to entertain a genuine nature of liberty, but could be improved by ways of contact and interaction, which would likely be a Darwinian understanding of our nature (J.S. Mill, 2002). Then the views from the group of distaste likely said that they become as equal to be civilized but in the limits of British hierarchy and convenience of imperialistic rule. I am not sure if Marx, who might be a close peer as a matter of time with Mill, had that point, but Marxist view may overstate the role and capacity of working class to reject the idea of evolutionism. This hypothetical bridge would not be incorrect if we institutionalized a tripartite convention among the labor, capital and government in Korea and Northern European states.

One other attribute in these times would likely be the experimental journey of new democratic rule unlike the Victorian system of world governance. The governments in the new continent around the mid of $19^{\text {th }}$ century had been aching to settle their system of rule and contested points about the democratic virtue and desires. Notably, the civil war and women's right to suffrage were lodged to contend and evolved. This means any vulnerabilities and weaknesses in terms of the public policy and administration around the times. As J.A. Hobson phrased, the elected officials now are true representatives of the community in competence, capacity and ethics than a mere defender of their wealth as formerly stigmatized (2013). The concept of social justice and ethics of bureaucrats began to maturate if we are in the D.G Richie's, "genuinely the government of the people and by the people themselves" (2013). This growth of government against the market or wealthier class rule would perhaps notably break into the New Deals around 1930's and the social welfare or justice concept tend to come into some of primacy for the public administrators. A subtlety can be raised between the views of John Rawls and the paradigm of welfare state, and that the 
term, "egalitarian liberalism" may more properly investigate the current context of humanity, social justice and ethics of administrators. While the welfare thesis highly tilted on any economic discourse, the egalitarian liberalism is prone to see the people and their social justice in some depth of philosophical justification as in Mill's case against the pure market theorists (Laureate Education Inc., 2013).

Interestingly, a point developed into the classical idea of Plato and his disciples about the function and role of individual in the community and the kind enabling concept between the deprived nations and affluent ones. A substantive justice or positive liberty would surge in the threshold to practice the liberalism as a matter of polity. For example, Ely asserted a social justice and positive liberty for the working class which replicated the ideas of postmodern constitutionalism about an enabling concept of rights on the labor and social welfare benefits.

\section{A Summary on Two Thoughts}

Then the liberalism may be classified on several of its basics as (i) thoroughgoing methodological individualism (ii) individualistic postulate' against all forms of 'organicism', (iii) expansion of an abstract conception of individual selves as pure choosers and ingratification of ideas on the cultural membership and other non-chosen attachments and commitments (iv) aims at development on a decent hierarchical society (v) horizon to explore the social cooperative structure and justice (2013). Interestingly, Mill adverted on the virtue of non-intervention on the non-liberal states which raises an ambiguities how this proposition could apply to non-British subjects or other powers at his time and contemporaries. For example, a previous illustration about Syria comes to be tested in his thesis. Also we can illustrate other ramifications of liberalism such as public reason liberalism and radical pacifism, which would adaptively propose to respond to the circumstances and demand of environment. For example, Republican liberalism could be epitomized in its new ways about the failure of free market structure globally, and economic in its vast aspect of proposition and arguments.

Libertarianism, as above introduced, could be viewed in a protesting thesis against the imprudence of social justice or dominant ethics they consider thematically unproved or overgeneralized. Hence, they question the prevailing ideas of contemporary society from a rule consequentialism and teleology or rule cotractarianism. The impression would likely be the context of Scooridge who churns on the legitimacy and justification of social justice or established course of governmental ethics. They may constantly raise a suspicion and demand any plausible ground to legitimate the actions and programs by the justice-promoting organizations. Nonetheless, they have a cause and rationale that the public administrators should not disregard.

\section{Two Thoughts and Ethics}

Ethics, in Aristotelian preaching, was viewed for phasing out of virtuous agent in impression and a paragon to reach the idealistic dimension of mean state (Stanford Encyclopedia of Philosophy: Aristotle's Ethics, 2013). Aristotle showed a contrast within three other characteristics, say, contient, incontinent, and evil. A good person chooses to act virtuously, and transcends the knowledgeable, yet inactive person without a public outreach 
for justice. Kalon, a Greek word in English meaning "beautiful," "noble," or "fine", would be an ideal that the kind of person pursues (2013). This character of agents or person perhaps would be a best lived life on knowledge and understanding as coupled with the second mode, a devotion to politics.

For the public administrators or students on the course of journey, I suppose that the ideals of liberalism would be a central point to tackle with to contest the virtue of administration every constantly. In this nexus, the ethics can come into an interplay, and libertarianism also would be an approach of neighbors which advises to communicate for and construct the system into a meaning (Laureate Education Inc., 2013)

\section{Reference}

J.S. Mill (2002). The Basic Writings of John Stuart Mill: On Liberty, the Subjection of Women and Utilitarianism. New York, NY: Modern Library.

Laureate Education Inc. (2013). Ethics and Social Justice "Fundamental Concepts" with Amanda Baker (approximately 16 minutes).

R. Nozick (1977). Anarchy, State, and Utopia.Basic Books.

Stanford Encyclopedia of Philosophy: Aristotle's Ethics (parts 1-4). Retrieved Sep. 7, 2013 from http://plato.stanford.edu/entries/aristotle-ethics/.

Stanford Encyclopedia of Philosophy: Liberalism. Retrieved Sep. 7, 2013 from http://plato.stanford.edu/entries/morality-definition/.

Stanford Encyclopedia of Philosophy: Libertarianism. Retrieved Sep. 7, 2013 from http://plato.stanford.edu/entries/aristotle-ethics/. 


\section{Ethics and Design Approach}

\section{Conflict and Ethics}

The public administrators are responsible to address the issues and agenda, and may, in some cases, need to make a difficult decision ethically viewed as divergent in ways of dealings. Most notably, they may be required to decide or act in the tension concerning the conflict of authority, interest and role. How the two concepts are connected and interact among each other often matters in the circumstances where the issue, task, course of dealings, agenda, and their role performance come to impose a difficult avenue of ethical consideration beyond the routine course of making a decision.

There can we identify the class of conflict which corresponds with the three elements, say, authority, personal interest, and work role (Cooper, T., 2012). A conflict of authority occurs when the ethical dilemma relates with the law, line hierarchy of organization or work structure, and other formal or informal work requirements in terms of control, cooperation or collaboration (2012). A conflict of interest often arises that the organizational course of performance, its goals or missions overlap the sphere of personal interest directly or indirectly, obviously or impliedly, as well as in the spectrum on purity and fidelity from the collective frame of organization. It does not necessarily require a loss or harm to the organization, and merely an improper or disloyal connection between the organization and interested administrator can suffice the conflict of interest test. The personal interest may not be the administrator's himself, but encompasses that of his spouse or close siblings in general. A drafting of ethical code depends on the nature of organization and public policy as seen in the case of New York code on the professional ethics of bar members. In that enactment, the conflict of interest was narrowly tailored to have a limited ambit about the financial aspect when it defines an impermissible scope of violating the conflict of interest requirement. A conflict of role would be found more flexibly, and pertains to some of professional dimension on the desirabilities, efficiency of administrative performance, as well as the organizational or social utility of agents or administrators (2012). The concept is less rigid in comparison with the conflict of authority, but dynamic and creative in pursuit for a better performance, which, however, interplays to comport with the laws and line hierarchy. The concept of role, therefore, substantiates the formal or perfunctory nature of authority, and intrinsically relates with the administrative responsibility. While both of authority and role incur an issue of administrative responsibility, the former more directly brings the problem of objective responsibility. The latter would extend to the dimension of subjective responsibility while the basics of role also interplay with an objective responsibility.

\section{Ethical Reflections and Responsibility on the Design Approach}

The topic, in nature, entails a difficult dimension in the course of professional service as a public administrator, and often reshores into the ethical dilemma or the conundrum of how to find a fit to resolve it (Hicks, D., 2013). According to Cooper, the design approach would serve a convenience and his or her ways to address the job duties about an ethical issue faced during the course of performance (Cooper, T., 2012). The paradigm, then, needs to be incorporated into his or her daily practice to chart and monitor his performance and standard. The use of this ethical model brings a benefit. This would serve finding a legitimacy of his or her authority and role, and particularly useful when he was questioned about his exercise of 
authority and role. This means that the design approach could be a useful tool to address any predicament from the claim on subject responsibility. He or she also would be smooth with an autonomous performance of learned behavior sequence, and remove an ad hoc trouble on each respective case (2012).

In his view, there are two types of ethical decision model, say, descriptive and prescriptive (2012). The descriptive model shows the ethical decision as the world is while the prescriptive one introduces the ethical decision as the world we would like it to be. His ethical decision model is prescriptive and framed into stages and factors. The first would require our perception about the ethical problem posed as a challenge. Then the administrators begin to describe the problems and define the ethical issues in forms to be explored and finally anticipated to resolve. He or she explores a scope of alternatives to be chosen, and will be required to explore a projection of probable consequences and its analysis. In the next, he stepped into the phase of selecting an alternative, a best fit as confirmed through the process. Finally, he or she imagines the picture that would be realized by implementation of his or her decision, say, state of resolution (2012).

The model would be an amalgam of device to enable a leverage of ethical analysis into the express design which would be a dynamic process, rational and principled, but also on human feelings and character (Laureate Education, Inc., 2008). The design approach could increase the attitudes of administrators, i.e., reexamination, respect for the principles, distinction between values and principles, and so on. It would also cultivate the public administrators to think in a principled fashion. The ethical dilemma in its most extent brings an agony leading that the ethical autonomy is reduced to zero, that character is eroded, and that integrity is undermined (Cooper, T., 2012). From this hardship, the design approach can shape some of stable process within the inner minds of administrator which facilitates the nature of ethical analysis, i.e., primordal, spontaneous, complex, logical, principled, and relatively comprehensive justification (2012).

\section{Ethical Dilemma and Conflict of Authority, Role and Interest}

Across three concepts, we may find a Korean illustration about the course of military coup in Dec., $12^{\text {th }}$, 1979. The incident may be known to US citizens if Korea is one of key allies and its rising prestige as a world class of nation. General Chun, a Korean of mid fifties, had served as a chief of investigatory authority to probe an assassination and cruel killings of presidential aids in the attempt to terminate the Cheng-hee Park's lengthy reign on a militaristic ground. Jae-kyu Kim, a chief of National Intelligence Service and conspiracy leader of the plot to assassinate, alleged his legitimacy of killings given the democratic ethos and popular quest to restore the democratic rule, as shown in the Bu-ma marches and confrontation charted around 1979. Mr. Kim was actually executed, and was rejected of his claim in the judicial process. General Chun, a chief of Military Intelligence Service, was appointed as a charge of investigation by Seung-wha Chung, General in Chief of Korean Army. General Chun is required to directly report to the command and order from General Chung as a matter of law and line authority. General Chun had been a key actor of informal fraternity group, what was called Hanahoei, which is powerful and potent under the shield of Park's support. General Chung's background was different, who is not a graduate of Korean Military Academy, but was educated in a general base of military training. Hanahoei is a firm club in the promise to share a same destiny, personal welfare, promotion opportunities and 
career success, and of course, a loyalty to the Park's administration. The two months from Oct. 1979 through December of that year apparently looked of peace and progressive transition toward the aspired democratic form of government. Three Kims, promising candidates for the next presidency enjoyed a public attention, and the nation gradually had maturated into a campaign mood and political flourishing. That appears certain in due course that Koreans would sooner witness a democratic government long aspired and in the moment of demise of militaristic regime. Chun's role is obvious in the eyes of public to investigate Kim and his conspirators or accomplice, while General Chung would govern temporarily in responding to the national emergency (Laureate Education Inc., 20o8). A transition to the regular regime seemed ensured in 1980. Abruptly, however, an unauthorized fire battle awakened Koreans in Dec. $12^{\text {th }}, 1979$, which broke out in the course of arresting activities of General Chung by General Chun. He later obtained an approval of that arrest by the acting head of state, Kyu-ha Choi, but in the demonstration of his informal power with his fraternity members. Some of implicit coercion can be noted in the evolution of one night revolutionary course of action. Chun's cause and rationale, later seriously questioned and debated in the courtroom and by many political analysts, were alleged to lie in the investigatory needs about a suspicious behavior of General Chung, at the night of assassination. General Chung was called to report by Kim, and attended a dinner in the near guest room of Blue House close to the place of assassination. Chun's version is that his presence had been necessary to support the coup of Kim and might imply a conspiracy connection with Kim. He, therefore, had no way to attempt an arrest of his direct supervisor without the approval of president, which had been required as a matter of law (20o8). A prior approval might fail the plan to arrest, but may bring a counteraction from the General in Chief. This scenario would be worse and Chun's claim was that a possible culprit to harm the national head might continue by sacrificing him. In the period, there was an alleged plan to transfer General Chun and his informal fraternity group to some of marginalized position. As said, they had been strongly associated to serve their spirit and prosperity in their military career. This atmosphere to counter the Hanahoeiprobably threatened their personal expectations that they would turn to react in defending their private interest and in the chance to forge their suspicion about a General Chung's quandary on the said night (20o8). What motives actually would be more imposing is still dubious, but might well be combined to make the decision to arrest. That night a number of innocent lives were sacrificed, and the divisions or special combat unit were mobilized at the military command order appropriated to serve their unauthorized course of military operation in arresting General Chung. At the time of arrest on Dec, 12, 1979, he spent his time off duty in his public house located at Hannam-dong guarded by the armed military police. This guard line was broken by the attack of his appropriated unit, and other forces were drawn to occupy the command center of Korean Army.

This story reveals the context of critical dilemma in terms of ethics and code of conduct on the public administrators. General Chun was responsible to investigate, gather the evidence, and transfer his findings to the prosecution authority of Korean Army. His competence and authority was prescribed expressly by the law and work flows in system and practice. He would also need to report to his supervisor, General Chung and eventually to the acting president. He certainly faced an ethical dilemma how to decide and what course of action he should have to undertake. His deliberation perhaps would go into any deeper analysis the administrators normally would not process. The design approach and ethical decision model might seriously work around the perception of ethical problems, defining an ethical issue, exploring the scope of alternatives, and finally a selection of alternative and 
state of resolution (Cooper., T., 2012). His ambition as a loyal and faithful cardinal of Korean Army, and human feelings from a Park's benevolence might move him ethically as a factor. A retreat from any radical action would undermine his and his peer's military career and personal welfare. His personal conviction to restore the justice and unearth the truths of that night might come highly to risk a military confrontation between the same armies, and eventually his and his peers' lives (Hicks, D., 2013). His status, however, stood in the conflict of authority which transgressed the law and expected course of action (Cooper, T., 2012). A formality of line authority was clearly violated, but the role analysis may, in some degree, come to favor his courage and blatant initiative to arrest. A conscience, loyalty, passion, and affinity may support his decision. One source confirmed that he called President Park as a father in the informal gathering, and both had been ethically tied. In any case, a US Ambassador as well as the commander of the Eighth Division for Korean Ambit at that time, got infuriated about his usurpation of authority. The Korean government also finally condemned his decision and course of actions as a military coup in the criminal jurisprudence. The context of subjective responsibility was, in heat and passion, contended and debated seriously in the courtroom around 1994. An argument to legitimatize their personal ground to defend their ways of making a decision and course of action was eventually rejected by the court. General Chun and his peer General Noh served as a president in 1980's and through early of 1990's, but their glory just stopped there. As we learn, the final destination within this nature of public commission may go more proper if to respect the constitution and laws since any ultimate findings of a fit might sway. The conflict of interest also comes into a play if he or his peers embraced some of personal pursuit for the career success and welfare.

Reference

Cooper, T. (2012). The Responsible Administrator. San Francisco, CA: John Wiley \& Sons.

Hicks, D. (2013). Dignity: Its Essential Role in Resolving Conflict, New Haven, CT:

Yale University Press.

Laureate Education, Inc. (2008). Ethics and social justice, "Ethical Decision-Making" with Amanda Baker (approximately 12 minutes). 


\section{The Ethical Dilemma and Ethical Decision Making Model}

\section{Introduction}

One of present controversy in Korea reveals that a chief of national prosecution offices (KPO) had resigned in response to his alleged wedlock child. He has been one of respected senior prosecutor trusted by a group of young manpower in KPO. Mr. Chae, now a popularity from the flak of majority party, Saenuri, and on some of split views from the public opinion, should wait for a completion of internal process on investigation and audit. His resignation was remitted and the Blue House endorsed a supervisory command delivered by the head of Ministry of Justice (KMOJ), Mr. Hwang. Dong-wook Chae, a week ago, announced his resignation in the press and public media right after the minister Hwang, formally a higher authority in ranks and files, decided to process an internal investigation about the alleged Chae's ethical failure. The story actually has stirred over the month involving one madam, called Lim, who runs a prestigious salon for the socialization and fraternity among the high technocrats and wealthier class of Korea. KPO had been reputed as one of prime justice-promoting organizations since the dismantlement of militaristic nature of government around the early of 1990. They had once been rated by the media as a top public institution attracting the public credibility and trusteeship. They had deeply been engaged to eliminate the evils and harms within the power groups and wealthier class in Korea. One young prosecutor mumbled, "I have been proud of my organization because the injustice and public ailment therefrom was remedied on my own hand... This incident actually frustrated the organizational members." Other man corroborated with his comment, "KPO may not be perfect if the political power intervenes. It, however, has been on public faith that it, at no exaggeration, worked effectively to correct the "past' political power."

\section{Situation, Factors, and Administrative Responsibility}

The context actually is complicated to encompass a scope of elements expressly and impliedly working (Laureate Education, Inc., 2008). The plain aspect of incident is an ethical misdemeanor allegedly perpetrated by the Chief of Prosecution Office (CPO), perhaps decades of improper relationship with the said madam and wedlock boy child. The practice of embroiled persons, in my personal experience, are not unusual to hold the kind of pattern behaviors that the prosecution officers have a tie and social coupling with a local pub or salon as the base for their informal contact and off time pleasure. If in worse, some of corruptive shade may exist ranging from the unpaid events of extravagant feast or gatherings and through a sexual brokerage prearranged by the interested private attorney, local potent or businessmen. Their interest may be unlawfully or unethically promoted against the proper administration of justice and professional rule of conduct required of public prosecutors. In the worst, some of prosecution officers may have a connection with the local gangsters to gather information, to subsidize a financial support, or to be engaged in more intimacy to a specific locale or potentials of crime network. Other factors in this kind of ethical issue are in need of consideration which is important to understand Mr. Chae's objective and subjective responsibilities as well as the context of Cooper's paradigm (Cooper, T., 2012).

First, Chae was not the only officer to resign during his statutory term of two years, but twelfth in roll from a total of 18 since 1988. The statutory term was introduced to ensure an independence of KPO, a quasi-judicial institution, against the abuse or dereliction from the political power (Maccallum, G.C., 1993). Hence, the president or ministry of justice should 
be restricted in dismissing a CPO at their will, but only statutory causes could justify it, which would be typical, of course and for example, a competence and health required to carry their duty, a level of crimes as provided by the law, and other basics. The bureaucratic line of authority was enshrined as a matter of public administration, but their intervention into any sensitive criminal cases of political nature was intended to be statutorily safeguarded by that very entitlement of mandatory terms. That was welcomed as one of wise institution by public in 1988, which was also grounded on the public trust about the separation of powers principle. Hence, Chae, like other predecessors, thought himself as a bulwark to defend an organizational identity or integrity and would like to maintain his good impression as a leader of KPO and as a courageous or impartial public prosecutor.

Second, the presidential election, last year, was tainted in the first half year of Lady President Park from the onslaughter of unlawful meddling into the election process. She was a candidate from Saenuri, a ruling party, and the major opposition party, Democrats, seriously contended that the National Intelligence Service (NIS) intervened unlawfully and manipulated impermissibly the public opinion through their grapevines. Of course, it is not only an ethical requirement, but also a legal issue that the NIS and their officers should remain neutral and independent from the public election (Laureate Education, Inc., 2008). The Democrats, still rallying in the public street by installing a camp for the months stay of Han-gil Kim, a head of that party, had initiated conducting a congressional hearing about some of NIS' issues. This initiative was actively pursued in the agreement of both parties, but had effected practically nothing with some of face-hidden witnesses, and insipidity of inaction and non-cooperation. Their filibuster or cause to passivism might be good on some legal justification, say, the national security or other public reason as specified in the statute, but the opposition party would be discontented with their defensive or non-engagement attitude. In this chain of power struggle, the prosecution offices decided to indict Se-hoon Won, a head of NIS, invoking its legal ground from a sensitive criminal statute, i.e., violation of the public election laws. This implies, as a matter of tone and attitude, that the prosecution office will go their way as insulated from a political discretion, and that they would be faithful to their job responsibility.

Chae, thus, undoubtedly suffered from an ethical dilemma across many competing values and moralities (Cooper, T., 2012). As the issue is highly cardinal for the national integration as a matter of politics, he may waive a strict enforcement of law and apply some of acumen to avoid a couterpressure from its direct application of law. As the issue involves a petit offense as a matter of law, this option would surge very strongly in the course of ethical deliberation on his subject responsibility. The challenge to the legitimacy of president would bring a serious consequence while the application of laws matter at lesser extent about some amount of fines or its equivalent. He may hover around other alternatives, which include an invocation of other available criminal provisions, or some of inter-branch measure on the collaboration and cooperation. For example, the education and learning session about nonengagement principle in political matters and bureaucratic ethics could be used to circumscribe an usurpation of NIS and Blue House political elites (Hicks, D., 2013). He or other concerned group to cherish the rule of law concept within KPO may initiate a legislative workforce to restructure the inter- branch control and more effective system to operate ethically and lawfully as well as for a sheer preserve of bureaucracy independent from any swaying political influence. A scope of alternatives come to play, and could offer the ground of justification as a CPO in terms of subjective responsibility. This inner process is necessary and might later be called upon to respond to the congressional hearing or investigative context of process (Cooper, T., 2012). On the other hand, there are also a range 
of factors involved in terms of objective responsibility and ethics as a CPO. Is the law applied correctly and could be sustained by the court? This is purely a technical issue of law, and centers at the heart of this organization's cause to exist. What is the legislator's intent to secure his term of two years in a statutory way? Are we entirely barred from any political discretion to keep neutral between the politically contending parties. Then the line of authority from the president, justice minister and through a CPO in ranks requires what extent of concession or compromise? How do the public laws on governmental employees, organizing and enabling statute of administration, the Act on KPO, and others interplay to guide his decision and course of conduct to handle this difficult ethical issue, i.e., more discretion v. strict enforcement of law.

Third, the factors would become intertwined that may produce an amalgam of professional administrators which a lay person may not be easy, but leveled to be likely a neutral mechanic through the course of his decision and leadership action (2012). He rose to the top of KPO, but was reserved from the last administration led by President, Lee, M.B. He was not chosen by the Lady President, but his nomination was endorsed with the support and acclaim about his trustworthy career profile. He had been publicly introduced as a respected figure within the organization that the young generation of prosecutors admires as a paragon of their professionalism. The event has developed in a pattern for one sense, and unexpectedly in other sense. While a backdrop is not certain, but on the basis of public conjecture, a political group at the center and NIS may leak his private matters on the public media. Now he has turned to be a kind of scapegoat about his wedlock child and the quality of controversy involves an ethically faltering dimension from the normal compassion and traditional morality of Koreans (Laureate Education, Inc., 2008). He is a promising public employee who has been responsible to administer the national justice. The profession is viewed as a sanctity and generally of high level of ethics and moral standard despite being not compatible with that of clergy or priest. He is also considered mightier in power with other citizens that his impious and nasty behavior could well undermine his public impression and imagery of organization, say, KPO. He was unethical and the point exacerbated about some of influence and corruption from his mightier status. As a matter of course in the business of public media, reporters and editors are exalted to divulge this allegation based on the rumor in some cases and independent research on other cases. It suffices definitely to provoke the curiosity of public and the course seems certain to condemn the Chae's case. He was pushed back to the corner and may be on groggy to become naught with nothing left (Hicks, D., 2013). He may highly wish to keep his good image on career and work profile, and likely detests the possibility to remain a gutless brass for his organization. The specters of Korea may approach to subject him to the kind of ordeal how you confront this dilemma. Inside his mind and on the standard of ethical code, his promenade in agony and exploration through the jumble of complicacies span extensively on the point of alternatives and consequences or prospects from his decision and course of conduct as in Cooper's generalization (Cooper, T., 2012).

The problem is serious in nature if to question and deprave fundamentally the basis of his morality and ethics as a public administrator. His alternatives, henceforth, may shrink to the simple option of whether or not he would resign and pomp his courage or a neutral and impartial carriage of job responsibility in his personal honor. On this front, he would not be best, however, if he simply decides to resign. That is principally because he has already responded by discrediting an accusation of wedlock child. Other important reason is that he would do better to maintain his current status and defend the statutory term. His instant reaction to resign would grow a more suspicion and distrust of public about the KPO. His 
many predecessors, had to quit during his term, and this may lead him to sustain his position as the modality of organizational heads. He actually dropped this option, and began to defend his case through a media coverage. He later vowed to file the civil action on the claims of invasion of privacy or defamation. The press media counteracted to pressure by mentioning a gene test and other medical ways to prove his purity. In this progress, a moment of critical measure was rendered by his direct higher authority, justice minister Hwang that the department of justice will respond by processing the internal audit and investigation on the integrity and ethics of employees. His measure is grounded on the pertinent public laws about a supervision and command, but historically undocumented to initiate since the quasi-judicial role, i.e., criminal investigation and prosecution, has to be institutionally separated from the policy reason of KPO independence. KPO is generally responsible for the KMOJ, but a final say on the outcome of specific criminal case is institutionally a prerogative of KPO not to be meddled by the minister. His measure, in any way, was legitimate as a supervisory action, but might be acknowledged in other perception, which would be from young prosecutors about its impact as a pressure. They counteracted to investigate the minister Hwang, but the president and minister repeatedly confirmed that the matter is just the class of public employee's ethics and sanctity required by the law (2012). Their intention is never to tame or control the independent authority of KPO, which should be on the conscience and law. This phase to any final process eventually led Chae to announce his resignation, but the president refused to accept it until the internal process of audit and investigation completed.

\section{The Ethical Decision Making Model and Chae's Case}

This case shows a typical pattern of ethical dilemma involving a proper function among the intergovernmental organizations, independence of justice administration, and political influence. The Cooper's ethical decision- making model stages in steps and feedback, which enables an extended scope of review and assessment for the respective ethical issue (Cooper, T., 2012). The idea involves a design approach, and the administrators, as C. Whitbeck proposed, can figure out what to do to deal with the ethical dilemma, as distinct from a normal attitude of merely making a judgment (2012). In application of the Cooper's framework, we may have some of summaries on his respective element.

Figure. Ethical Decision Making Model (Coopers) 
Perception of an

Ethical Problem
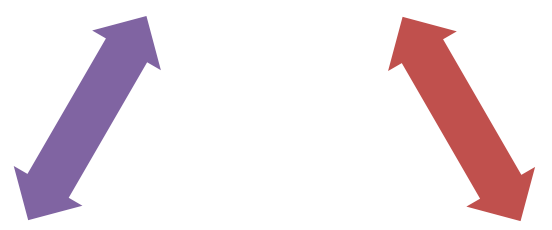

Describing the Situation

Defining the Ethical Issue

A. Identifying Alternatives

B. Projecting Probabale Concequences (Moral Rules/Ethical Principles/Reherasal of Defenses/Anticipatory Self Appraisals)

C. Selecting Alternative

D. A State of Resolution

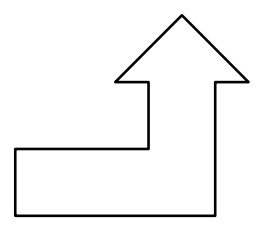

Table. Application to the Chae's Dilemma 
(a) rich odor of ethical corruption and infidelity on the basic social morality (improper relationship with a madam and wedlock child (b) political instability from the former administration, Noh and congressional hearing on the NIS, legitimacy controversy about the last presidential election and the NIS's unethical support and alleged plot to intervene (c) criminal case and KPO's unbent decision (d) suspicious leakage of private information and public controversy (e) announcement to respond with the civil action, KMOJ's reaction to process the internal audit and investigation, resignation and pending context to continue by not accepting it (f) typical public issue of Korean judiciary and quasi-judiciary for its independence and proper administration of justice, De Ja Vue of many Chae's predecessors to quit intermittently.

\section{Defining the Ethical Issue}

(a) Is it ethical and the ways of responsible administrator that Chae decided to apply the election laws in the indictment of NIS head, Won? How would it be working if he applied other available provision for the perhaps bigger cause of political stability? (b) Did he act properly and ethically that he stayed to maintain his office once the allegation stirred the public and raised a public distrust? (c) Is it proper and ethical to instantly respond with the public announcement of KMOJ to process the internal audit and investigation?

\section{Identifying Alternatives \& Projecting Probable Consequences}

On the first issue, we may consider several alternatives-indicting as the law dictates, applying an acumen and political sense by avoiding an application of election laws. On the second issue, (a) it may be better to resign instantly if the suspicion has a strong ground and for its severity in the breach of ethical code; (b) he did well to stay since it is a kind of plot and must be subjugated by the public consensus about the traditional ways of leakage and public menace; (c) he did well to stay since his predecessors often happened to resign consecutively, which undermined the legislative purpose of statutory term and seriously tainted a public impression of KPO (Maccallum, G.C., 1993); (d) he did well to stay since his career and profile are high and merit to preserve from his followers. On the third issue, (a) he did well to announce his resignation instantly because KPO has to be insulated from the authority of KMOJ; (b) he did well to announce his resignation instantly because weeks of media coverage are enough to forge an awareness of the nature of controversy and KMOJ's involvement made it firm about the public sensibility of political influence; (c) he did well to resign instantly since the public damage and debase had grossly aggravated from weeks of media coverage on this depraved unethical incident; (d) he should have continued on his job responsibility since he should respect the measure of higher authority and until his measure was completed; (e) he should have continued on his job responsibility since he initially avowed he did not have an improper relationship and the child is not his wedlock baby.

\section{Selecting an Alternative \& A State of Resolution}

I consider his decision and course of action about the controversy and ethical dilemma would get better off provided if he instructed the public prosecutor in charge to act on the principles and law, but to defer a criminal prosecution on the statutory basis and also on the exculpatory clause because Won had been one of top bureaucrats, and contributed 
much to the national interest, and because the offense was committed not by direct engagement in the alleged crime, but merely in the context of improper or lagged supervision (1993). In this line of thought, he also may consider a political instability if continued on the election laws.

The conduct to counter a grapevine nature of disclosure and stay on his office seem proper given the context had been chronicled in the Korean society. This option could also be supported if it is fairly probable for the NIS or political core to intervene. If he plainly gets off his sacred job duty by resignation, it means that Koreans have no final resort to ensure their national justice and KPO's cause to exist was highly damaged.

He should have stayed even if KMOJ announced the process about an internal control. His instant reaction to announce a resignation evoked the public feel about his credibility and trust on his previous statement of innocence. He may see it cardinal or as a first priority to bar any exterior pressure or influence of KMOJ against KPO, but it is considered not to contradict the statutory mandate provided that KMOJ took a process to respond with the public turmoil arising from this surprising issue (1993). An organizational supervision about the integrity and ethics of public employees may be seen in a different light from the preservation of independent authority concerning the quasi-judicial function. Then the final outcome could be resolved by a gene test or findings of judiciary. The problem would arise from any continued media coverage, which cost a misleading and unnecessary consumption of public energy and time as a gossip or extended damage to the KPO's reputation and honor of public prosecutors. Ways to eliminate this problem might be strived, for example, a faithful inducement to limit its coverage on public reason or others, and it could effect although not completely settled. That would be a proper expense to yield the best outcome in this serious circumstance. Then we have some improvements from the traditionally undesirable practices, a quandary of intermittent discontinuance of the KPO's head, an unfounded allegation against the public figure, cult or myth on the KPO's role, and public distrust or disinterest from any of manipulative or defrauded event. The alternative may restore an institutional interplay on the basis of law and statutes, public trust, and could enhance the right to know and serve in ways more than others.

\section{Reference}

Cooper, T. (2012). The Responsible Administrator. San Francisco, CA: John Wiley \& Sons.

Hicks, D. (2013). Dignity: Its Essential Role in Resolving Conflict,

New Haven, CT: Yale University Press.

Laureate Education, Inc. (2008). Ethics and social justice, "Ethical Decision-Making" with Amanda Baker (approximately 12 minutes).

Maccallum, G.C. (1993). Legislative Intent/Essays Madison. WI: University of Wisconsin Press. 


\section{Differences and Similarities among the Human Rights}

\section{Civil or Political Rights in the Comparative Viewpoint}

In a major classification, we have two groups of human rights which include civil or political rights and social rights. The civil or political rights are classic and an antedated group of rights which often are considered foundational through the democratic governance and modern constitutionalism. The attributes of these rights, among others, are (i) their competing virtue against a monarchy or dictatorship, (ii) principally driven to limit the governmental power (iii) negative rights from the abuse of governmental power (iv) to serve the new wealthier class of society (v) to champion the human dignity, autonomy and democratic virtues. Hence, the typology of this first generation of human rights actually has led the world political history to transform the feudal mode of rule to the modern form of Republicanism and democracy. The scope of rights are typical as we often encounter through the modern constitutions and international norms, which span over a writ system against the personhood, freedom of expression, and free exercise of religion, freedom to travel, economic freedom including the sanctity of property right and freedom of contract, equal protection of laws, right to privacy, and others (Stanford Encyclopedia of Philosophy: Human Rights, 2013). These rights are typically placed in the bill of rights, notably in the State of Virginia and US constitution. A principled spirit enshrined in this set of rights are eminently pronounced in the preamble of US constitution or other classic declaration with such beautiful words, like inalienable, inviolable, god-bestowed, and etc. They projected the concept of classic liberty interest and often are considered to include the strands of natural rights.

The rights in this group actually worked as a revolutionary thesis that should be achieved, and had been incorporated into the liberal constitutionalism. They are constitutional rights which deserve a special status as a matter of law. Plainly, they could not be repealed or negated by a mere majority of Congress or state legislature. A weightier process of constitutional amendment only could modify or abolish the ideas and requirements. In an indepth theory, some of modern constitutional scholars argue that the fundamental liberty interest and human dignity could not be derogated even by the constitutional amendment (Hicks, D., 2013). They are the ground in most probabilities to conduct the constitutional review against a suspicious act or statute. Therefore, it has a root nexus with the idea of higher law or hierarchy tenet across a type of norms in order, constitution, statute or treaty, and executive orders. The federal system complicated this structure from the federal laws down through the state laws and in ranks across a type of norms. Practically, the judiciary had performed much role to protect the civil or political rights, nonetheless, it is a prevailing view across the jurisdictions that the rights in this kind are a guideline for all three branches of government to act and comply with. They could only entertain their power and authority under the sanctity of these human rights (2013). The concept, in this stand point of view, would relate with the separation of powers principle and tenet of limited government.

The rights are enforceable as a technical matter of law concretely in the courtroom while the social rights are merely declarative or the kind of policy package the nation has to endeavor on programs or as a vision (Stanford Encyclopedia of Philosophy: Human Rights, 2013). The rights are not goal-like one nor any moral standard, but can well be framed as a cause of action in a specific litigation. We often experience news stories which arise from the 
human rights controversy. For example, the accused in the criminal proceedings may argue on a validity of death penalty statute on the ground of Eighth Amendment. White male students may argue on a violation of admission policy practiced in the public university provided if the policy infringes with his constitutional right of equal protection of laws by an unreasonable and affirmative treatment for minority groups.

They share similarities that they are rights of public law. This means that the holders of these rights could claim against the state or federal government, and in theory or principle, could not intervene into the interpersonal affairs. This attribute may be revised in a social perception as we see in the state action theory. For the civil or political rights, we now consider that potential violators should not be confined to the government or public entity, but can, in a limited ambit and under the legal coherence in scheme, expand to some of powerful private enterprises or other organizations. For example, a discriminatory policy in the large shopping malls may impact on the society in the similar extent of influence. Then the shopping malls may properly be viewed, in the purpose of constitutional application, as something like the state in their function or activities. This constructive logic, then, enables that the human rights can be applied to the private entities. Of course, the social rights would be less friendly with the concept of application extension as a matter of nature.

\section{Social Rights in the Comparative Viewpoint}

Other group of human rights would be called social rights, which possess the nature and quality as distinct from the first generation of civil or political rights. The paradigm would have a different basis where each concept respectively corresponds with the liberal staticism and social welfarism. The social rights would differ in notion and attributes, which are (i) positive rights to claim an intervention and social programming of government (ii) cherishing a more focus on the social justice than a liberty interest, (iii) of collective and social nature for the common prosperity (iv) principally driven to expand the governmental roles (v) to serve a socially vulnerable class such as the working class, consumers, and post-modern context of individual realities. The class of rights would spread from the right to labor, humanly labor standard, right to the collective action, right to the basic education, right to the pleasant environment or decent housing, etc.

In view of its practical operation, one illustration would serve as charted from the news paper stories. An issue of the child or prison labor would rise to the global attention. It is concerned of the labor standard, and hence entails a social right controversy. It also comes into play as one of international constitutionalism while the underdeveloped countries often perpetrate the kind of inhumane violation. As T. Talbott stated, however, we may see the issue likely as some of structuralist perspective and turn it within a possibly distinct context of compassion, culture, economic capacity of nation, and etc (2013). Therefore, an argument would be unwise if to compel a universal standard of labor as enforced by the developed countries. The problem also relates with the international trade issue which involves the WTO and ILO. The social rights have emerged to restore from a fundamental injustice and gross disparity which a laisez faire system of capitalist economy had brought in the $20^{\text {th }}$ century. Therefore, we often call them as a second generation of human rights which is in contrast with an $18-19^{\text {th }}$ prevalence on the civil or political rights. The idea of social rights was officially recognized in the adoption of 1949 Bonn constitution, and many new born states after two world wars have imported that way of dealings in shaping their national framework. It later developed in 
the context of international constitutionalism in the leadership and initiative of United Nations. So we have two significant achievements to encompass both sphere of human rights, what are known the Universal Declaration of Human Rights (United Nations, 1948b) and International Convention on Economic, Cultural and Social Rights (United Nations, 1966). A constitutional status of social rights would differ in US, so that they had not been entitled to the place of written constitution and pursued in the leverage of US Congress and Executive (Maccallum, G.C., 1993). Notably, new deal programs ambitiously elaborated to rescue the national economy and promote social rights were framed within the series of federal statute. Some critiques would also raise a suspicion about its status as a right since they could not be claimed in the courtroom. Other reason to question its status lies in the tremendous expense and financial burden that make them at least be programmatic or package of idealistic state vision. A counter argument would point the similarities of both groups on this point as we see a positive aspect of state engagement in instituting a criminal justice system, costly public measure to ensure a liberty interest, and so.

\section{A Summary of Comparison}

From a foregoing brief on two groups of rights, we can illuminate a summary in view of the similarities and differences.

First, it is similar that they concern human rights the standard of which centralizes on the concept of human dignity. Therefore, they are dynamic and evolutionary to respond with various factors, to say few, a political concept of society, circumstances and intellectual leverage of society (Donnelly, J., 2013). Therefore, the human rights student needs to see its attribute of dynamism and static aspect across the global jurisdictions. As a representative example in this concern, it is noteworthy that the constitution explicitly provides a concept of "unenumerated" rights. The rights set forth in the constitution are just illustrative that the policy makers can exercise their wisdom to define each specific human right. The right to privacy has had no language in the constitutional text, but a product of judicial wisdom. The right to die, right to know, and many others had been shaped and endorsed on this ground by the pertinent authority.

Second, both enjoy a constitutional status except for few cases that could not be tarnished from the normal political power. In reverse, the governmental power is required to respect the spirit and command arising from the human rights purpose. A universal and regional covenant also confirms its status as fundamental and essential although the enforcement context would come meeker unlike the national dealings.

Third, the idea of human rights presupposes a political community, and generally corresponds with then prevailing political virtue. Our dualism of human rights classification corroborates with this assumption. A liberal capitalism and social welfarism had driven to realize the two groups of human rights.

Fourth, as a matter of definition and practical operation of those rights, there could we note a plethora of differences as described above.

\section{Reference}


Donnelly, J. (2013). Universal Human Rights in Theory and Practice. Ithaca, NY: Cornell University Press.

Hicks, D. (2013).Dignity: Its Essential Role in Resolving Conflict. New Haven, CT: Yale University Press.

Hunt, L. (2008). Inventing Human Rights: A History. New York/London: W.W. Norton \& Company.

Maccallum, G.C. (1993). Legislative Intent/Essays. Madison, WI: University of Wisconsin Press.

Stanford Encyclopedia of Philosophy: Human Rights. Retrieved Sep. 20, 2013 from http://plato.stanford.edu/entries/rights-human/. 


\section{The Attributes and Quality of Human Right}

\section{Human Rights in the Preview}

What are human rights? How do we conceive them? We often hear of human rights and their social consequence in various aspect and levels, but we may become less definite what the words precisely denote. Someone may say the human rights are the kind of list in the bill of rights pronounced in the Constitution. Others may illustrate a political control or suppression against the free speech or press in China or North Korea. They, however, often have lacked an awareness if the African states' children are starved and deprived of some of minimal standard to human livings. They also would become less attended that the middle Asian states have a unique culture to abridge the equal right of different sexes for the very reason that they have a religious justification for a different treatment. In the yardstick of western human rights group, their standard or practices would be inconceivable. In this impasse, a legal pluralism would probably be only way to understand their social dynamism. Therefore, the concept of human rights would have no clear cut to define in the aim of universal comprehension, but would be circumstantial and depends on the purpose of users. This leads to six or more families which are considered to describe the concept in most of influence through the history or political diversities (Hunt, L., 2008; Stanford Encyclopedia of Philosophy: Human Rights, 2013). Asked to give a summary form of definition, the human right is the scope of desired status of humans or some groups to be protected legally or by ways of the high extent of social force which often is deemed fundamental and essential to get along in any of human dignity. As they are fundamental and essential, they are high-priority norms as M. Cranston stated (2013). In this definition, we can derive attributes to entitle the concept as something of human rights.

\section{A Right: Human Rights as Static}

First, it is the right, not any of moral command or religious adherence to worship, which is viewed fundamental and essential (2013). Hence, the concept is presumed that the entitlement of human rights enable to claim the holders to pursue a legal protection, and through the vehicle of special institution. The ways to ensure them as a right may vary to cover a legislative enactment, judicial decision, or custom, but eventually leading to being part of the actual human moralities (Maccallum, G.C. , 1993). The statutory rights, in this ambit, are not human rights since they are neither fundamental nor essential. The right to tort damages, claims in many types of civil action, or administrative relief of industries against the foreign dumping practices would not be covered on this ground in view of the human rights concept. The human rights, therefore, often involve the kind of sensibilities found in the words, like sublime, idealistic, inviolable, or inalienable as we recourse the vintage of classic notion. The preamble of US constitution, the article $10^{\text {th }}$ of Korean constitution, Declaration of Universal Rights in $18^{\text {th }}$ France, and many new born constitutions in the $20^{\text {th }}$ century confirmed this approach utilizing the dealings as the heart of national administration. Since it is the right as a conceptual dealing, we need to investigate how they are realized in any of specific ways to enforce. Now most of nations have instituted the constitutional proceedings to review a violation of human rights by way of statutory provision like in Korea and Germany and by the case law as in US. In the United States, Marbury v. Madison pioneered to legitimate a constitutional review of the federal or state laws under the "case or controversy" requirement. 
It is the right to protect an individual, but the group may be triggered as in the human rights consideration. For example, females would come into play concerning the domestic violence, reproductive choice, and trafficking of women and girls for sex work, assistance and care during pregnancy and childbearing, custody issues in the case of children, and the loss of historic territories by indigenous peoples (Stanford Encyclopedia of Philosophy: Human Rights, 2013).

\section{Emergence as a Protesting Concept}

The constitutions as a matter of concern often rise in the context of national politics. The classic idea enshrined in the human rights is quite protesting in nature against the power of monarchy or from the fear of mob dictatorship. The constitutional drafters of US notably went that way that they saw the institution of human rights herald their first priority. It is rebellious idea and virtue to question the dominant governmental power. Therefore, the human rights concept is crucially intertwined with the assumption of higher law, national constitutionalism, political democracy and presupposes some of political community. Then it may be connoted in the purview of justified political morality and to identify a preexisting moral consensus. The concept of international constitutionalism had surfaced at the moment of UN inauguration and bitter reflection of the past two world wars. In our characteristics as a right, the international constitutionalism would not be tight unlike the domestic context of constitutional review, but we can witness notable achievements about civil or political rights and economic, cultural and social rights (2013). The regional organizations, Africa, Europe, and South America, also have been proactive in this area of concern (2013). Their extent of engagement would not be ensured by the judicial enforcement or concrete decree, but they are empowered to monitor, propose, and recommend. One cause for the action of UN security council, which would be a unique organ to enforce the mission of UN by a compulsory measure, arises from the violation of human rights. In this point of view, the international constitutionalism is not merely a paper tiger but could be supported by sanction or other forcible means.

Human rights, as said, emerged as the ethos of protest against the abuse of governmental power. They had been, in the history and tradition, achieved in a revolutionary way and conceded in complicity with the higher law concept as advocated by the ancient common law lawyers, Sir. Coke and Blackstone (Hunt, L., 2008). Two notable incidents are the French and American revolution against then monarchy and exploitation. A British progress undertook a modest nature of evolution centering at the parliamentary system. A comparative view also shows this distinction that the Great Britain still has no written constitution besides the human right statutes while France respected the universal declaration of human rights as their essence of constitution. Other critical event as a protestant ethos of human rights perhaps would be the foundation of new world regime by inaugurating UN. An intolerable abuse of human rights in the two world wars and depraving cruelty, inhumane debase of human dignity drove to envisage some of international constitutionalism (Hicks, D., 2013). UN made several steps to realize that errand as mentioned above in terms of two classes of human rights respectively in 1948 and 1966. Therefore, the emergence of human rights often involves a shame status of politics and basic human dignity. They could be viewed in aspects not to be transhistorical, but minimal, or at least modest standards as Henry Shue pointed out (Stanford Encyclopedia of Philosophy: Human Rights, 2013). They usually do not include a splendor of policy package, but could well tilt on the metaphor, for example, "how this can be tolerated as in the case of recent Syria?" 


\section{Static, but Dynamic into an Extension of Application and Scope}

Since it conceptually differs from the moral or religious command, the nature of right deserves more points of review about its legal status. The human rights are a public law concept which deals with the state and an individual. How to circumscribe the scope of individuals in terms of the entitlements or privileges also comes as a matter of constitutional interpretation. Is it to denote "people" as in the case of $18^{\text {th }}$ French declaration or "US citizen" encoded in many provisions of US Constitution? Are foreigners a beneficiary of constitutional shield in the issue of equal protection of laws? Korean constitutional court takes a view in general purview that the right to public office or election is limited to the Korean citizens. That is not the case when they face with an infringement of foreigners' privacy right. The concept, then, is deemed a pillar to support the rule of law ideals against the abuse of state power. If the US Constitution has the nature of dual sovereignty between the federal and state governments, who is the addressee of constitutional dictate to protect the human rights also arises as a constitutional issue. The first ten illustration of bill of rights triggered the federal government, however, it could not reach the ambit of state sphere. This lacking, as we know, contributes to the contentious split of nation in the mid of $19^{\text {th }}$ century, and caused the civil war. The thirteenth and fourteenth amendments, and others were designed to cure this flaw that the mandate prescribed in these amendments was made imposed on the state power. By way of incorporation, the due process requirements, say, the privileges and immunities clause, could not be interfered by the state government. The contemporary problems about the constitution and human rights extend our deliberation on its nature. It contains, as we plainly encounter, many of sublime ideals to merit the extension possibilities as a guide or in a principled way (Reichert, E., 2011). In prolegomenon through its current status, it must be public and limited to react against the abuse of governmental power. Hence, they are not ordinary moral norms applying mainly to interpersonal conduct.

On the other hand, the social evolution and increase of economic capacity allowed a new assessment or perspective how the constitutional affords could be received. It actually provides the moral standards which possess a universal appeal (2011; Donnelly, J., 2013). Furthermore, the classic liberalist view to check and balance as well as to limit the governmental power does not exactly fit within the contemporary passion. We often no longer need to be thrilled at any of tyranny or dictatorship unlike the circumstances of mightier Kings or revolutionary contingency. The practical problems had shown its extension of application that the private nature of contract might be invalidated from the human rights consideration. For example, is the private contract void if it includes a discriminatory clause against the minority? If answered no, how the response would change provided that the contract was enforced in the lower court, and appealed to the superior court? In the latter, the context may transform into a public matter since the lower court enforced such discriminatory contract for the black people. The court now can find an avenue to apply the constitution. Of course the ways or extent of discrimination should be weighed in given that it is private nature of relationship and submissive to the party autonomy. The case actually debated in the courtroom included a shocking arrangement to disable an access to some of residential zoning entirely by the rental agreement. In multiple factors of consideration, the courts now find a violation of human rights within the private sphere by applying the state action theory. This implies that the contemporary constitutions may be the kind of moral document in a limited context, allowing to meddle into some of private dealings beyond the rule of law concept. Therefore, it exists as moral and/or legal rights conceptually. On this 
strand, it is interesting to see T. Pogge's view that we can generate individual duties from human rights (Stanford Encyclopedia of Philosophy: Human Rights, 2013).

\section{Dynamism in a Conceptual Understanding}

The initial phase of human rights henceforth evolved in progress to address the circumstantial needs and shape a new understanding of this concept. This means that it is dynamic to interact with the wake of history (Donnelly, J., 2013). Its quest to place it as the supreme status of national attention came from the bottom line, but had been conceded with the democratic rule in interplay and development. The government now accepted it as a first priority to respond that the negative cognizance of human rights turned to underlie the state duty to protect. Now the tone, "the government should not interfere with the freedom of individual," changed that "the government has a constitutional duty to design and implement an adequate institution or policy to prevent the crimes." The constitutional document would less be for a check and balance scheme, but could be a positive ground that the public administrators may recourse to base their policy choice or implementation. In this context, the human rights are not static that can be invoked only in the case of infringement or in the purpose to remedy the evils or harms. Given the passive quality of judiciary, however, this aspect of dynamism would range in a limited ambit that only can be addressed by the political branches, the US Congress or Executive (Maccallum, G.C., 1993). The separation of powers principle then factors circumscribing the span of constitutional dynamism. The court has no authority and resources to command positively to realize the constitutional virtues. The aspect of dynamism, as said and not perfect though, would differ if the court strives to connect a nexus in the purpose to apply the constitutional mandates to the powerful private entities. In the state action theory, the court tends on the modest stance in progressivism while it comes restrictively if the issue goes to the structure and function of government.

The concept should be dynamic in its very aspect of human dignity (Hicks, D., 2013). The notion generally depends on the circumstances and status of society. A desired status of human condition would not be the same as centuries ago although the extent is not on a speedier turns like decades or years. A rapid transformation of society from the technological advancement, notably on the aspect of informative society, may shorten its turns. In any case, the desired human status may be conceptualized in responding to the evolution of society. This context can be evidenced from the generations of human right, i.e., first generation, second generation, and third generation. The waves of this new formulation may correspond with the political history, say, feudal, liberal paradigm of industrialization, and post-modern context of our livings. The feudal governance and social structure incur a serious injustice for the rising class. Their quest to restructure the system was collected into the bill of rights which reflected the fair share of new wealthier class. They then quested to freely express their idea, freely assemble to organize their political voice, and to be ensured of the property right and freedom of contract as well as personal liberty against the unlawful search and seizure, and so on. The second generation of human rights purported to react against the wrongs or social dilemma from the liberal capitalism. Now the human dignity became only to be restored by ways of social right concept (Hicks, D., 2013; Reichert, E., 2011). The right to labor, mandatory labor standard, right to the social benefit, and the kind of collective response were deemed ways to ensure the desired status of human condition. A predominant scope of them would cover the economic justice. The third generation of human rights advanced to ensure a decent living or human condition in this complex and challenging society. Then the class of rights requires a recognition and awareness as well as constitutional protection, which encompasses the right to decent housing, right to education, and right to the 
pleasant environment, and others. On this point of dynamism involving the human rights concept, we also can note the attitude of concept and current practices, which span over the concern of human rights inflation, God-given natural rights, specific and problem-oriented ways of approach, feasibility to administer, too little or too much of international documents on human rights (Stanford Encyclopedia of Philosophy: Human Rights, 2013).

\section{A Concluding Remark : State Administration and Social Progress}

I may, in addition, deliver two points which concern a dynamic nature of human rights or constitutionalism. As T. Talbott expounded, the human rights issue would be fairly nationalistic, and reflects a specific culture or compassion that entails the kind of structural issues as less susceptible of any universalistic generalization (2013). This idea has a root ground from the ancient thoughts and primordial intuition of communal primacy. This view is less done on the ages of enlightenment or human attributes that can be shared, which may go extreme to betray. The logic and argument, however, have strengths in the practical aspect. For example, the developing status of national economy may lead to a different level of human decency or the non-intervention policy as a matter of international politics may find their theoretical ground from his proposition. It also can be more adaptive to the concept of state sovereignty rather than the international commitments of human rights. This view also offers an easy way to account for the public emergency which threatens the life of the nation. The second point is why a plethora of contemporary constitutions have a written commitment about the second or third generation of human rights. The critiques argue that the scope of those human rights would not be enforced as a matter of legal right. This constitutional policy of direct incorporation would vitiate our understanding as a right. It is merely prescriptive to expose a vision or ideals that the state pursues, hence, is not a right in the strict sense. This goal-like dealings would blur the notion of human rights. This perspective, however, relates with the concept that human rights are negative rights, but it would be wiser to consider that the first generation also requires a positive engagement, i.e., creating an effective system of criminal law and property rights (2013). The US constitution would not be subject to this criticism, but it vastly matter with other progenies of contemporary global jurisdictions.

The critiques also argue that they incur too much expensive cost to realize and their constitutional status is dubious, particularly for the non-enforceability. We may agree on this criticism as a public policy student, and probably find that the financial burden of poor government come at first. One idea could elicit the cause of this constitutional policy that the classic human rights also face with any same dilemma since the rights, as said, also can be afforded a constitutional protection by incurring costly institutions. Then there would be no explicit reason not to declare those rights as fundamental or essential.

\section{Reference}

Donnelly, J. (2013). Universal Human Rights In Theory and Practice, Ithaca, NY: Cornell University Press.

Hicks, D. (2013). Dignity: Its Essential Role in Resolving Conflict, New Haven, CT: Yale University Press. 


\section{A Human Rights Violation and Workplace}

\section{Introduction}

The public employees, as we learn, have a duty to respect the human rights in the course of execution of their position power. The kind of dealings to respond with the human rights violation may involve a court proceeding where the context would be posed and resolved in some more stricture of legal terms. The officers of government other than the judiciary, nonetheless, would shape their conscience and position ethics in the adherence of constitutional mandate. The congressmen would be specifically phased out in Article One, and their ambit as well as course of work demand, organization and other key features would be delegated by the Constitution. The president is prescribed, in a direct way of constitutional provision, "he or she is obliged to faithfully execute the laws and..." This mandate, as a matter of logic and line hierarchy of Executive, would be pertinent to a scope of Executive officers. Public organizations other than the government may not be immediated to the constitutional mandate, however, we can see high chances to be regulated by the Constitution, as we see in the cases of affirmative action embroiling the public universities and public bidding. Other private organizations also may not be complacent with their status out of the force of constitutional vision. The reason would be that the state action theory may apply to defame their business reputation and can incur a loss from the damages or others. This awareness, in other aspect, conforms with the ethics of business, entrepreneurship, and social justice. It would be desired from the concept of state action theory that scholar practitioners would bring the social change (Laureate Education, Inc, 2013).

\section{Three of the Prison Mistreatment}

I like to brief on three cases of human rights abuse in the workplace, and present some thought in the assumption that I was charged with the job responsibility at matter.

The cases involve a prison setting in which the prisoners are treated unduly in violation of human rights. Korea, in the ethos and passion from a Paris initiative, instituted the National Human Rights Council (NHRC), whose role and power of institution would be similar, in its nature and extent, to HRC of UN (Universal Declaration of Human Rights, 2013). It collects the events of human rights violation, reviews their profile, advises on a correction and alternatives, publish the case books as well as comment and opinion. The human rights violation about the prisoners are serious that reported 35 percents of the whole complaints filed within NHRC (Mun-Wha Daily, 2013). This accounts for one case among the whole of three in math, which deserves a nickname of prison, a "worst devil" about the human-rights public moral. One prisoner, aged around his twenties, was appalled at the sudden demand of body examination when he was escorted to the prison upon a completion of criminal interrogatory in the prosecution offices. The prison officers told that it is an internal regulation to conduct a physical examination when the prisoners came back from outside. He ordered to take off a prison uniform in the public place where other persons are present. Mr. Kim pleaded that the process could be enforced in other confidential place, but was rejected (2013). So he was compelled to expose his body as undressed entirely in the public vision, which includes female prisoners. The context of process imposes an extent of personal shame and debase of human dignity, which caused to file a complaint. Other prisoner, who was aged around forties and now released from the prison, experienced a 
cruel measure from his altercation with the inmates. The prison authority ordered a handcuffed status of two hands, his upper body being tightened in ropes, and eventually was delivered into a solitary room (2013). This violent measure incurred an aftermath of hospitalization from the callous wrists and fingers. Another prisoner, who was in his forties, was served an inhumane and cruel decision that his petition to an adequate medical care for his chronic illness of bone disk was denied. He suffered from a serious pain and was disabled to walk nor move. The medical assessment that he should be afforded a systemic treatment for one year failed to effect.

According to the statistics published by NHRC, the prison context of human violation is a most popular cause to bring a petition. Among 56,415 reported in the section of public institutions, the prison explains $35.3 \%, 19,932$ in number which is most notorious. The police and its supplementary facilities came second in rank that 12,038 cases were reported (2013). The third in row is a public mass camp for the homeless and social protection services $(9,071)$ and the fourth in other unclassed categories of government $(5,630)$. In the last year of 2012, 1,737 cases were reported to claim an intra-prison human violation while the number never reduced this year. One officer of NHRC commented, "The reason for an abundance of human rights violation in this facility would lie in the nature of institution as well as constant monitor as well as on-site activities by the NHRC" (2013).

\section{Assessment and My Viewpoint}

The human rights abuse within the prison exhibits a good point of consideration about the role of public officers and concept of public value. This is because that the nature of public administration requires pursuing a public utility in the sacrifice of private or personal interest. This focus would well be churned in Bentham's philosophical works extensively (Postema, G. J., 2006). His episode about the dilemma arising from a highwayman and housebreaker shows a hard-reconciled tension as well as pleasure and pain, which are a primal point his thesis begin with. His wry wit can well be understood if the public service is deserving of the kind of sinister persons. It is an irony, however, that the public administrators are required to execute their role and responsibility for these vile people and in conformity with the liaison or network concept as arranged to administer the maximization of happiness (2006). It leads to a free riding injustice, the concept of which can also apply to the contemporary cases. For example, we consider a more due framework about the extent and scope of intellectual property in the international plane. The developed countries argue on a more extent of legal protection while the underdeveloped ones countered. The sense and concept of justice differ that the developed countries impute a free riding accusation for their opposites.

In the precept of Cicero, the rulers and public administrators seek a justice, which could only lead to a human solidarity (2006). The state of human solidarity also can only be procured in the event that the private and personal interests coincide with the universal interest according to the Bentham's calculation. This interplay would be only an avenue that the humans can find a pleasant public life provided if they are any political or social animal. It controls and determines the pleasure and pain, and may influence a final state of happiness as we pursue in the context of definite human goals. 
That said, we consider a prisoner's predicament and our personal state based on the fact brief as disposed above. Some may get instantly conflagrated to elevate the standard of prison regulation. The others may see the treatments deserving since he or she is a sinister actor in contradiction to the overwhelming public cause. The four elements, as envisioned by Bentham and composing the universal interest, would not contravene this view, which are a "maximization of subsistence, abundance, security, and equality" (2006). Their status as a prisoner would well be responded with his "fallback principle," such that the standard would be lowered to suffice four elements (2006). It satisfies the condition that an equality and security would be ensured among the prisoners themselves. Their claim to seek the same status as his law abiding neighbors on those four would come never merited. The points of focus in these cases could be posited in the light of "centre of gravity" argument. The interests to be weighed in involve a sensitive area of personal privacy or right to the basic health and humanly living within the controlled context of prison administration. They might be intervened with less a persuasive reason or deprived implementation not carefully designed about the abuse on human rights interest. The physical examination could be delivered in a confidential area or in decency without costing much. The handcuffed status, particularly on both hands, and upper body in ropes, would make a prisoner appear like the beast immediately captured and delivered into a public shelter. The confinement into a solitary room might be sufficient to prevent any post violence problems. It also can be put to improvement if the prison authority respected the health petition more generously.

\section{Reference}

Laureate Education, Inc (2013). Ethics and Social Justice

"Human Rights: Applications" with Amanda Baker (approximately 8 minutes).

Mun-Wha Daily, Sep. 24 2103, p. 10. Seoul, Korea.

Postema, G. J. (2006). Interests, universal and particular: Bentham's utilitarian theory of value. Utilitas, 18(2), 109-133.

Universal Declaration of Human Rights.Retrieved Oct.1, 2013 from http://www.ohchr.org/EN/UDHR/Documents/UDHR_Translations/eng.pdf. 


\section{The Utilitarian Theory and Human Rights Violation}

\section{Introduction}

The primal strand in the public utility or utilitarianism recourses the human elements, in which many theories, tenet, and polity would undertake as a niche of intellectual persuasion and account. For Bentham, the pleasure and pain are a destination and point of shipment to project his extended concern and philosophical dialectics (Postema, G. J., 2006). His discourse and systemic contention to explain and forefront an inchoate liberalistic society, later highly influenced the work of Mills in terms of political moralities and political sociology. Both are generally considered most profound authorities to marshal intellectually the ethics and public virtue of English speaking concept which had been developed and adapted by the elaboration of Rawls in the twenty century. A revolutionary ethos and turbulence actually dismantled an injustice from Ancien Regime, but the practical consequence had to suffer from the emergence of Napoleonic contingencies in Europe and interstate contention or incongruence leading to the civil war in US. New philosophical wave has been received as inviolable or inalienable, however, how it could be practically achieved posed a challenge to the scholars and public authority. In view of Cicero's precept, a human solidarity, an equivalent of justice for the rulers, could only be settled on "societas et communicatio utilitatum," the community or public utility in modern words (2006). This concept would be compatible that the humans are a living creature within the community and only could possibly exist in that context. That said, the human elements now turn to have a meaning in the context of interplay with the community and public. Humans can only be solid in the eyes of such strong Rome and its state theorist within this concept of justice, and their true interests can be negotiated or delivered. In the Napoleonic errand, the public administration has been made rather solid when a modern major genre of national codes was erected and applied in France and the conquered lands, i.e., civil, criminal, two procedurals to serve the substantive rights and duties, as well as administrative law. It is a notable achievement to substantiate the new wave of bourgeois public or democratic virtue. Nonetheless, his background and ways of militaristic imagery had confused his mission to be politically interrupted. His contribution to advance the democratic concepts is assessed positively from the historians. Particularly, his vision and realization of new public virtue into five major national codes are now followed by both of major legal traditions notwithstanding the common and civil law distinction. While the constitution was not declared in an independent scheme, the universal declaration of human rights serves that purpose and more classic or deemed fundamental given no nomenclature to dress it up as a constitution. The new continent began their public administration on the basis of federal constitution, but the federal power was contested in the initial phase. The scope of federal administration would expand and be adjusted to serve the public value and humanly government or public administration. As we note, the commerce clause and contract clause as well as the necessary and proper clause offer the ground to deliberate both standing concerns.

\section{A Survey of Basic Tenets on the Utilitarian Theory}

As a pioneering engineer for modern public administration, Bentham's concern should rise involving the concept of universal interest (2006). What is universalism? It, as a matter of nature, takes the ways to keep on the logic, tone and metaphor from the kind of fundamentalism, rationalism, and idealism. In order to be universal, it has to be reasonable and also should be idealistic to possess the quality as a universal appeal. It also could serve if 
to ground on some of fundamental dealings that the mankind could commonly share. Then, he would be a good student who borrowed the concept and theory from David Hume or German idealists. His moralities argument had suffered from multifaceted challenges on the civilian quest for the personal or private interest, which should well be expected from the aftermath of civil revolution. This context can be evidenced from his words, "the world now is fleeting and rare,... insanity" (2006). He also explored the context of international politics in his book titled "Constitutional code," and exposed a sentiment in his critique of Spanish colonialism, "Typically one's recognition of this commonality produces a sense of solidarity : by this very community of interest is produced a community of sympathy" (2006).

Hume's influence, as from "Enquiry concerning the Principles of Morals," would be a necessary condition to develop his humanistic public philosophy, but not a sufficient condition leading to his tremendous contribution for the modern substance of postrevolutionary administration. As we consider, his view also influenced the Weberian concept of practical capitalism and bureaucratic practice while the work of $\mathrm{M}$. Weber, as we see in the ethics of bureaucracy, explored an extended scope of factors, which cover the social custom, religion, compassion and tradition beyond a raison or principles (Murphy, A., 1998). In any case, the perception of Bentham would be more urgent and immediate to bridge the rising quest of civilians and dilemma of how to shape a political sociology or political moralities. Therefore, his nexus comes forward with the communal consequentialism and may develop into the compositionalism as the kind of end state that the public administrators envisage. The social welfarism and individual welfarism may correspond practically with his basic exposition between the universal and private or personal interest. He has some aspect of distinction between the private and personal interest, and his narrative massively relied on the scale of interest given his errand on the public good or utility (Postema, G. J., 2006). So the personal interest may come more trifling than the private interest while both are merged or adjusted to the grand scale of universal interest. He saw that an individual happiness can only turn legitimate or possible to coincide with the universal interest. This ideal comes rather authoritatively and as structured between the public and private dualism (Audard, C., 1999). First, he waived much of contemporary understanding about the role of education. Rousseau and other European thinkers focused on the importance of education and could be corroborated from the work of John Dewey, one of eminent public thinkers from the United States. Second, he also overlooked the potential civil power particularly within the traditional operation of civil laws. His book dealing with the civil code discourse connoted implicit difficulties along with the civil justice on economy and personal status. While we consider an importance of these strands in this contemporary public administration, this may bring his work on a formalistic philosophy, but it is undeniable to proffer a vertebrate organism of it (Murphy, A., 1998).

Then his dilemma may revolve about the fundamental confrontation between the equality and utility (Postema, G. J., 2006). Everybody would claim an equality to be static in view of the post-revolutionary imperative. It poses challenges in leading a social or economic reproduction. Nobody would do more, which means just a sacrifice to labor or submit to the public service. It merely would be a heroic sacrifice that Bentham saw a kind of worst or trifling scenario. The equal liberty or equal happiness in the Bentham's word, other than equality, would engineer their motive to labor given the new capitalistic economy. For example, the equality, which might be graced from the Christianity under the God, now turned on the new political and economic arrangement. They now can claim the property rights and freedom of contract. This emancipated a bourgeois class, however, should be 
reconciled from the constant tension between the public and private interests. His alternative to deliver this tension comes from the concept of utility or public utility. His analysis draws on the basics of us so as to realize a happiness, which he also perceived as a sovereign master of human motivation and behavior. Therefore, his dealings may culminate in Chrestomathia, which churned on the ideal of public welfare (2006). His junction also could not be compromised in any plain version with the kind of ideas, monarchy or oligarchy since it, in normal conditions, contradicts his ideal of greatest number of happiness. His adherence with the happiness conception never is an abstract nature, but could be substantiated with his words, "greatest equal happiness" (2006). In order to find a proper principle to achieve this end, he has not neglected to deal with the problem, such as identification of interests, genus et differentam, the centre of gravity, and etc. His philosophical disposition on these points are fairly echoing for the modern public administrators. We often consider that a superior public official is competent to identify the conflict of interest involved in the specific public agenda or sensitive issue. They also need to possess a talent and concern about the genesis and differences involved in the object, challenges, issues, projects, and public programs.

Then his frame of argument turns again on the tenet between the universal and particular interest in the Book of Fallacies, which he perceived as challenges against his concept of public value, what he called a sinister sacrifice or interest. He saw a constant tension and implacable hostility, and an individual only could maximize his sum of happiness to conform his private or personal interest to the universal one. He, however, degraded the heroic sacrifice since it results in yielding all the instrumentality of felicity and even the life itself (2006). He saw it mere altruism which is neither welcomed nor in comport with his tenet on the sacrifice to the universal interest. His adherence to sacrifice for the universal interest is called upon the premise that the individual has a share in cause of sacrifice and has a genuine basis on the individual ground or human attributes, such as felicity or pleasure, and others. Therefore, he cherished an individual aspect while he stressed on the public cause or reason. This way of approach reflects then dominant assumption on the life, who was endowed of the right to pursue a happiness in the preamble of US constitution. The idea also endorses the role and extent of dominance of civil society between the "subject many" and "ruling few" as well as their protestant ethics or conviction on the revolutionary spirit. An individual, now in a new framework of politics, is the person to be motivated in their interests, which would be prurient or commercial. He was shrewd to look at this aspect, so that he never overlooked the genesis of human or individual. His idea is fairly liberal and democratic, as we see in Kamikaze in the Second World war. The incident, of course, was militaristic and serves the totalitarian cause of imperial Japan. Therefore, the concept of "compensation" arose to bridge the civil interests and public authority. Kamikaze had no basis of individual interest who was pushed forward to sacrifice their lives. Bentham also staggered critically about the aristocracies which he would be reluctant to endorse on his theme of public value. The politicians, landed aristocracy, clergymen, and legal elites were no longer the main of social or economic reproduction, who were idle and predatory (2006). The oligarchy or well structured classic society was seen largely failed to correctly reflect the social justice which came contrary to maximize the greatest number of happiness. In perversion, his illustration involving a highwayman and housebreaker shows the context of social injustice and well provoked a free ride's calculation. He hardly found any point of public utility for this group, which would be yielded for normal citizens from the public service, such as national defense or policing. In this case, the fallback principle, a close concept of specified justice, could be applied to ensure a maximum happiness.

\section{Three Cases of the Human Rights Violation}


In the application work of Bentham's tenet, I like to illustrate three examples of human rights violation in the purpose of ranking them on the basis of maximum public utility. That might not be less accurate in a strict terminology of human rights violation, but was drawn in the close context (Universal Declaration of Human Rights, 2013). In the militaristic nature of Korean government during the early of 1980's, Jong-cheol Park, who was a college student at that time, was tortured to death, and stirred the public sensibilities and antipathetic reaction. The government, at that time, was of hard nature to control and overwhelm the civil society. Korea was then one of underdeveloped countries, and the environment of dictatorship could be fertile. There had been a scope of public cause for the central control and tightened context of rule, for example, development of the national economy and assurance of the social welfare and justice, national security from the aggression of North Korea, and so (Laureate Education Inc., 2003). The incident involved an outrageous conduct of government, specifically the police branch of anti-communist team. Mr. Park was just a suspect, who was allegedly engaged in the public demonstration to restore the democracy of nation and legitimacy of government. The atmosphere of society was well tamed and structured, though questioned seriously on the ground of its legitimacy, under the ideals of national stride both in economy and national prestige in the international community. A limited scope of students in vigil and civil monitors occasionally mobilized a public campaign and street demonstration to react against the undemocratic practice of government. The opposing politicians might have a link with the progressive group of society including the college students. The incident led to the national controversy, and its consequence was serious with the series of protest and picketing in the public streets, and public rally of mass people. The initial response of government was ironic and bought a public outrage that the fact was fabricated. They alleged no torture, such as water boarding, electronic stick, nor application of irresistible physical force from several of torture technicians. This allegation actually proved false from the testimony of one conscientious clergyman, and all the truths were revealed with the aid of public media and civil activists (2003). This incident, which occurred in 1987, conflagrated a public cause of June march of Korean citizen, and led to the consequence adopting a direct election of president. The constitutional reform was realized to restore the separation of powers principle, five years term of presidency, endorsement of privacy right, and others. Most importantly, a superficial method to elect the president in the stadium by an highly dependent electoral body, which, however, represented the national cause monopolized by the ruling party and practically governed by it, was replaced so as to ask a direct will of nationals. The concept might be formalistically similar to the electoral college system of US, but the practical operation would come closer to the communist mode of secret election.

One other example would rise from the present context of Korean politics. Lady President Park once promised to design a national welfare system for the aged people. His promise contains the policy that the people over 60 in age would be entitled to 200 US dollars on an annual basis unconditionally. It would be idealistic, and serves a universal interest in the Bentham's calculation (Universal Declaration of Human Rights, 2013). It now became floated away in the face of tough national treasury. Her administration may well buy a public antipathy since the promise was made during the presidential election and should be kept. The reaction could also be organized in the opportunity of opposing party, and still contended in the National Assembly. This year's budget will likely face a stiff response in the end of this fiscal year, and may have high chances as usually charted with such physical confrontation in the floor. A physical confrontation and violence is practically an equivalent of phillie buster in Korea. The nature of issue comes ironical as similar to the US case, named 
"Obama healthcare." The direction would be perverted, however, that Korean government, in this case, initiated to reduce the welfare benefit. Lady President presented a public apology for her breach of promise, but her action would be supported by concerned intellectuals and professional policy makers. That is because the government frankly would mislead the public if to keep her promise. The debt of government became tremendous and her promise requires an excessive budget without any economic impact to breed the national economy. A disappointment of social minds and ill consequence on the deprived class, however, would be obvious.

The last example would be a Mr' Chae's ethical violation and its consequence, which has covered months of media coverage, his retirement, and intervention of supervisory body, say, the Minister of Justice and President. As a chief prosecution officer, he was accused of his wedlock baby while he may consider himself as one of scapegoat cases. He may have been disgruntled with the attitude of public media, or personally apprehended with any of political plot against the carriage of his official responsibility. He may esteem himself as to lead the KPO impartially and had a belief of sanctity on the institution's quasi-judicial quality of public power. He would like to execute a statutory term as the kind of modality unlike his predecessors. He also may deplore an invasion of privacy as a lawyer, and may now have an awareness about the serious consequence from the leakage of private information. He also would consider his status as a public figure and may weigh in factors to be in pertinence. He actually resigned yesterday, and held a public memorial to honor his retirement. His plan is to withdraw a civil action, yet to keep on his promise about the gene test. However, it is dubious whether it could be realized since the consent of biological mother should be acquired.

\section{A Possible Rank of Three Cases in View of the Utilitarian Theory}

Three examples described above would involve the human rights violation. In the first case, we can note a serious nature of human right violation patterned through history (2013). The torture is just the point of focus that the modern civil movement triggered to abolish. It relates with the fundamental civic virtue to ensure against, and has duplicated as a constitutional mandate across the scope of global jurisdictions. The third example also elicits the kind of confrontation between the liberty interest and public cause. The privacy right is classic, but comes into a legal province rather belatedly in the new frame of modern virtue. The second example involves the human right to any entitlement of social benefit or privileges. In the purview of Bentham's, we hardly rank them in any order concerning "pleasure and pain," the greatest number of happiness, equal happiness, and maximization of public utility (Postema, G. J., 2006). That is particularly because his idea was never intended on any math or quantification. This is not to say that the quantitative analysis should drop or comes meaningless. It could base well in force to persuade on the policy strengths or urgency to implement. However, I mean that it possesses a quality element as we see in his thesis, the "center of gravity" (2006). That aspect is important particularly because the policy makers often face with the issues and dilemma of multifaceted and complicated status. A social passion, tradition, administrative custom, prevailing concept of politics, morality, and many others beyond the economic factors of cost and benefit would come into play. Therefore, the intuition and instance also has some prongs to perceive the challenges and shape the policy response to address the harms or evils. That is particularly because the "pleasure and pain" as well as the concept of happiness as a measure of public utility are ultimate as we can share, yet not to be definite as a matter of quality. I am not sure how we can finely rank the above three. But I suppose that we may agree if it could be first, second, and third in order if we 
exercise our intuition. His point about the centre of gravity would tell much to leave the last two behind. Bentham's concept of universal interest also plays to make the first case more serious and safeguarded (2006). We may well conceive a fear and would fail if to let such practice to go in that way. Bentham's four prongs of public value also corroborate that a security or maximization of subsistence would be fundamentally depraved in the first case as compared with the last two cases. An equality and abundance come to matter in all three cases, but come poised in the balanced consideration. For example, the equal liberty claimed by Mr. Chae would be legitimately traded off in the public interest. He is a public figure which is an enabling factor for some extent of public disclosure. The equal liberty claimed by the aged people of Korea would have a stronger profile than Mr. Chae's case. However, that is also amenable to the discretion of government and other competing virtue of Korean Republic. The maximization of subsistence interest may rise in the second case, but it is dubious how much the policy can lead to the after-years lives in peace and affordable subsistence. Abundance also is a very difficult concept to weigh in any definite direction on our examples. Then we now apply his tenet of universal and private or personal interest where the individuals should comply with the former in the maximization of his happiness. If the human rights violation were to be resolved in other way, the private interest and universal interest would comport among another. On this test, the outcome would be similar that the first case only can ensure definitely to share both concepts of interest. In the second case, we see the universal virtue of social welfare, but could be well rivaled from other kind of public interest. The third case would go into a jumble of different values across the culture, social attitudes, legal theory, custom and intellectual divergences. Given the universal interest comes not in any clear context, the third case would be ranked in the last.

\section{A Concluding Remark}

His idea is foundational in theory and tenet, and can persuade many challenges and issues to be resolved. His contribution would convert a youthful idealism into a practical ground with the weighty responsibilities of public organizations. Our lesson also lies in his view about the nature and function of public administration, for example, "liaison" uniting them and "public felicity." He also recognized the hard nature of public cause or engagement in contrast between a "chain of iron" and "rope of sand" (2006). Although the private interest is only to be endorsed if to coincide with and share the universal interest, there often would be so a strong of private interest like the iron, and the public role would likely search a rope of sand. As we acquiesce in his dealings, "community of interest" and "community of sympathy" in the Spanish America or the concept of "alliance and partnership," it might be a product of influence from the colonial experience, hence, international in quality, but also coincides with the national dilemma, for example, civil actions in the courtroom between "procedural and substantive." How to design the civil procedure in the end of speedy, fair and impartial administration of justice would be a concern of public felicity, however, secondary and merely supportive to the serious contention about the property right or private interests. One example could be a former form of GATT, 1947 GATT, in the contemporary international politics, in which the GATT council was relegated as mere a "liaison office" without any decisional power. In any case, his idea is actually ambitious and persuasive to cultivate the public officers, as we agree on his four elements of public utility, i.e., maximization of subsistence, abundance, security, and equality (2006). This quality can immediately subordinate the right, a most enhanced form of private interest, serve the proper ends of government, and comport with the foundations of civil law, and are considered as constituents of universal interest. 


\section{Reference}

Audard, C. (1999). Anthologie historique et critique de l'utilitarisme, tome 1 : Bentham et ses précurseurs (1711-1832). Paris: Presses Universitaires de France - PUF.

Murphy, A. (1998). Reason, Reality, and Speculative Philosophy. Madison WI: University of Wisconsin Press (1996).

Laureate Education Inc. (2003). Ethics and Social Justice "Human Rights: Applications" with Amanda Baker (approximately 8 minutes).

Postema, G. J. (2006). Interests, universal and particular: Bentham's utilitarian theory of value. Utilitas, 18(2), 109-133.

Universal Declaration of Human Rights, Retrieved Oct. 3, 2013 from http://www.ohchr.org/EN/UDHR/Documents/UDHR_Translations/eng.pdf. 


\section{Equality and Distributive Justice}

\section{Some Thoughts on the Concept of Equality}

The concept of equality is dressed in a different ethos and understanding in history and tenets. It certainly does not connote the kind of identity or nor cohere the objects in any identical finding. It is, therefore, a relational and social concept, which is directed to the human beings. A morality-based equality does not compel to treat the objects same, in general tense, but similar, and complete or absolute equality might be envisaged, but either practically hardly achievable or deemed undue to address the equality challenge. Hence we consider the general and specific context of justice which presumes the idea of distributive justice and can respond to an argument on equality. As a modern critique, R. Dworkin lodged his viewpoint of disagreements about the proposition of absolute equality (SEP: Equality, 2013). He rather cast a competitive strand drawn from the value concept where the equality quest should be contested in a respective province of society. It is interesting given his scholarly pursuit as a legal philosopher. He is generally considered to bridge the common law tenet and ethos with explaining some of coherent uniformity and possibility of governance. As we are aware, an ultimate purpose of law underlies the liberty and equality within the subject. These concepts would be sublime and enjoy a sanctity that undertake, however, a scope of realistic challenges. Particularly, the pragmatic measure and perception from the common law lawyers like to substantiate them to expand the rule of law ideal in the hybrid or multifaceted layer of international structure of governance (West, C., 1989). In his framework, the concept of value rose to center in penetrating a new wave of demand in the international politics. The legal pluralism can also be projected in his ambit and law elements to enable the picture of ideals as we note in his treatise, titled the Empire of Law. So the value, in his thesis, plays leading us to a legal plutocracy and legal pluralism, which opens the eyesight to the realistic posture of our legal system. Then, his perception of equality would not be one of formalistic generalization, but enriched a scope of distributive justice to the emerging diversities via emancipation and post-colonial new republics on earth. In a most comprehensive context of equality moral could be encapsulated in the nomenclature of egalitarianism under which a tack of principles or specifics would be proposed, contended, argued, and debated.

In approaching the concept of equality, there are two ways in deals as a matter of intellectual strand, which would cover a descriptive equality and prescriptive one. This view was proposed in most extent by Oppenheim, and accounts for the realities of equality narrative (2013). The descriptive equality concerns the kind of story telling practically shed in our realities, which also could be afforded in an enhanced application in the tradition of common law jurisprudence and post-modern context of intellectual exposure. The ways of approach can lead to an inductive reasoning practiced on the attitudes of common law judge. They never mind to become a story teller to expose a lengthy fact about inequality or harms on injustice. Of course, their final destination would not be merely descriptive so that they analyze the facts to find a most proximate precedent to be applied. In rare cases, they undertake a solitary role to shape his or her own rule given that he fails to find a binding precedent. The context of judge-made law begins with the concern of descriptive equality to finally produce a forest of prescriptive equality. It may be compiled in order, as in the Restatement, to respond with the civil code and prescriptive justice or equality. The ways of approach would be quite opposite in essence concerning the civil law tradition, which, 
nonetheless, sees an extent of convergence in the practical viewpoints. The prescriptive equality would come, in the first, as to the statutory requirements or provision. A deductive reasoning would be undertaken to apply the law to the facts presented. A phase in the intellectual deliberation, in any case, may often be resolved in tertium comparationis to allow a distinct preserve of jurisprudence as in other area of disciplines. This view can also expand to other disciplines that we often class them in the inductive and deductive formalities (Jeffreys-Jones, R., 2013). The sense and attitude about this point may pose a grand disagreement between the creationists and evolutionists in the past years. We may reflect on our intelligent strand as a public policy student, which would also be advisable given an increasing number of public laws, hence, in a form of statute, as well as needs to refer to the case law in dealing with the public agenda.

In consideration of the equality concept to be realized in public administration, we may deliberate on morality and justice in general and distributive justice in particular (SEP, 2013). Actually the policy environments would be constituted from actions, persons, social institutions, and circumstances, which drives us on how to pillory certain inequalities. We may defer to an ethical individualism, but keep on his or her voluntary action and can allot the responsibilities, who would be a policy subject. In the course of weighing, we can learn the general and specific concept of equality as Rawls and Roe expounded. We may revert, in some cases, to the basic about the formal equality and presumption of equality. Within this province, we are required to treat like cases as like (2013; Aristotle, Nicomachean Ethics, V.3. 1131a10-b15; Politics, III.9.1280 a8-15, III. 12. 1282b18-23). In view of moral equality, the humans or policy subject in the public administration should deserve a same dignity and respect as founded in the stoicism, new testamentary of Christianity and a scope of religious branches (also for example, Déclaration des droits de l'homme et du citoyen of 1789).

The presumption of equality would be sustained in various rationale and scholarly propositions, i.e., relevant reasons approach by Williams, a conception of symmetry by Tugendhat, default option by Hinsch, and even for criticism of the presumption of equality (2013). Also one useful tenet involving the equality concern can serve the foundation of our governance structure from the ancient times through the present context. The idea is about a proportional equality as meditated by Aristotle. The concept then comes applied beyond the moral aspect of equality by dealing with a numerical and proportional dimension (2013: Aristotle, Nicomachean Ethics, 1130b-1132b; cf. Plato, Laws, VI.757b-c). Therefore, it turns to possess the quality of being incorporated as the political ground, a virtue of head count in the equal election and governance measure, involving the proportionality concept, so that it enables a hierarchy and inegalitarian treatment. The findings of justice come to be pluralistic, realistic, and circumstantial, but on proportionality principle about the leeway of policy measures on different treatment. Aristocrats, perfectionists, and meritocrats would rely dominantly on this concept of equality and may be seen adapted in the kind of value argument from Dworkin (2013).

\section{A Case Review on the Equality Concern}

Let me brief on the case of equality controversy arising from the context of WTO measure. A preferential treatment for the underdeveloped countries in terms of tariff was deemed a kind of substantial justice or positive liberty in the initiative of UNCTAD around 1970 's. The rules and principles of WTO embedded a non-discrimination and liberalization 
of trade, which governs the international trade regime. Hence the member states are owed to respect the fundamental principle which crystallized into the MFNT and National Treatment as provided within the scope of multilateral trade agreements. These principles ensure, for example, that the member states are required to levy a same rate of tariffs if the goods are of "identical product." Hence, the concept of Aristotle, "treat the like case as like" was employed in the end of acquiring an equal justice. The concept of proportional equality also is assured that WTO, through its policy vehicle, monitors and controls the nation's trade policy in advance, and provides a legal stability and predictability in some of hierarchy and governance structure. A numerical concept of equality also was incorporated by instituting a political consensus system generally on equal vote concerning the issues and agenda of WTO.

The threat to equality, then, would be obvious that the preferential treatment on tariffs violates the equality because of its nondiscriminatory imposition. Country A would be prejudiced about a different rate of tariff while Country B may benefit from such preferential treatment. Country $\mathrm{C}$ has to keep on her promise, say, a tariff concession, often effected in advance and as general to the whole of member states, toward or with Country A. However, a preferred status from the lower rate of tariff for Country B operates yielding an unfair outcome to decrease the expected share which should be entertained by A. A relational concept of equality would be obstructed, and obviates the requirement of MFNT.

The factors in this contradiction is notorious involving a popular contention between the underdeveloped group and developed countries. This dilemma also relates with the concept of positive liberty and substantial justice. We perhaps may share a same concern and ways of approach in the ontological argument about the first principle of justice and distributive one as found in Rawls. His conclusion to legitimate a justification of international aids or grants would hint on an attribute of contention underlying this dilemma. If we apply the value approach from Dworkin, the value could be endorsed in some cases, but may be rejected in other context. For example, the controversy about any due extent of legal protection covering the intellectual property among the two groups are notable that the value to guide a shape of legal dealings about the extent of protection can still be arguable on its merits. Then the general concept of equality now turns on a specific nature that a morality aspect of equality, often endeavored on the laissez faire concept of equal opportunity, would be recast involving factors, as said above, actions, persons, social institutions, and circumstances and so. The positive liberty, in some stronger ethos, rose as we see in the enabling provisions, that justifies an exemption of WTO obligations based on the statutory causes. The provision of General Exception would also indemnify the duties and obligations prescribed in the trade treaty. Here also was involved a political commission of UNCTAD, whose role is expected to support the underdeveloped economies. However, the attempt to institute a preferential system of tariffs on behalf of the underdeveloped countries initially failed to find a space in chapters of GATT. The way to recourse so as to pillory these inequalities could only be practicable through resolving the issue politically. A political nature of provision to deal with the exemption of duties and obligations is the Waiver clause, which can be granted by the weightier majority vote. This course actually was followed in the course of instituting the system, what we call GSP.

\section{Some Cases on the Distributive Justice}


Please let me outline several issues entailing some of dilemma in our intuition of justice or equality, which I have considered to reflect our realities in the contemporary society (West, C., 1989).

First, the UN framework is interesting to operate, in major, within two dimensions between the General Assembly and Security Council. The former organ accommodates all member states as their constituent in dealing with the organizational responsibility. They, however, have no realistic power to decide on a coercive action or remedy unlike the National Congress. The UN Security Council would be a unique organ to impose a compulsory measure or sanction where we also have two types of member states between "permanent and non-permanent." The permanent members of UN Security council are comprised of five major powers, and non-permanent ones would range at ten. The latter serves a two years term, and the permanent members have the power to veto where one dissent may null any possibilities of coercive measure for the international justice and against intolerable challenges. Given the equal right of state to her sovereignty in the international community, the non-member state may complain about their status, particularly if the state is economically powerful or maintains on international bearing as the kind of lead or influence.

Second, the global economy, in this contemporary framework, requires the states to be interdependent among another, and virtually could not survive if in shutdown from the international trade regime. This leads to such a high number of WTO memberships, about over 150, and recently allows us to witness the entrance of Russia and China. The advent of this behemoth was achieved in 1995 through the valiant efforts of international policy makers and on extensive negotiation of so long a seven years, from what we call Uruguay Round. The scope of jurisdiction expanded and many intricacies to catalyze their public role and function were instituted. For its foundational vision, almost all of significant global states were incorporated that the component and attribute of member states would be highly incongruent. Some states may be unable to the dire needs of people, and the national system of economy may take a different path as we find in the Communist case. In this background, the contention in basic ways of approach is notable, what we often call the North and South issue. The southern states, located in the southern part of hemisphere, are populated by low income earners, hence, massively underdeveloped countries. That is posed as opposite for the northern states. They are nevertheless as tuned, in tons of proposition, with the liberalization ethos and framework, which WTO envisages as its ideals and coincides with the developmentalist claim on the "level playing field."In the counter thesis, the less capable states may raise their position in favor of the more concretized concept of substantive equality.

Third, the admission policy of public universities are expected to administer fairly based on the quality and his academic achievement. That is required given its nature of organization which would not be compared to the private universities. In some cases, we bubble on a gossip about lots of donation, esoteric or other exterior element involving the children of famous politicians or superrich, which allegedly factors an admission decision of the prestigious private universities. However, that is just the case for pass time. In the context of public universities, it could be disputed as a matter of law, what we are familiar with in the label of affirmative action. The context gives us a useful point when we think about the nature and essence of equality and social justice. It exposes a scope of elements in contention which are often raised as a focal point to deliberate. To say, the simple or complex equality, 
equality for welfare, choice and responsibility, equality of result, equality of resources and functioning, and so on, which many scholars visited to consider.

\section{Principles of Equality, Resolution and Points of Thought}

Let us consider the first case through the thoughts. The libertarianism has a repercussion to claim its primate value from the right to original freedom, being largely critical about the social right and redistribution policy (SEP, 2013). The state entity is often considered to enjoy the kind of similar aspect on an individual, hence, inviolable nature of selfdom and right to equal treatment in the international norms. We hardly find whatsoever reason to any privileged status, in principle, for the class of nations. A realistic lesson and history may influence the shape and work role within the UN enabling the concept that even a political issue is not to be complacent with the simple equality (Jeffreys-Jones, R., 2013;West, C., 1989). The concept of complex equality may be of use to explain this exposure if the permanent members are viewed to possess the power of policing the international community. A historical contingency upon the bitter World War II also factored to create this power structure, so that the utilitarian concept of equality would less be pertinent to arrive at persuasive reasoning. That is because the theory presupposes an equal share in tenet to maximize the happiness of constituents. Japan and Germany, for example, however, would no longer be saturated given the elapse of long decades and their rise or emerging impression nowadays. The choice and responsibility argument may enlighten a ground for this contemporary structure. Since two nations voluntarily assumed to wage the war and incurred a breach of peace, they should be responsible to be excluded from the sensitive foundation of world politics. From the camp on equality of resources, the "veil of ignorance" works importantly to explain the distributive justice as in Rawls, so that the difference principle may find its dimension on justice (SEP, 2013). They are, therefore, innocent from an unjust consequence from the circumstances beyond his or her control. They are responsible, however, to the consequence grounded on his decision or action. The tenet came rather applied in the case of Dworkin or Sen where the former shed a more emphasis on "ambitionsensitive" as a prelude to the Sen's "equality of functioning" (2013). Both stressed on a human element and the life conditions more emphatically than the resources or economic elements. In this sense, we can note an "endowment-insensitive" plane that Dworkin has played to enable an equal intelligence, choice, decision, and value. He, then, would be more callous about the materialistic anonymity or capitalistic logic embedded on the autonomous or inhumane dynamism. His illustration, "hypothetical auction," also implies his undertaking about the importance of human strands, which perhaps would be tuned most vividly with the choice of each individual. This way of thinking is less helpful in the first case given the realistic road of international politics would see the materialistic elements, such as the extent of nuclear capabilities and the national strengths dominantly from a materialistic quality on the basis (West, C., 1989).

However, the creative economy and web-based business or industry, now in public attention, could be discussed intimately on his version of justice. Apple may have no manufacturing base or large facilities of factory. It earned a tremendous amount of dollars simply with some of high tech web network, which could well surprises the global public about its aggregate of corporation value in the stock market. We also occasioned, in the newspaper, a success story of information business, the function of which is distinctive from the traditional ways of business. Even the scholarly sector of business, say, contribution of 
article to the journals, e-books and articles, and the mode of education and so, turns on the internet-based interplay. The equality of functioning, as Sen focused, needs to be adjusted by incorporating a technological advancement. For example, unincorporated limited liability entities (ULLC) are now to be a dominant form of internet-based business, which provokes our thought about the ethics, fiduciary duties of officers and directors, and possible misuse of business form as well as due regulation. What is an endowment in this case, in the sense of Dworkin, would perhaps be gotten in a different strand like the Apple's case.

The equality of resources concept can yield a very instant conclusion to support the current standard of WTO practices, and that would also be complemented with Rawls and Sen (SEP, 2103). How to boost the underdeveloped economies is a serious concern that we need to ponder through the delivery of trade justice in the international community. They may well be viewed to manage on the veil of ignorance and within the circumstances beyond their control. For example, they plainly would be frustrated with the level of high protection given the current standing of national science and the needs to draw any requisite knowledge or technology for their developmental paradigm. We perhaps would find no ways to accuse them of any control or choice on their behalf. The context also corroborates with the "equality of welfare," though in some variations toward any "maximization of welfare" in the WTO commitment. A theme of WTO would likely be on the tons of welfare advocacies often available from the politicians. This attribute contributes to a special treatment of underdeveloped countries by exempting them from an instant institution and implementation of the western standard of legal protection for the intellectual property rights. They may be privileged by obtaining a legal counsel under the aid of WTO administration bureau and institutionally from the special proceeding requirements. This is because they are less competent to legally claim their interests and rights by formal proceedings. This status is also pertinent to the ambition-sensitive or functioning version from Dworkin and Sen (2013). In this aspect, the privileged group of states would be ambitious to play within the WTO system despite a less endowment and vulnerable capacities in disparity with their developed peers. That may be remedied from many provisions and practices instituted to procure the substantive justice and equality.

I suppose that the third case has a distinctive element as notable against other two, say, the past wrong. The affirmative action designed and practiced in the US involves the concern and policy strand to cure the past wrong. Other justice theories most always trigger a progressive and future looking moral argument as in the equality of resources and functioning, ambition-sensitive equality as well as the equality of welfare. It poses, therefore, challenges about the equality and responsibility, perhaps pluralism and democracy or merits based approach. The affirmative action may serve a pluralism or democracy leading to the social congruence, but may damage some of merit based approaches often considered pivotal in the public education. That may relate with the equality of welfare in a distant picture, directly in some extent involving the affirmative action of public bidding, and rather constructively in the school admission policy cases. However, the countervailing argument based on the merit or quality of students is also strong. For example, they argue that a female would be assessed inferior to the male students in view of the learning and intellectual capabilities. Their message cast a suspicion of why only the black students are preferred in the admission decision. Part of countering argument may rely on the theme of curing the past wrong. It perhaps requires, however, undertaking a long journey to persuade from the different principle and veil of ignorance. We may be reluctant to endorse the factors beyond an 
applicant control, and our usual criticism on the "brute-luck egalitarianism" can find a ground (2013). This generally pushed the court back from the generous stance by wavering on the case-by-case basis concerning its constitutionality.

\section{Reference}

Jeffreys-Jones, R. (2013). In Spies We Trust: The Story of Western Intelligence, New York, NY: Oxford University Press.

Stanford Encyclopedia of Philosophy: Equality (2013). Retrieved from http://plato.stanford.edu/entries/equality/.

West, C. (1989). The American Evasion of Philosophy: A Genealogy of Pragmatism (Wisconsin Project on American Writers). Madison, WI: University of Wisconsin Press. 


\section{On the Equity}

\section{An Outskirt Highway and the Equity of Traffic Fare}

Seoul is the capital city in Korea, and furnished an outskirt highway to round travel the city. The city officer recently announced that toll booths for the fare to use would be installed. In other words, use of highway now turns to be managed of the paid basis from free of charge system. The public now critically assess the nature of policy shift in square points of contention. One expert, Yong-hoon Park, who serves the Traffic Culture and National Campaign (TCNC), commented, it would be inextricable to change the system. In earlier years, the free of charge system would be effective and mutually beneficial. That is because a number of toll booths require an extended budgetary burden to install at all the lamp entrance places.

In this case, the equity interest would not be well served, but the feasibility and overall value on the public benefit would be traded off (Laureaute Education Inc., 2013; Cooper, T.L, 2012). It is, as we know, highly related with the regional transportation demands, and the situation changed rapidly to aggravate toward an intolerable inequity among the region. That is caused by the increase of use exploiting a free of charge system. Other challenge also thrills the policy makers that some specific cuts of entire highway is conspicuously congested with many cars, trucks and buses. This incurs the traffic flows in the problematic cut of area would be baffled at lower speed by two times. Then the Seoul citizens, who would be a major clientele in this issue, can ask, "Why was the change not implemented initially, but after ten years on the free of charge system?" The answer is that the fare collection management has been upgraded recently at the aid of technological provision. This enabled to lower an installation expense, and could be afforded an equal distribution of public service. One problem is still unresolved that the identification system of auto license number has not been 100 percent-proven quality. Therefore, the follow-up measure and efforts are necessary to verify the capacity of current identification instruments. Other chores to trouble a perfect implementation of new system would be the post-travel collection attached on the HIGHPASS exception. In this case, the collection rate is less, so that the course of collection management needs to be tightened and strictly enforced.

In terms of equity, the north and south division seems to incur a graver disparity. The above scenario only would pertain to the south division which the Korean Road and Highway Management (KRHM) is responsible for. As in cases, the equity in this Division may be improved. However, the north division, unlike the south, was launched in the responsibility of private enterprises, and the fare to travel has already doubled to the southern case. How do we evaluate this context of inequality between the north and south. The south division, as antedated to the North, was not privatized. However, due to the fiscal cliff, the north division took a different approach to increase the fare at 2.6 times higher. This disparity in the use of public service yields disgruntled clients and highly wavers the residents as depending on the financial problem. If the government is financially affordable, it could purchase the privatized section of highway, the north division. Then the problem may be lessened, but still pounding is it that it could not settle on the challenge of beneficiary's rule. For the non-users, the inequity would be obvious about why the government appropriated the tax only for the class of highway users. Under the current status of issue, a most plausible alternative is that KRHM purchases the privatized north, but with some countervailing option 
to complement a fiscal deficit. The precedent could say some that Korail once has the same fiscal dilemma, but that they could be aided by taking over the management of Inchon Airport Rails. The policy wisdom can solve to lower the fare of north (2013).

One other issue in terms of equity and social justice is that some highways had been replete of their basis of collection since the construction and maintenance expense was already recovered. They, nonetheless, continue to collect the fare. This problem also leads to think about the inequity among a various nature of clients. Some may reside in the area where the highways have a long history. Others may live to be adjacent with the newly built highway cut or section. This inequity, in nature, could hardly be addressed that the citizens of Inchon have no way to share tolerating. Some policy discretion could diversify the operation by building an underground road on the free of charge system. It can diminish an excessive use on the on-land highway which is a culprit of squeezing traffic congestion. A mere delivery of policy for the free of charge reform could not cure effectively the overall dissatisfaction of Inchon clients. Any imposing factor to the traffic users would be from the congestion more than a little higher fare to travel. In any case, this section in the coverage from Seoul through Incheon would bear the same way of solution that the management responsibility should be clarified and transferred to Inchon city (2012).

\section{Between the Two types of Medical Service}

One other public issue to be related with the equity concern in Korea has been discussed in the National Assembly. Eon-ju Lee, a congress woman from The Public Health Committee in NA, raised an issue about the inequity of the National Health Insurance between the Western mode hospitals and Eastern Methodist clinics. Korea has two types of health service which is official. That differs from the US and other western states. Probably, this dual system, which is sustained from the public education, tax and public insurance program, and others, would often be practiced within the Oriental states on earth. Mrs. Lee cast her critical viewpoint, "the public health insurance needs to be designed on the basis of medicare demand, scientific basis of health service, as coupled with the patient's financial burden. Any most important standard to weigh the various factors of policy issue would be an equity. The Eastern Methodist health service now achieved an international standard of health science, and the national demand has increased steadily. The public education to breed its professionals often had been included in many universities along with the western mode medical college. Nonetheless, it is unreasonable to discriminate the types of health service in terms of the national health insurance program. Mrs. Lee illustrated the statistical data by pointing to some grossly limited ambit of national insurance policy. In Dec. 2009, the Eastern Methodist physical treatment was incorporated as the policy item of NHIP. Afterwards in the next four years, it turned to be a stalemate without any addition of policy item. This stalemate would be get worse if the initial scope was found to be limited about three sub-strands of policy item, not all of scope we often denote with the meaning of "physical therapy" The total amount of subsidies from the government is as less as 24.4 million dollars in 2011, and 21.7 million dollars in 2010.

This passive nature of number shows the government has been unresponsive to the emerging demand of nationals for this type of health care. According to the statistic bureau of government, the satisfaction rate of nationals from this type ranges at $55.9 \%$, which indicates some higher than the western type. Given this, she saw no reason if the scope of physical 
therapy was limited in the insurance purpose, which would be contrary with a comprehensive recognition for its counterpart.

This flaw of system and an unequal treatment without the proper ground about classification would bring a discriminatory effect on the share of patrons within the health service. It also exhibits the harms to make a chilling effect against its universalization. The expansion of insurance scheme is now greatly demanded, according to her view, to increase the public incorporation of Eastern Methodist as well as equity among the different taste of nationals.

\section{Some Reflections on the Equity}

A promise of equity often is desired to restore the fundamental justice, hence, possesses a quality in subtle difference from the equality (2013). Most plainly, the common law system has two types of court division between the Court of Chancellor and ordinary court. The ordinary courts are responsible to administer a technical issue of law and often involve dealing with the issue as a matter of law. The whole concept of justice often can be graced from the Court of Chancellor as a matter of equity. The tradition of legal institution rooted in the equity court also could be found in the contemporary US laws, such as the specific performance, injunctive relief and so. The equity concept often requires a grand scale of wisdom, whose nature can be more salient in the public administration than in the administration of justice. For example, it appeals to the nature of humanity and social justice so that the jumble of difficult legal theories may be avoided. While the public administrators need to understand the law, the policy measure and its shaping would be creative to respond with the political and social challenges. This attribute can be seen as distinctive from the nature of judicial role.

Across the two cases imposed now in Korea, the clients of public service and other parties involved would be impacted to incur a possible loss from the inequity. The nature of issues was posited in the economic justice and equal access to the provision of public service. As we see in the doctrine of commercial speech concerning the first amendment issue, the issue would be dealt less serious when we approach in the shoes of judicial business. Unlike the library case of disabled, it does not entail any intrinsic of humans. Then the library case would be more amenable to the logic and metaphor in equality as we often encounter in the case laws (Kranich, N., 2007). The highway fare and different treatment of two types of health services, on the other hand, may be looked into from the road of equity quest. There would be a lesser of accurate rules and any common law justice, rather the public administrators can tackle the issue vastly from his professional inner mind process, which would be evaluative, analytical, politically and economically sensible, and socially agreeable, and also comprehensive beyond a specific rule of law (Cooper, T.L, 2012). Through the Chevron, the court developed this aspect notably in the label of "judicial deference" about the administrative actions.

\section{An Equity Issue in Inchon Nam-Gu and Its Impact}

Inchon Nam-Gu is the prescient that functions on the independent statute ground and as a local government. Mr. Park served as a major of city, who is responsible as an ultimate decision maker about the permit and license to construct. He recently revoked a 
construction permit around the time when the Muslim temple was virtually completed and foresaw to lay a cornerstone. As the completion embarked and it had been progressed under the construction permit, this sudden and unforeseeable drastic measure surprised the public. The people suspect if the measure is arbitrary and abusive as well as in violation of the universal rights, such as free exercise of and equality among different religions (Laureate Education Inc., 2013). The Inchon Nam-Gu Branch of Civil Association claimed a full disclosure of administrative dealings including a background, motives and reason to reach the revocation conclusion. According to the source of branch, "the decision was rendered that one section of parking lot was not furnished as legally required to meet the permit change from the educational to the religious facilities." However, the decision was impermissibly drastic and in contradiction of equity or common concept of justice, which forecloses any cure and correction. Nam-Gu, in the progress of construction, has affirmed the change of design and purpose of construction, which incurs a problem of public distrust concerning the city administration. This concept has been affirmed by the court and in theory of administration law in Korea that the government is precluded from the action, decision, or disposition as contrary to the established trust from those of past dealings. A public excuse announced by Nam-Gu elicited that the terminal measure of this kind often is purported to sanction or invoked in the exercise of disciplinary authority. This case has gone in the same context. The Branch raised its tone of criticism that the public administration has to keep a neutral and balanced concept of diverse interest groups and public. It is required as a matter of administrative ethics and to ensure a responsible administration (Cooper, T.L., 2012). Absent this prudence in the score of public issues and resolution, it is, as a matter of course, deemed illegitimate, usurped of power, unethical and irresponsible, as well as arbitrary against the equity and justice (Laureate Education Inc., 2013; Kranich, N. , 2007; SEP Economics and Economic Justice, 2013). The Branch also elucidated that the Christian society petitioned with 50,000 signatures containing their resentment and opposition against the construction. This may work as a pressure and may present an implied and hostile circumstance leading ineluctably to reach this decision. Of course, the suspicion could well be based if this inequitable decision was to avoid a possible backlash from the Christian society. A political compromise in the coming election with a major religious group and as discriminatory of the minor one would factor this prejudice as well as the odd administrative decision. The Branch also heralded that the present decision would hardly be sustained. This is evidenced that the suit already was brought to the courtroom and the boycott of Asian Games is being considered seriously in reaction. It expressed gravely that the present decision would undermine a national honor in the international community in the face of Asian Games. Against the sprit and expectations from the Games, it may provoke a distrust or antipathy among the Asian countries. Finally, the Branch urged a reconsideration of this issue to restore the equity and free exercise of religion. An Equal treatment between the different religious group is expressly ordained in Korean constitution, and history lets us to make sacred and sensitive to correct.

In any case, a narrow focus on one sphere only often may invite a contention, turfs, or public criticism. This means that the neglect on any one essence would pay a due price as we notice in many of public controversies. The case above introduced can be seen well in this context. Other point to merit our concern would be autonomous and self-serving tendencies of the large and bureaucratic structures. As Appleby suggests, when functioning properly the hierarchy is, the structure of responsibility would tell its axiomatic process of justice and equity (2012). That could, however, encounter a high chance of variance from 
the challenges, the nature of complicacies in the agenda and issues, political wind, personal interests, and particularly moral mazes or callous routines. Other useful dualism in approaching an equity or ethical decision making would cover the deontological (dutyoriented) and teleological (consequentialist) dimension in philosophy, and could facilitate the difficult technical strands or requirements in more principled resolution. This way of thinking also serves much to address the challenge of equity issue in the workplace (2013; 2007).

An ethics issue involved in this case is serious to impact on the Korean people and Nam-Gu officials as briefed above. As the officer of local government is paid in wage as less than the private employees, their sense of honor and personal conviction as a fiduciary trustee are any principal factor to pull their vigor of service. His or her self-esteem would be affected to discourage their followership. They suspect if the decision could comport with societal expectations of the nation (2012). The Asian Games will be some Korean favorite in the process of years on its preparation, public sharing of progress, occurrence of events, and through the aftermath in economic benefit to the locale and international prestige conducive to the success. They could even be frustrated from the neighbor's criticism and ill ways of dealing to invite an international controversy. The leadership of mayor also can be derogated by the suspicious and disloyal attitude of officers. The local autonomy and its constitutional subscription in chapter had long been debated since the nation is small in the scale and function and on a congruent basis in view of ethnicity and national history. The opposing views perceived that the restructuring of national administration in a dual dimension would unnecessarily burden the national budget and may operate as contrary to a fiscal soundness. These views had been held throughout the decades of militaristic government in 1970's and 1980's, but the democratic passion of nation has, in a tough assumption, endorsed it as one of constitutional mandate in the late 1980's. This foundation may well be vitiated at this incident in the mind of officers and Korean people in general that the mayor lost a strategically paramount side of his policy decision. The Muslim people, who resided in Korea also has a worse impression from this unanticipated overhauling of initial undertaking. As the right to free exercise of religion is universal in tenet and human rights framework, their disappointment would never be surprising. They consider gravely the contradiction of decision to the requirement of ethics that the responsible administration has to respect. In the substantive aspect of issue, it would be dubious if such minor point of violation could result in such serious consequence, say, a revocation of license continued in effect over the years. Hence the proportionality principle could be weighed in the negative force against the decision of mayor.

\section{Recommendations, Decision Making Model and Factors}

In applying the decision making model to the equity issue, I found it finer to rely on the four planes of deliberation model as reflected below (2012).

\section{(A) The conscious delimitation of commitment to an employing organization and the cultivation of identities that transcend its boundaries.}

A propensity and perception of mayor could be questioned to have a bias and narrowly focused to being misled by himself. He is an elected official who would calculate and plot on the public response and impact on the election. In this aspect, the decision can be compromised or even bribed with the majority religious group. He seems quite to be 
dismantled to apprehend the nature and quality of issue. It seriously transgresses the normal standard of equity and justice element to prejudice the Muslim minority (2007). The conscious delimitation of commitment to en employing organization would be failed in coming into any reality and practical force to determine the issue. He seems to be overwhelmed by his personal interest of re-election. As a professional, he also seems to craft his own ways to cultivate the ethical identities, and neither on any continued practice with the design approach in shaping an ethical decision. Given a respect of this advice, the chances to render this type of ill decision would be inconceivable.

\section{(B) Legal and institutional protection for individual rights and conscience}

The local government operates under the constitutional structure and its mandate is a guide in hierarchy to be faithfully honored. It is also an ultimate factor often recommended to respect in face with the difficult and multifaceted ethical dilemma. The mayor's decision seems to contravene this requirement so that it harms the equity and justice well assumed to be due for the Muslim minority. His personality can also be questioned if to cling to the reelection possibilities by attracting the majority voters, in this case, the Christian group in Nam-Gu. It obstructs a conscience often seen essential to be required of responsible administrators as a public fiduciary. Overcoming the conflict of interest might be pressing leading to the impermissible emphasis on a minor requirement of laws and regulation as well as the breach of principles

\section{(C) An ethic of awareness and cultivation of principled thinking.}

The mayor, as a responsible administrator, has to practice an ethic of awareness which cover a scope of elements, i.e., adequate knowledge, exposure to the general ways of approach and specifics in issues, organizational structure and culture, as well as societal expectations. Being more aware of the nature of issue and standing points of controversy, more ethical and practically efficient policy decision can be shaped and implemented. The issue, in this case, includes a sensitive policy area about the religion of minority in Korea, and also entails an aspect of diplomacy as well as the universal notion of human rights. The mayor should have to comprehend an enhanced level of the Korean culture in this light. Korea is a nation of international esteem due to its public virtue and culture. The selection as a host country of Asian Games plainly vindicates our international status in this respect. He failed to apprehend this aspect to disappoint the heat and passion of Asian countries from the commitment and trust by selling his responsibility to his political transaction or personal interest. As mentioned above, if he accepted the lesson and practiced a cultivation of principled thinking over the course of his professional career, the ways of dealings and outcome would develop in other ways.

\section{Recommendations and Factors in Implementation}

A solution to facilitate the correction of perceived evils in his final rendering of decision seems straightforward, say, revoking the decision of revocation of license and endorsing a completion of construction on the pertinent statutory basis, but upon a condition to fix the flaws of parking lot requirement. As the Christian people are a mass of their constituents, their support seems pivotal to administer a city politics and governance. Hence, the public forum could be planned to explain the course of development concerning the issue and obtain their recognition of legitimacy and propriety about the cure. 
The factors operating in a contrary or facilitating influence may be explored if to pertain to the individual attributes, organizational structure and culture, as well as social expectations. The individual attributes of city mayor can factor in facilitating the cure and proper remedy to the public condemnation. The city mayor may be stubborn on his decision, and can think if he may bent to the public pressure (2012). However, the civil monitor group worked effectively to enable a full disclosure of the administrative process. The high chances would be that it also can facilitate the administrative cure to restore an equity value. Over the decades, particularly in the recent trend, the head of local government often has been arrogant and stresses the local autonomy in neglect of the national needs in uniformity. The governor of Kyung Nam Province showed a determined attitude against the call of National Assembly to make an appearance in the investigatory session. He actually went his own way to shut down a public project for the aged people in the claims about the fiscal deficit of local government. His testimony was deemed precious, but his logic and understanding was fairly entrenched that the any subpoena of NA would be repugnant to the separation of powers principle. He eventually sustained himself his views and NA took no action to escort him in the purpose to realize his presence in the session. This implies that the heads and directors of local government entertain a greater conviction as an elected official leading to a tension between the central and local governments. The social expectations in this case, however, come higher than other cases so that more chances would lie to favor the possibility of cure. In terms of organizational structure, the mayor is placed at the center of power to remedy his vulnerable action. He would be directly responsible to cure the revocation decision, but the practices often do not submit to that way of dealings. The local government often cherishes the stability of decision that most cases to be remedied would process in the judicial proceedings. As the nature of issue is highly sensitizing and touches on the core of Korean concerns, say, the international games and human rights, the organizational structure and culture may possess the quality of dual side of coins in view of limiting or facilitating my recommendation.

\section{Reflections}

As we learnt, we expect the public administrators would be ethicists to make a legally valid, effective and efficient decision to maximize its utility and happiness of organizational members and constituents. Their decision, hence, could be examined in the organizational strategy and planning to have an essential bearing with the imagery of organizational development specialists (2012). The case briefed above entails a miscalculation of policy sequence and actually created the gash that now, amid the public reaction as acid, hardly avoids the alternative to squelch on its basis. While the public administrator would be a juggler managing a multitude of competing obligations and interests, the case actually revealed a vicious aspect of unethical contemplation involving the political interest of mayor himself. Often we believe, as Michener commented, that he or she, as a responsible administrator, needs to pay a due respect to the real moral problems in the abstract where character is formed, hence, they may not be fragile to be a miscreant of policies and specific decisions of challenging nature (2012). This would require, over the course of professional development, of ethical identity beyond their title and status, and can appropriate the mechanism to reach the ethical decision as suggested by Cooper (2012). Four levels would foreground the process to deliberate on behalf of responsible administrators, what we staged in the inner mind process on evaluation or assessment. They would cover the expressive level, level of moral rules, ethical level and post ethical level. The level corresponds in dimension with the process espoused in the Cooper's design 
approach including the identification of issue, available options of ethical decision, and probable consequences, and so. The public administration often involves some share of leeway in the spectrum of public values and ethics as leading, lesser in extent, to any ineluctable conclusion. We often rather are susceptible of ample choices to deal, and often reach more like an aesthetic logic or gestalt in the end purpose to attract the citizenry (2012). The public administrators are postulated well in its practical role to respect the obligations to the citizenry and the organization established to serve the citizenry. The public employees would favor to develop a professional career and buy in, in many probabilities, the compensation in the monetary form or promotion, which their conduct or activities may lead to. They nonetheless can see a vignette well-rounded life outside the work. This well vindicates the thesis about the spectrum from the individual attributes through societal expectations.

That often, as a tenet in the basics, coheres, and should do, but the issues or agenda may be complicated in a contradictory demand or in conflict of interests. As the policy issues, in this diverse society, are staged amok over the factors and interest groups, the admonition from Ralph Kilmann's to avoid "quick fixes" would help and they could base their dealings on the more practical and comprehensive context (2012). That said, it would project over the internal and external controls as general approaches and specific techniques. The responsible administrators would also be attached with a deep awareness and professional attitude to interplay with the individual attributes, organizational structure, organizational culture, and societal expectations. For example, we would know ourselves that an inherent tension exists between the individuals and the organizations where they are employed. On this point, we need to take an in-depth reflection about the possibility of individual ethical autonomy in the organizations. Then we may explore the useful suggestion about four elements so as to be responsible and in the ambit to produce a working ethics and interactive leadership; "(1) the conscious delimitation of commitment to an employing organization and the cultivation of identities that transcend its boundaries, (2) legal and institutional protection for individual rights and conscience, (3) an ethic of awareness, and (4) the cultivation of principled thinking" (2012).

\section{Reference}

Cooper, T.L. (2012). The Responsible Administrator, San Francisco. CA: Josey-Bass.

Kranich, N. (2007). Equality and equity of access: What's the difference? Retrieved July

10, 2008 from the American Library Association Web site: http://www.ala.org/offices/oif/iftoolkits/toolkitrelatedlinks/equalityequity. doi: 388396

Laureate Education Inc., (2013). Ethics and Social Justice "Equality and Equity: Applications" with Amanda Baker (approximately 6 minutes)

Stanford Encyclopedia of Philosophy: Economics and Economic Justice http://plato.stanford.edu/archives/sum2008/entries/economic-justice/ 


\section{On the Liberty}

\section{The Disabled in South Korea}

The disabled in Korea perhaps like to ride on the public bus to go somewhere they wish to reach. The subway was not well exploited to suffice the details of specific destination. The public bus was most catalyzed to serve the travel needs of public in Korea, however, we often cannot find the disabled on the bus. The distance from a road to the bottom of bus normally is 98 centimeters (Kee-ryong, K, 2002; Graff, J., 1985). Even for the normal people on the inconvenient knees, riding onto the bus could be challenging. This would certainly exacerbate on the case of disabled. For the manufacturers in Korea, the disabled has long since not been assumed as the scope of passenger. They are treated in discrimination as same like the aged, pregnant woman, children, and the patient to suffer on his legs and knees. The developed countries, i.e., Japan, US and France, have earlier lowered the gap in 30 centimeters, and also provided an equipment to support the users of wheel chair $(2002 ; 1985)$. Striking is it that Daewoo, a Korean auto manufacturing corporation, already produced this special bus in system, but its purchase has been made on the special order only to meet an occasion. For the improvement of environment, the public bus was mandated to use LNG. The road and traffic sign was neatly reformed to enhance the international events. However, the concerned people regret to find no policy or public support to provide for the disabled. A higher gap about 98 centimeters now frustrate the types of disabled which even include a brain damaged and deaf faced with the insufficient public signs. Particularly, the scene of hurried bus departure to leave the blind drastically often disappoints us. They would have no way but to ride the wheel chair lift which is highly vulnerable to risk his life. Their only way to reach his destination, however, is to use the subway loosely scattered and to undertake a long way to walk.

The disabled has been described as a cursed creature in Greek myths. They are treated incompetent to labor and forced to be subject to a public charity or benevolence. They have to hang on his tough life through a deceased in time (1985). The Universal Declaration of Human Rights incorporated their status as a national, who became safeguarded from an infringement on his or her bodily autonomy or freedom. The Weimar constitution enacted in Germany in 1919 could pioneer a state commitment about the social welfare and provision of public program for the disabled. The MB administration of Korea in the past five years had been reluctant to expand the social welfare program and the ethos or passion of society often perceived the disabled as poor and as merely the class of social benevolence (Kee-ryong, K., 2002). Their status may not be elevated to a certain of right or personal interest so as to be protected by law. A previous point of financial burden or declaratory status of constitutional prescription also is not an exception for Korea. Nonetheless, it would be problematic if the Korean constitution lacks an express language to cover them in the ambit of constitutional policy (2002). This leads us to any contrast with the ways of Bonn constitution, which incorporated the class of disabled as one factor if to centralize on the pursuit of social justice. As the constitution is a ground law and often to be referred as a basic morality guideline of nation, this lacking pushed back the critically deprived class of people, namely disabled.

\section{A Free Mobility of Disabled and its Infringement}


A free mobility of disabled in Korean society would be concerned of positive liberty since it does not require the absence of coercion from external factors. An approach to this societal issue rather mandates a public commitment to increase the freedom of person to move and travel. It presumes a certain provision of public aids and would underlie the concept of social justice. Rawls intuition, a "veil of ignorance," may echo that we are responsible to address that entrenched inequality and their challenge to freely move. How much extent of inconvenience and frustration in the personhood of disabled perhaps would be immeasurable for well persons to sense and apprehend. It would entail both issues on equality and liberty. In the traditional concept of negative liberty or lassies faire liberalism, the problem could well be blinded to let it as is (SEP: 2013). The concept of positive liberty or functional focus on the societal virtue may have some strength to ground any of public measure. Rawlsian concept of social justice would consider a scope of factors, personal talents or competence, resources or wealth as distributed in comport with the first principle, the kind of liberty capitalized to found the basis of modern society, and others. The policy makers are assumed, in the power and competence to find an avenue to realize the social justice, and shape the proper and most effective policy instrument to bridge the first principle and social justice. The group would generally be considered to have surfaced in a more extent of legitimacy and democratic representation from the beginning of $20^{\text {th }}$ century. They may be posed a challenge by the libertarian circle of orthodoxy on the property right and absolute freedom to resources. As we see, what basis would entitle the owner and user of resources, then, provokes a serious contention around the abusive social welfare program. However, I suppose that an aid to the disabled would often fit within their ambit since they lodge a highest emphasis on the liberty interest.

An issue of disabled presented above entails the nature of positive liberty since it triggers the target group to be "liberalized to certain thing," as not in meaning "the liberty from something." However, the shape of issue may differ in a subtle context although the argument of positive liberty in ways of approach would look into the internal factors on a true self (2013). This often implies that the agent would exercise a moral process in deciding to act or omit to act. Nonetheless, the issue of disabled on free mobility touches on the basic operation of bodily liberty, and concerns an intrinsic mishap in the distribution of resources. $\mathrm{He}$ or she is innately paralyzed to be disabled from movement. Some of them may acquire his unfortunate state from the industrial accident or war sacrifice.

\section{Factors to be Considered}

The profile of issue then develops into a complex equality by not being submissive to any simple notion of equality. In view of liberty, they share a common ground, however, as to be physically depraved to something. Their function to make him or herself as a social ego would be infringed to get incongruent and his personal liberty was critically abridged. The enhanced concept of liberty now requires that the principle cannot serve the whole of requirement if to merely let them to free in the absence of any external coercion. An enjoyment of certain condition to the decent human standard is often envisaged by the policy makers and explains for some of prevailing understanding of liberty discourse in the contemporary society. A liberty discussion also can be made to require the whole of picture if the agent actually does certain things in certain ways? The triadic way of approach involving the agent, purpose and constraints proposed by Christman may direct to be sucked into the topology of liberty assessment (2013). A constraint would constitute the key factors in 
concern, and the absence of any kind of constraint whatsoever on the realization of one's true self could be a critical test to the desired state. It would also be corroborated by the simple standard as Green and Bousanquet encapsulated, say, "the absence of all factors that could prevent the action $x$ " (2013). The modern views also put an emphasis on the comparative assessment to arrive at the sound stream of societal justice on liberty. Hence, as commented below, the US ways to deal with the issue would illustrate a desired state in protection of the disabled to assist with their physical handicap.

A comparative view with the US institution could help to comprehend how the liberty or personal freedom of disabled in Korea was discriminated. It is obvious that they actually cannot do certain things in certain ways. The context of Korea involving the liberty of disabled would clearly fail on this criterion. The US has also experienced a challenge and public debate split in contention concerning the extent of pubic provision and ways to boost them. A first statute to deal with the issue of disabled perhaps would be the Urban Mass Transportation Act (UMTA). This Act includes a policy goal that the aged and disabled have the right to equal access to the public transportation. It also prescribed the mandate of federal government to exert a special care in designing and planning the facilities and program of transportation service. In 1975, the Federal Aid Highway Act was enacted, which purported to mobilize a federal grant or subsidies to facilitate the public transportation for the disabled. A most ambitious and powerful scheme was arranged in the statute, what is called the Rehabilitation Act Section 504 in 1973. This act enabled a scope of public measure by incorporating the duties and obligations of private business.

We may consider the standard of liberty for the disabled may be evaluated in variances, which led to the different extent of welfare provision for them. However, it is deplorable that a very basic liberty for the disabled was not succinctly addressed in Korea.

\section{The Concepts of Liberty and Politics}

The liberty would be an epistemologically cumbersome in any hard way of definition, but a ground to be explored and contended seriously in view of human intrinsic, social desirables, morality argument as well as the political terms of society. The liberty, therefore, would be on a due course of dynamism which exposes some incompatible interpretations of a single political ideal. For example, the relationship between the liberty and political ideals or desired frame of political process would not see an agreement between Constant, Humboldt, Spencer, Mill and Rousseau, Hegel, Marx or T.H Green (SEP, 2013). They would probably conceive a same extent of importance or value attached to the liberty, but their vision on the political dealings to address a modern sovereign state would diverge. Often the liberty would constitute one of ultimate goals that any respective political community envisages, pursues, or in the least not to taint the essences enshrined in the value of liberty. That would not be negated by both liberal and communist framework of politics. And even the regime of monarchy could share the idea of liberal subjects in the comprehension of value and in shaping a moral structure of society. Hobbes may be perceived in this purview about his proposition of social contract. He played under the assumption of authoritative monarch as a justification of politics, but ideated the ground of individual liberty to a safe condition, interests of life and limb as well as his or her property. It is an irony that the absolute power and sovereign can shake hands with the liberty concept. Rousseau's collective will would dispose another errand to respond with the emerging thoughts on enlightenment and political 
freedom. His idea made the rising class exuberant to entertain the liberty, and enabled to lay the positive concept of liberty by participation and activism to constitute the public will. It could be echoed in a similar fashion as coupled with a labor idealism that the communist society would be paramount in championing a human morality and liberation of self. An emancipation of the rising class in reliance with the social contract principle could be developed in any refined manner by Locke in his treatise on civil government. Based on his bureaucratic career, he derived many strands of public governance, and has been considered as to proffer a lee way of new understating from inference and interpretation (Murphy, A., 1998). His theory would be realistic in practical dialectics about the value of civil society and loyal government to process their responsibility. He recourses the public power from the social contact and an eclectic bridge between the civil power and sovereign. His idea, however, will culminate to favor the former so that a Regicide would be legitimate if to be exercised in the end of preventing an intolerable tyranny. His ways of governmental process could be seen in the separation of powers principle, which was to merit two or four independent attributes and to include the power to legislate and execute or power to consolidate on the different states. Perhaps in order over Hobbes, Rousseau and Locke, the primal concept of modern politics could be classed in view of the extent of authoritarianism, but three version would converge to the ideal of individual liberty (1998).

\section{The Positive and Negative Liberty}

When we deal with the concept of liberty, a most popular way of approach may be found in Berlin's classification between the negative and positive liberty (SEP, 2013). The negative liberty, in essence, requires the absence of obstacle, barriers, or constraints, hence neither coercion nor intervention from the external strands, such as institution, society, notably government and other forces or influences. Its implication would bring a serious consequence in terms of political rightness and foregrounds in vast extent the basics to constitute the political community. It, in the application, led to the virtue of minimal state and has been most contributive to an economic dimension in developing the modern prosperity of liberal capitalism. The tenet would also still be maintained in virtually no diminution about the practical dominance of metaphor and logic in the contemporary global market. As the concept is presaged, the nature would be on prongs to be related with a biological freedom, natural law ideas, the kind of Darwinian ways of apprehension, and economy. For example, the pursuit of commercial interest would, in some light, be perceived as insurmountable and hardly curbed toward the impractical accumulation of wealth or capital. It can grow indefinitely to stage at some terminal self contradiction according to the communist moral perspective. It is plainly self-evident that the negative liberty would be most favorable that the enterprises would embrace. Recently, the public controversy aggravated at the news paper report of tax heaven. A plethora of Korean superrich allegedly exploited an opportunity of lower tax with the unauthorized export of their wealth and in a hidden way to evade the higher tax duties in Korea. As a host country, Haiti or Virgin Island under the British rule, manages on a benevolent national tax schedule and the banks or intermediaries in trust or estate could conspire to serve their unlawful purpose. A tax issue also created a public resentment in the Boston tea party, hence offered a revolutionary moment to liberalize the colonial merchants or land class. The nature of plutocracy in use to denote an early colonial state is generally undisputed and, in some respect, a more embedded interest and spirit to guide the structure of 1789 federal constitution. The wealth and negative liberty would be a close peer to fit as being championed inviolable (Murphy, A., 1998). Other area in an 
important interplay with the negative liberty would concern the freedom of personhood. An unlawful seizure and arrest would be in a primary focus when we deal with the concept. A prevention of torture and privacy right to bear a personal appearance can also be exemplary at matter of negative liberty. The militaristic government in 1970's of Korea enacted the statute to regulate the length of hair whose type would be often patronized by the entertainers and popular artists. The authority of government had ample ways to freeze the pedestrians on the street and imposed a fine or several days of detention in the police station merely on the basis of his hair look. A comrade court of former Soviet Union and the criminal justice system in Great Britain would serve the public goal by imposing a public requirement by the light penalty, but if the negative liberty may not be ensured in a perfect extent. This kind of institution can convivially disclose the operation of negative liberty which would be simple, basic, universal, and through the ultimate of personhood. Interesting is that the criminal justice system in Great Britain would rely on the lay judges, whom we often call a knight and which disposes a petit crime involving the breach of public peace. It is a greater way to exercise the state cause in interacting with the traditional virtue, but may possess the quality to impose the kind of positive liberty in an authoritarian understanding of public or personal moral as in the case of 1970's Korea.

The positive liberty, as hinted, rather deals with the whole of person beyond the nature or personal autonomy. It would be more friendly with the belief of Creationist version where the origin of human being is from the God. The nature and quality of human being would be cast to entertain a self-mastery and self-realization or self-determination, and they would intervene to define the concept of positive liberty (SEP, 2013). In this purview, the internal factors to hinder a liberty could come into play that a psychology or individual morality compounds the argument to shape any true nature of liberty or freedom. While the negative liberty would be framed "the liberty from something", the positive one foregrounds a dynamism as "the liberty to something." Hence, it is an applied level of understanding to interplay with the system and political process. As in the Rousseau's introduction, the agent is required to participate in the political process to ensure their liberty interests. As Marx delineated, the human ought to understand a false consciousness and materialistic injustice or fallacy to betray the nature of humanity. They often call their army as a "liberation might," as in the case of Korean war, and the liberation theology may develop a similar way of thought on the contemporary society. However, their failure to see the pluralistic nature of humanity, as entirely hallucinated with the materialistic dynamics, would be questioned. A tenet and ethos of positive liberty now offers the conceptual ground to the paternalist or moralist state intervention, and intermediates the third way of European politics, for example, as Giddens suggested (Crocker, L.H., 1980). A most opposing promise of western politics against the paternalistic intervention would be the neo-liberalism espoused by Reagan and Thatcher, which was founded to restructure the flaws and inefficiencies of $20^{\text {th }}$ welfare paradigm. The examples of positive liberty would be omnipresent in the contemporary affluent society. A Special District of public education may enable their students to function positively by providing a free IPad to support their study and leisure time. The temporary unemployed people in Korea would be afforded a small amount of pension money to reproduce their quality and standard on any job vacancies (Laureate Education Inc., 2003). National pensions for the teachers and government officers can be settled for the decent standard of living upon the retirement age. We can see "the liberty to something," say, a decent living after some statutory age in this case. Around these cases, we can note that the simple absence of external coercion would not suffice to bring the positive liberty (Crocker, L.H., 1980). Hence, the concept of positive liberty envisages an assumption about the divided self, which 
hypothesizes a higher self and lower one. On this concept, we note that our empirical desires would be complicated to enhance the dimension of liberty, but the positive liberty may be criticized to neglect on the external factors or political ultimatum which often is determinative about the mode of our existence and interplay. In other review, the critiques pointed to the similarities by illustrating the moral nature of proposition as we encounter in the ascetics, stoics and Buddist sages (SEP, 2103). An unilateral emphasis of the positive liberty can also be misleading because it involves a 'retreat into an inner citadel' - a soul or a purely noumenal self (2013). It is noteworthy, however, that some modern thinkers capitalize on the personal growth as the essence of liberty, which could compromise the above dualism and in the illustration of plants.

\section{The Political Liberalism and Contemporary Debate on the Liberty}

A sphere between the liberty concept and political liberalism actually would pose some practical challenges, but unfortunately hardly be reconciled in any expressive framework. This context can be adduced in the perception of Christman that the society is composed of supposedly heteronomous individuals (2013). Absent any definite answer, it would serve to "remain as is," which would comport with one tactics of oriental wisdom from Paduk (Oriental chess). However, merely non-interference would say little that the virtue of liberty presumes an enjoyment of certain conditions. We consider a most influential promise over the wake of western democracy as neo-Roman (Quentin Skinner) or Republican liberalism (Philip Pettit). It can bridge the concept of liberty and democratic governance on the tradition and inviolable virtue long upheld in the statecraft. The concept of human rights, separation of powers principle, deliberative feature of democratic dynamism, and philanthropic assumption on a fiduciary duty, trust, frugality and others, would ground its ways of recognition and thinking (Laureate Education Inc., 2003). It also substantiates the institutions to practice democracy, and hence interplays with the liberty interest on an individual. A political liberalism in the contemporary context can also be contended as we note in the shutdown of federal government and national crisis of default. The kind of skepticism, "is it any subservient to the increase of positive liberty of Americans," may be captured in the face of tremendous debt. However, we also question if it would be acceptable to paralyze the federal government which is responsible to ensure the basic liberty of American citizen. A defense and police service may be affected or the national park may fail to ensure the liberty toward a decent living and pleasant environment. The Republican liberalism or neo-Roman would proffer the institutions to regulate the permissible ways to interact with an individual. In this point of concern, the ways that the desire is formed would be emphatic and the government would be expected as neutral about the content of freedom as in the illustration of Muslim women by Christman (SEP, 2013). The same idea could be found in the time, place and manner regulation concerning the First Amendment right. This implies that the content- based regulation on expression, in comparison with the content neutral, would be deemed more culpable and constitutionally suspicious subject to more chances of condemnation. Under the philanthropic ambit of liberty discourse, however, the educational exposure or cultural environment may affect even empirical desires, hence, the content of freedom, and a higher level or course of moral judgment. In other words, the internal factors would be created from his or her personal learning and experiences according to the view of Christman.

Other strand entrenched in the Republican liberalism lies in non-domination and the kind of ultimate belief embedded on the positive correlative between the domination, 
arbitrary power and threat to the liberty (2013). Hence it would be a virtue on their conviction to implore on the partisan switch of political power on a regular basis and to filibuster against the prevailing power in the Congress. In their wellness and conviction, the constraints on the political branch are always greater to secure the liberty interest. In their vision and tradition, the kind of Berlin's fear about an infringement on the negative or positive liberty, mutas mutandis, the Chrysippus' understanding of self-determination, may be structurally eradicated since his fear would be cultivated by the fact that the political power may be liberal only on a whim.

We generally consider that there is no distinctive use of two terms in the lay world and even in the academic or historical context, which are between the liberty and freedom. There could be a contingency to favor one word, but the definition to a different note can hardly be ordained nor occasioned. Hence the concept can share a same attribute and meaning to denote a certain state or human condition that the personal autonomy would be protected by the absence of coercion and their desire can be in comport with their moral standard to act for or forebear from something. The concept of freedom would be attractive to gear up toward a new discourse of liberty or freedom beyond the dualism and other classic controversy entrenched in the wake of history. Nowadays, the comprehension of liberty proposers or critique rather focuses on the overall aspect of human condition so that they detest to be exorbitant in the dealings of analytical philosophy. Hence, the comparative stance between the societies may be one of useful attitudes for them. They also suspect if the three variables or triadic views of "agent, constraints, and purposes" could still be powerful in taking account of the contemporary issues or dilemma involved in the liberty. Their concern may be driven in any more intense level to see whether the agent is "actually doing certain things in certain ways" (2013). For example, the people of China or North Korea may trouble with the liberty or freedom, and cannot be comprehended in any clarified way to assess their problem. Are they free on the popular use of internet or can they actually be free to express an opposing view or to critique the legitimacy of their regime? Are they actually residing within a decent housing from the minimum standard of human condition? This kind of overall and consequential ways to assess would be phenomenological and useful on the realistic ground. A merely different focus on variables or extension of them across the respective theory would be inefficient or mislead to the fallacy of concept. The concept of overall freedom would presume the absence of any kind of constraints whatsoever on the realization of one's true self. In other words, the absence of all factors that could prevent the action $\mathrm{x}$ would be triggered, in the view of Green and Bousanquet, leading to the elimination of elementary confusion and convergence toward the whole of free or liberal person (2013).

\section{The Liberty and Freedom or Other Concept}

Despite this feeble use in distinction, the liberty and freedom may well be in contrast with the concept of license as Locke ascribed. He elicited that a license ill deserves the name of confinement which hedges us in only from bogs and precipices" (2013; Second Treatise, parags. 6 and 57). A liberty would often tackles the universal context of human condition and the state of personhood, which generally squelch the sectarian concern to any discriminatory effect. It would go otherwise if a license means the kind of authorization to qualify the sectarian liberty or freedom to do something. For example, any business license, driver's, or professional license to practice their expertise would pertain to this scope of freedom. It may assume some of special factors to contravene the universal context of liberty or freedom on the general basis. The concept of license or charter and incorporation for the business 
corporate, later subsidized the capitalist economy and amenable to the national control in any uniform fashion and about the factors. It represents a part of human state, but can chill the scope of agent's liberty. Therefore, it entails an attribute of positive liberty if to examine the internal factors in the purpose of analysis. It often is directed to the dimension to do something freely and intervene to coerce the unlicenced agent to forebear. Furthermore, the bar ethics and standard of practice, for example, often require to maintain a level of integrity and professional morality.

Over the history, a dualism on the positive and negative liberty perhaps would impose a highest tension between the liberal and communist scheme of governance or polity. One point of contention underlies the exploitative nature of capitalist economy. In the occasion of bar license, I like to mention the context of working and compensation method on a hourly basis in the law firms. They are paid on the hours for which they are working. The law firms often operate on the basis of partnership agreement, and they liquidated on the fare share for each partner. As coupled with the hourly charge, the law firms, perhaps if they be a small firm, may offer the kind of model and prototype of work mode, to marginalize any extent of exploitation possibility. In the political approach of liberty, some may perceive that the work mode of such law firms, as in Mondrean or cooperatives, may mediate the extent of universal generalization concerning the liberty. Of course, the waged lawyers in the big scale law firm may not develop in this way. Nowadays nobody would suspect if the license to practice law would narrow the scope of liberty or the licensee deserves the name of confinement as a skilled machine on law. Therefore, the concept of liberty in this advanced civil society has pose an intertwined and compounded panorama to stream over the pluralistic dimension or sectors and society. 


\section{Reference}

Crocker, L.H. (1980). Positive Liberty: An Essay in Normative Political Philosophy (Melbourne International Philosophy Series), New York, NY: Springer.

Graff, J. (1985). Adapting interiors and furnishings for the disabled, Madison, WI: University of Wisconsin-Extension.

Kee-ryong, K. (2002). A Free Mobility of Disabled in Korea, The Citizenry and Lawyers. Seoul, ROK: Seoul Bar Association.

Laureate Education Inc. (2003). Ethics and Social Justice "Human Rights: Applications" with Amanda Baker (approximately 8 minutes).

Murphy, A. (1998). Reason, Reality, and Speculative Philosophy. Madison WI: University of Wisconsin Press (1996).

Stanford Encyclopedia of Philosophy : Positive and Negative liberty, Retrieved as of Oct. 25 2013 from http://plato.stanford.edu/entries/rights-human/. 


\section{Liberty and Public Organizations}

\section{The Assessment System of Court and KBO's Policy}

The Korean Bar Association (KBA) and court as well as the prosecution offices are triadic branches to sustain the Korean legal system. The court is particularly placed to serve the administration of justice and assumes the role to protect the human rights. It functions and execute the judicial power as a constitutional organ. It is responsible to adjudicate on the cases and controversies, and redresses the grievances arising from a legal dispute. Korea has a dual supremacy in judicial terms between the Constitutional Court and ordinary courts. One of organizational policy to interact with the liberty interest of judge would be the assessment system for the tenure review. In order to attain an institutional goal for the fitness and character review of judges, the assessment system often is regarded indispensable. However, it could deviate, in practical effect, from the policy objective, but to obstruct the independence of judiciary and eclipse a full-fledge exercise of conscience, individual or professional conviction (Laureate Education Inc., 2013). Given the nature of meritocracy deeply rooted in the personnel affairs, it assists by advising on and informing a requisite assessment. Since it could be misused to exclude certain judges who are conscientious, but politically dissidents, it often would be raised as a public concern about the commitment of judicial independence. This would be same when we consider a budgetary subjectivity of Judiciary to the Executive. While the liberty of judges would arguably be lawfully restricted on his official duty, the term, liberty, could be apprehended in any organizational, not in a strict legal sense, or informal leeway to administer his personality.

For example, some excessive pressure to use a decent word in the bar or to enforce a courteous conduct to serve the sovereigns in loyalty and public trust may bring a tiresome or inefficient outcome in the administration of justice (KBA, 2011). Most problematic is that the assessment system may undermine the professional integrity by forcing them to comply with in his promotion or retention wish. So his or her secular interest on the promotion and retention of office can distort his inner side of moral conviction or due way to be personally held. This personal preserve of mental and intellectual disposition or conviction would be a very strand on which the judicial organs are presumed on. Hence the infringement with a conscience or belief of judges would lead directly to unsettle the judicial independence. The liberty issue then approaches in the same structure about the conscientious objector or antiwar vigils.

The court has managed long years the assessment system and graded judges who are to be referred to the tenure review. However, a dominantly conservative ethos and public monitor about the judicial independence or suspect on the system, its practical impact would often be minimal and an automatic renewal for another ten tenure years sees no difficulties for grant. The public attitude has improved to identify the pros and cons of system, and the concept of democratic servant-ship recently has been emphasized to secure a loyal and faithful quality of judges. Also the peer pressure to ensure a fair and democratic quality between the counsels and judges at bar would grow, and could be correlated with such popular attitude. These situational variables affected the culture and ethical paradigm of court judges, and KBA, since 2010, instituted a regular process, on the annual basis, to complement with the assessment system of Court. KBA launched a peer survey to collect the opinion about the judges on the list of tenure review during 8 days, from Jan. 6 through 17. KBA 
announced its background to meet the end to cross-confirm the personnel powers of the Chief Justice (2011). It pointed to the potential flaws that CJ exercises a plenary power to grant the long years of tenure. This kind of institutional vulnerability actually factored to yield no case of renewal denial which makes the process autonomous and meaningless. Some unethical judges who are verbally abusive in bar communication or indecent to provoke a shame for the clients could not be filtered according to the public report of KBA. This undermined a public trust for the judiciary, and KBO claimed that it was the most objective, relevant, and competent agency to assess the judges. The peer survey was conducted to cover 153 judges on the list of 2011 tenure review (2011). Over 1017 attorneys at law participated which was starkly gross than a previous occasion. 79 judges were found to be defaulted for an entitlement of new tenure. 74 judges were rated superior and qualified for the renewal. The grounds to make up such an impeachment would be, in rank order, the authoritarian or charismatic attitude (45 votes), bias, prejudice, predisposition, and abusive verb or behavior (25 votes).

\section{The Liberty of Public Officers and Organizational Integrity}

In furtherance about the liberty and transgression of assessment policy, I may brief on the public fear or excessive attention on the ideological propensity of judges. Korea is a divided country on this very reason between the leftists and right wing. Often we see it desirable that the court would be composed of diverse judges to represent a social philosophy. This context was seriously suppressed not by the governmental intervention but by such enthusiastic Right Civil Association in Korea (Chosun.Com, 2011). They often would be veterans, middle class of conservative ethos, and those who have a family background to detest North Korea. This created the social circumstances, which may be received as the kind of societal expectations for judges as in the Cooper's components on responsible conduct (Cooper, C.T., 2011). Hence, they could be affected, and his personal interest on the promotion or retention of public office, in combination with the assessment system, may facilitate the inner process to convert his conscience to a prevailing ethos. This not only abridges the liberty of judges, but also could adversely touch on the core theme of judicial independence and social diversity. The internet portal of Chosun, often viewed as a most strong Korean conservative, hints on this point, "It is a constitutional mandate that judges are amenable to the tenure review for every ten years, who will not be dismissed from the office, but only on the causes exclusively of impeachment from the Congress and criminal conviction leveled above a confinement penalty. The Court Administration of Korea has not been practical to play a minimal role with the perfunctory apparatus of assessment system and tenure review. The tenure system was introduced in 1988, but only five judges during 25 years were denied a tenure" (2011). This quote was complemented by other conservatives so that they perceived this phenomenon serious about the rise of leftism adhering judges. Their tone and criticism has been acid that this lack of proper institution or flawed policy implementation would lead the Republic to collapse. They also expressed a concern of fear if the leftist judges could influence to shape the policy of Supreme or Constitutional Court. Now the public criticism surges to deprave the last election about the political intervention and unfair context of election campaign. It poses serious challenges for the president, ruling party and conservative group that the allegedly leftist circle now are legalized to plan a massive candle vigil in the public place. In their view, the Constitutional Court, in a last case dealing with the US imported mad cows, deplorably has dispatched a generous policy about 
the right to assembly and demonstration in the public street. In their version, this outcome, of course, would show a weird network with the leftist powers in the judiciary (2011).

The threat or evil from the assessment system and KBA's policy could be illustrated convivially in the case of Kee-ho Seo, who was a middle age judge and alleged to uphold the virtue of leftist ideals. He also has been notorious to lead an e-critique on the court leadership and prevailing judicial policies. He was a recent judge to be dismissed on the ethical ground. His accusation was examined based on the assessment system, but the grades were found to be assigned as misled by the subjective stance of his higher authority. Objectively, the amount of caseload and the rate to dispose or complete would range above the middle of whole judges. He later exploited another career as a congressman, and now is incumbent to impanel within the Government Audit and Hearing Session in 2013.

\section{The Benefit of System/Policy and Their Prospect}

In any way, the assessment system and KBA's policy likely would sustain ahead in view of its fundamental role about the personnel affairs, quality and character of judges and democratic practice in the consort with KBA. Seung-tae Yang was appointed as a Chief Justice of Korea on Jan. 18, 2011. The nominee was roiled into an interview of public media, and made a brief comment, "most capable judges would be the ones who deserve the public trust." In broach to this comment, he adverted, "the public trust should be more hardly achieved other than legal research or knowledge." In his view, the judgment has to be tempered and consonant with the common sense of justice and shared apprehension (Laureate Education Inc., 2013). This would be any authentic role of judiciary so that the clients could be persuaded. In Korea and perhaps universally, a miscarriage of finding the facts or implausible criminal sentence often would be the point of contention and dissuasion. The parties and his counsel would be a most knowledgeable person about the case. The counsels are qualified as a matter of law to represent the party and could share a common step on the progress of litigation. He would be virtually same to the party in the disposition and sensibility about the case. Hence, to obtain his respect and sharing would be really imploring. In this light, KBA's policy to factor the assessment system could complement its flaws, which is a statutory mandate and overly indispensable (KBA, 2011). Some of court critique perceives it improper since it is odd for the players to evaluate an umpire. The Supreme Court still is reluctant to use the survey result as any definite variables in managing the official assessment system. As said, however, it seems most plausible and convincing to recourse the counsels, a direct peer of court judges, in assessing their quality, integrity, and personality or propensity. It directly is connected to build in the public trust. This policy may be expanded to cover the prosecution offices in Korea. As for its organizational nature of quasijudiciary, the public trust is urged as a pivotal value than any other governmental branch. This actually underlies in an organizational concept that the key leaders of organization often reiterated to implant its ultimatum. Unfortunately, its genuine implications and moral requirement have been neglected. Now the people are suspicious if KPO were to be committed seriously to improve its poor image on public trust. A meaningful change has been noted recently so that now a large number of criminal cases on a statutory complaint basis are litigated with the counsels being appointed. This phenomenon would be in the sharp contrast than in past ten years. Counsels could be an agent to be fully aware of the client's satisfaction. They could be more usable to ground the genuine basis of assessment than the previous system, mere a KPO survey of clients. 


\section{Reference}

Chosun.Com (2011).Judges and Korean Society. Seoul, South Korea.

Cooper, C.T. (2011). The Responsible Administrator, San Francisco, CA: Josey Bass.

KBA (2011).Internet Newspaper of Lawyer. Seoul, South Korea.

Laureate Education Inc. (2013). Ethics and Social Justice"Liberty: Applications" with Amanda Baker (approximately 7 minutes). 


\section{The Organizational Culture, Policy and Ethics}

\section{The Society and General Aspect of Organizational Culture}

An ethics and responsible administration now draw any more popular attention in history. There is a scope of variables to bring this context of societal phenomenon. First, the public monitor and pressure activities have become increasingly active and flourishing to advocate the democratic process of politics. As the theme of democratic government deepens and becomes well settled, the bureaucrats turn to be assumed and required to be loyal with the servant-ship to the sovereign people. It can be traced back to early years of new Republic so that Andrew Jackson defines their peer or political group as common men (Cooper, C.T. , 2012). The prevailing view in earlier politics, as we can note, may well be a spoils of victory to staff and administer their governance. This tradition may still wedge in the presidential system, but the cleavage, in another dimension, can be ascertained. An ethics as a fiduciary servant and the imagery of loyal public administrators would be highlighted in the more systemic way in the proposition of Max Weber.

Around the industrialization turbulence, he perceived the importance of social factors to sustain a right direction of capitalistic growth in the western society. The continental morality and new frontier of material advancement were engrafted to inculcate the due course of social evolution rooted in the western tradition. Hence, his requirements in ethics and morality about the honorable bureaucrats are practically plausible to account for a realistic exposure and value guides to vitalize on the capitalistic system of statecraft. The press and public media also may interplay to ensure the Weberian virtue by imposing a criticism and monitoring activities. The advancement of e-technology and revolutionary impact of social media or other communication culture also contributes to the increased public attention on the ethics of public employees. A civilian recourse has developed into the "hands and palpable breaths" of the political or social elites in pursuit of social justice and procuring their loyalty. The ruling elites now are circumscribed in any distinct environment of disclosure and strains. Once seen as mere a gossip, the social culture may no longer tolerate an ethical or insensible public decision making with the readily organized force of civil group. A democratic apparatus on the liberal concept of constitution also increases its profile and scope, for example, recognition of the right to know as one of fundamental rights. It is to be noted, however, that there are differences, according to Cooper, in a practical effect among the public tools, such as the code of ethics or law and public media (2012).

Second, the public administration itself has been on the trajectory to fortify its discipline as a science with the assistance of modern psychology and sociology. A theme concerning the act of ethical management began to feature in an increasing profile since Bowman published the article titled "the ethical issue for the public manager." Don Menzel developed this concern by imploring on the systemized and consistent effort to promote ethical organizations (2012). The ethics and responsible administration often would be impacted by several institutions in the combined force including law, history and organizational mission. This would generate a certain of organizational culture in which we derive the essential factors in coverage of normative structures, referent others, obedience to authority, and responsibility for consequences. As I refrain from first person in academic writing. adverted, the society witnesses the changing circumstances in fashion to recourse their public avenue of sovereign role. This larger environment may lead to a new shape of factors. For example, obedience to authority, in some cases, may shift that the civil monitor group could be more pressing and be viewed as the kind of authority to compromise. A 
responsibility for consequences, in some cases, may be upstaged as deviated from the responsibility chain of line authority.

For example, a Congressman in Korea may fear from the public opinion more than the Congressional Ethics Committee and its guidelines. Turning to the discipline, it is highly advisable to ensure the integrity and continued ethical practice that the ethical decision makers plan on and design a scientific model, as the Cooper's model illustrates, and prevents a self- serving attitude of bureaucrats and public administrators (2012). Other useful framework would be the Person-situation Interactionist Model developed by Trevino (2012). According to that model, public employees may process on the stages beginning with the ethical dilemma, cognitive stage and through the ethical or unethical behavior. The model identified four scores of influence to reach an ethical decision, which incorporates the individual attributes, immediate job context, organizational culture and characteristics of work. It also elicited subelements with respect to each dimension. For example, the individual attributes are determined by assessing the field dependence, ego strength, and locus of control.

\section{The Organizational Culture and Organizational Policy Making}

As sketched, the organizational culture would presume a general ambit through the specifics of organization. It is a societal creature to be rooted in the history, tradition, moral and ethical virtues to be implanted in the bureaucracy and organizations. The changing circumstances on an increasing intensity or compression of society as brought by the technological development as well as popular control along with the increasing power of public media, all accounts for the new shape of organizational culture. The issue of whistleblower, its moral basis and argument, as well as its protection as a public policy plainly proves the upstaged or societal context of organizational culture. In light of the specifics of organization, we need to note the importance of scientific contribution leading to the understanding of ethical or unethical behaviors as well as policies. For example, the Lucifer effect can elucidate the individual character traits and organizational culture as well as other situational variables (2012). The Trevino's model also employs the organizational culture in four elements as an important variable which brings an ethical behavior or policy making. In this way of thinking, we may infer two dimensions of focus and in the primacy of attention which are elaborated by Finer and Friedrich (2012). Finer emphasized the role of external controls so that the law and code of ethics must be ensured in proper terms and in the nature to control the organizational members to adhere with their ethical requirement. Friedrich rather stressed on the practical importance of internal factors enshrined in individuals. Hence the ethical policy making or behavior would hardly be achievable without any genuine submissiveness to the ethically required way of behavior or conduct. His view, therefore, shed an intense weight on the learning and developmental program for the policy makers or administrators.

Remember paragraphing is important to separate points. Otherwise, the reader does not know when a point begins and one ends.

If the elements cherished by both camps are not mutually exclusive, they often become concrete in one concept of organizational culture by way of law, history, mission as well as a basic tone of the civilized understanding of public organizations. Of course, the organizational culture may be taken distinctively due to its nature and quality. For example, the Finer's qualm may have a nuance between the legislative assembly and normal bureaucratic structure (2012). The latter may be more meddling on discretion to favor doubt while an ethical pattern of the latter case often likes to clarify the course of ethical 
deliberation in the face of public monitor. Hence, the former case would be more amenable to the Weberian concept about limiting a discretion in ways to prevent the civil servant's remonstrances and to place them in order. In the standing point of view, if the organizational culture needs to be examined from ethical policies, the critical inquiry would be if the organization now operates in the symptom of nonfeasance, malfeasance, and overfeasnace (2012).

\section{The Korean Judiciary, Organizational Culture and KBA’s Policy}

For the purpose of illustration, I consider a recent public focus on the courtesy and ethical behavior of judges, public prosecutors and counsels in the court proceeding. The area of ethics often stems from the professional code of conduct, but, in some cases, related with the criminal response on the contempt of court. They share an enhanced level of covenant as if they fall within the notion of New Adminsitration Movement, so that the smacks of professional eliticism and the concept of "client other than citizens" may apply to explain their status (Cooper, C.T., 2012). The virtues prevailed in the Movement, such as courage, commitment to human values and integrity espoused by E. Dvorin and R. Simmons, could also be the point of sanctity to be respected in the Korean case while some technical standard and specifics will combine to effect in producing an acceptable course of ethical behavior (2012). While the civil power has traveled over the sectors of society in enhancing a compliance with the democratic ethics, the Korean Bar Association erected an assessment policy of judges about their attitude and manner in the courtroom (Camp, J.C.V., 2005; Phillips, F., 2004). The assessment report was regularly disclosed to the public attention that poorly graded judges may suffer a disadvantage in the promotion and decision-making of personnel matter. In the last years, one judge committed a verbal abuse to the party by stating an indecent word. He allegedly affronted an aged party in the civil dispute, who was incompetent to delay the court schedule and had a less sense to present his case, by saying, "If a man turns to be aged, it might be better to die." One other case involves a similar misconduct so that a presiding judge in the divorce proceeding libeled, "you would get awakened to see your spouse in the same bed with other males." There are many other examples revealing an abusive or indecent communication with the parties.

It seriously disparages the human esteem of client who, in this case, would be the party on the ride of civil service about any justice administration. The organizational culture of Korean judiciary, as in many other foreign examples, has long been distinctive on the dominant flavor of conservative ethos $(2005 ; 2004)$. The judges would often be respected as honorable, and the ethics are often required of the citizen, or clients to maintain his honor over the court proceeding. The Japanese imperial rule, in early of 19th century, impacted profoundly on the organizational culture of court. That exposes a court scene that the judges look a kind of authority or charisma with the robe dressed up. His statement would be authoritative to direct, command and reprimand the parties and audience. The spirit of public service massively retreats as focused on the requirement of authority and respect of law. A liberty interest often safeguarded to ensure a human dignity, an ultimate destination for all purposes of national constitution and enacted in the Art. 10 of Korean constitution, was directly or indirectly affected (Laureate Education Inc., 2013). For example, an indicted suspect may be suppressed by a possibly overwhelming conduct or words which divert them from fully exploiting a due chance to defend his case. The judges in Korea, in some cases, may carry a wrong form of short court opinion that fails to fully disclose the points of contention and court opinion on the respective issue. This ethical failure, as reported in the 
last news paper story, may jeopardize the context of party's right to appeal and the client's satisfaction (Camp, J.C.V., 2005; Phillips, F., 2004).

While there is a separate view about the liberty or human rights viewpoint, the public employees often are conceived as a special group and fall outside the scope of protection. For example, it would be answered in a limited scope of recognition if the government employees enjoy the freedom of expression. The judges and prosecution officers would also be deemed as a natural person entitled to the scope of constitutional protection. The new policy from KBA may infringe upon the liberty interests of judges, but the prevailing view would likely be reluctant to shed on that strand in this case.

\section{Some Solutions for the Ethics of Judges}

Assuming that the Cooper's decision model is to be exploited in phases and specifics of this illustration, I now could comment on some of the ethical standard as a solution for the concerned parties (Cooper, C.T., 2012).

First, the courtesy of "bowing and saying hello" needs to be revisited. The counsels to travel a corridor or courtroom had been usual to nod their head in ways to pay a recognition and respect. This courtesy seems still practiced in the local district, but the buzzing environment of Seoul may have changed on the practice. Now only a small number of attorneys in Seoul follow this routine way to elevate the professional integrity and sharing. This change of personal ethics may be due to the increasing number of new entrants to the profession. The number tripled in the past decade. The lesson from the American scene may be practical where a predicate "Your Honor" is held uniform to refer to the judge. This ethics can increase the public respect and trust in the end of strengthening the rule of law concept.

Second, the examination or cross-examination procedure requires the counsels to comply with an impartial, speedy and decent process purported by the law and professional ethics. It needs to be discouraged or banned to disparage the integrity of prosecution authorities which is impertinent to the facts or profile of cases. Often counsels may complain in informal ways to tarnish the prosecution decision as irrational or attack an ill aspect of criminal practices. It entails a serious deviation if the accusation involves an imprecise or wrong fact. For another, it needs to be avoided to intervene in the process of examination or cross-examination. It would be ethical to wait for its completion of prior interrogatory and proceed to his case. An attitude to examine the witnesses also needs to be put to improvement and correction. It is unethical and contradicts to the covenant of democratic rule if the counsels behave in the authoritative or indecent manner. Often an oral statement not taken care of can affront and insult the witnesses. Other ill aspect may be perceptive on the technical standard so that opinion-seeking inquiry or questions about the immoral character of witness would be improper and in violation of the ethical codes.

Third, the court judges need to be modest and common so that they never behave pretending to be potent or mightier to teach the counsels. This point would be emphatic about the removal of counsel's grievance. They are common peers to administer the justice in collaboration and cooperation. Now the judges are no longer the class of public nobility. He or she, as a public administrator, needs to find his standard of conduct and workplace ethics from the virtues of American public administration, say, equality, freedom, beneficence, respect for individuals, popular sovereignty, and justice. This does not mean that the principal role of judges to shape an issue and marshal the points in contention could be derogated or disobeyed by the counsels. A bias or arrogance of judges as if in the step of prosecutor's case and to squeeze the counsels in his ways or understanding would be problematic, especially in 
the criminal proceedings. In some cases, it brings the consequence to break the fundamental assumption of party system by exceeding from the scope of indictment statement or prosecution's claims.

Reference

Camp, J.C.V. (2005). Ethical Issues in the Courts: A Companion to Philosophical Ethics. New Tech Park, Singapore: Cengage Learning

Cooper, C.T. (2011). The Responsible Administrator. San Fransico, CA: Josey Bass.

Laureate Education Inc. (2013). Ethics and Social Justice "Liberty: Applications" with Amanda Baker (approximately 7 minutes).

Phillips, F. (2004). Ethics of the Legal Profession Portland OR : Routledge-Cavendish. 


\section{On the Nature of Social Justice Issue}

\section{Poverty and Homelessness in 1998's South Korea}

Around the end of 1990's, Korea had undergone a serious financial crisis, and the IMF role only could settle the unsavory condition of national economy. In these years, the poverty class in a ghetto, often unemployed and homeless, had posed the challenges to justice and deserved a social attention. As learned on Frederickson, a poverty also emerged to shift the traditional paradigm of public policy which concerns the race, gender and ethnicity in US (Frederickson, G., 2005). Its extent has gotten worse that the assumption for these elements to imply a poverty would be made inadequate in the face of a rising threat to the social justice in US. A social stratification now rolls back to call a more engaged attention beyond the narrative of diversity or multiculturalism. If the nature of social issue has a profile on the universal element of humanity, it would be a matter of our attitude or disposition rather than any evolution or progress in the time sequence. I mean if the kind of Maya or Inca civilization or others beyond the level of contemporary one, could flourish or perish in mystery, but could be plausible. As in a science film, we may have unknown a superior alien civilization in any other time, but may hardly be recovered into a reality for other reasons. The poverty issue may have been quite that of improved form in 1950's than the current status. This area of public policy may bear such kind of irony that the attention or maintenance to mend in continuance as well as on constant watch to respond with would be necessary. The kind of apprehension, "the poverty in the past on this level, economic status and social welfare on progress over time, and the present status of poverty issue would be easy," should not entertain as any convincing ways of thinking. As the concept of justice expounded in the Republic by Plato, the poverty may pose a serious challenge to the ruler and ethical administrator (SEP: Justice As a Virtue, 2013).

It is related with the basic standard of humans, and very sensitive as sufficient to question the social justice, ethics, as well as legitimacy of polity. It has a root over the history as we can find a plethora of authority, i.e., the pleasure of moral person or ruler in Plato and Cicero, pleasure and the greatest happiness for the greatest number of people in Bentham's case, a refined persuasion in German rationalism and Weberian ways of bureaucratic ethics, Rawl's concept of justice, and even the functional equality or positive liberty circle for the social justice in most modern thinkers (SEP: Distributive Justice, 2013). In this line of thought, I may derive some of implications. First, the issue of social justice would be omnipresent across the polities both in time and geographic distribution. That is because the issue would be interwoven with the universal or human intrinsic and attribute. It could be conceptually shared in any common concern, and may not be submissive to any time rationale. The elapse of time and economic progress never absolutely mean an improvement of poverty in view of the social justice. Second, this aspect alerts the public administers, who are required to be courageous and vigilant to realize the social equity and justice. Now the system is not static which is unlike the aristocracy. As said, roundreasoning has been embedded to ground the human cause for social equity (Frederickson, G., 2005). W. Wilson' stated, "it is harder to run a constitution than to invent it" (2005). As an implementation is urgent than policy making, it needs an extent of positive engagement. For example, the employers are to improve the hiring practices, which means even to touch on the human resource than mere implementation of social equity program, project and policy (2005). 


\section{The Status, Threat to Justice, and Factors to Address}

Poverty may well be conceived as a worst factor leading to the social injustice. It poses a fundamental threat to the justice of society. The poverty class would be often deprived of adequate public education, and the status could persist over the generations. They may economically suffer below the minimum standard of human subsistence. Their social and economic reproduction may be threatened that they often lack a due provision to function as a laborer. They may suffer in the street since they have no shelter, which contravenes a basic right to a decent housing in the commitment of UDHR. We may have a due kind of reference that UDHR would prescribe a standard on the current status of social justice. It is obvious that virtually no human can have a pleasure to face with the reality of homeless. How do we have a pleasant sleep if we have been disposed palpably on their case? The rulers and public administration would be responsible as we learn on the ethics, public value and other sources of moral administration (2005).

In Korea, the unemployment rate has sharply increased in the first and third quarter of 1998, 5.7 percents, 6.8 percents, and 7.3 percents respectively (KBA, 1998). The so-called IMF crisis began in 1997, and the firms or enterprises executed massive layoffs in the initiative of rationalization of their business. According to the statistics of Labor Department, the Poor Household Loans for the unemployed sharply increased from 65.5 million dollars per month through 113.2 and 117.3 million at the end of year. This data implies that the unemployed began to exploit the governmental loans to subsidize their living. In other words, the subsidies and pension alimony could no longer support completely to meet their basic needs. The Labor Welfare Foundation also managed a public program about the unemployment loans, but the terms and conditions were tougher to frustrate many unemployed workers (1998). It was ambitious to rehabilitate all scope of unemployed workers, but the loans actually was provided only for eight cases during eight days in the year. This program has envisaged drawing the funds by marketing the unemployment settlement securities, but the goal proved impractical by selling only 12.8 percents of securities in the stock market. It affected an initial plan so that it was reduced seriously and viewed as one of critical policy failure.

The government initially shaped the plan to create 270,000 jobs by inputting 544.4 million dollars, but the unexpected growth of unemployed required an additional allocation of funds in the same (1998). A public project committed to the increase of employment purported to ensure a basic right to subsist as well as create the jobs. The factors to be considered would be a marginalized pay, which would be a principal driver for the $3 \mathrm{D}$ (to avoid the dirty, dangerous and difficult jobs) vogue in the society. One other point in consideration is to frame an adequate policy vision and its operation in an interplay with the public aids and social welfare program, which were intended for an ineligible person from the unemployment insurance ambit. It is critical to systemize an institution to clarify whether or not the public project on labor, in its quality, is social welfare or labor based. The factors to be taken care of would be that the issue is familial as well as personal. Hence, the policy makers need to shed a light on the starved students in the school. Therefore, it could be timely to provide a free lunch from the next year, 1999 and could be afforded in the vacations. One difficulties lie in the status of schools about the availability of space and other practical strands, which troubled the uniform fashion of administration. The context of 1998's Korea exhibited a serious injustice between the cause-arouser and victims of society. Many critiques 
were conceived that the management and capitalist class could be culpable to bring the anomaly of national economy. However, the economic and social benefit for the Chaeboland haves inclined to expand while the lower income class was stigmatized to suffer. They were often deprived of a due status in the employment relations and could be dismissed without any due respect and at the will of employers. The distributive justice may well be seen seriously depraved by the dip between the haves and have-nots. The social injustice henceforth would come into any serious context. It then fell within the responsibility of public administration beyond the private sphere. Unless they were responded with adequately, they would get worse to a homeless status and the crime rate for economic reasons would likely double (Frederickson, G., 2005). A disorganization of family could frequent and harms on its value would be challenging. The foundation of society would be put into a jeopardy.

Concerning the homeless issue in Korea, we consider two classes of homeless people between the long-settled vagabonds and dismissed employees in the close years of economic decline. As the latter class often are similar so as to falter from the social alienation, members of disorganized family, marginalized economic status, the classification would less powerfully serve the policy response. With respect to the national attributes of homeless issue, the temporal response to provide a labor opportunity or free meals are not seasonal to attain a more effective outcome. A major portion of homeless in Korea are the fifties in an age range, and the success of British case could give us a lesson. The practice to afford the social safety network in the United Kingdom would yield a best result than any other alternatives, which led to a drastic contrast of 1-2 percents in the age range of fifties. Hence, a systemic provision leading them to rehabilitate as well as the housing welfare program would be seriously explored in the forefront of decades (Frederickson, G., 2008).

\section{The Concept of Justice and Social Equity}

Justice and social equity often arose to be public ideals that the respective branches of government pursue and undertake to struggle through their professional lives. Two dimensions in structure or in the least some of hypothesis other than this preserve would be a politics and civil capitalism. The politics or political science would concentrate on the power, structure of government, political process as well as the virtues or criticism that the specific or universal context of political community need to be addressed or contended. In view of the rule of law or public administration, they would rather be akin to the creation of laws than implementation of them. The views of W. Wilson elicited appealingly, "it must be harder to run a constitution than to create it" (Frederickson, G., 2005). The ideals could be shared by both minds. However, the political scientists often would travel in any philosophical relativism so as to be submissive to the interest of their core theme, say, the political power. It often proves in a convincing force and tack of experiences that the public administrators, including the judges or lawmakers, particularly incumbents or those of majority parties, would be armed with the concepts and practice through their course of responsibility. Given a justice is received in the sort of social quality, the two concepts would be related in any same tone, logic or metaphor leading the ethics of public administrator (Frederickson, G., 2008).

Both concepts have projected into the western intelligence as a persistent and enduring guide to practice the ethics of rulers which would hardly be traced nor supervened by other ideals. Monarchs, oriental or western notwithstanding, often recourse their daily business of politics in this way, and stressed the sublime status of justice or social equity although they might be more eagerly disposed to expand their terrain or threat to his might or 
political power. The socialist states had been notable to cherish this logic, which would go farthest to entirely revolutionize the traditional virtue of Christianity or prevailing thought of Republicanism. The concepts have been embedded on the very notion of human disposition as we have been illustrated in the Cicero's subscription to justice in fundament of his ruling philosophy. In the ancient times, justice may converge to the same destination between the ruler, who often would be one person and as discarding a check from the Senate, and political community. The ruler's justice also would be a social one. The context would transform if the public governance began to practice on the free election, equal vote, and representative democracy. The deliberative nature of democratic tradition may negotiate to bridge the kind of conscience, justice, equity, often being ascribed to the absolute figure only, with the science, due process, as well as the traditional virtue of western society. Therefore, the two concepts would not differ, but come congruent to serve the realities of public governance, the ruling and ruled, ethics and community, and in compliance with the pleasure of ruler or that of citizenry as its equivalent in modern terms (Meyer, M., 2008). It could be antithetic to the general thesis of liberalism if to speak for the absolutism of pure market, and could be mediated in a lesser force if some stress the institution of free market as in Hayek and ground laws to support the system. As the laws become complicated in the public pressure and political voice, the social legislation would be coupled to impose an implementation of social equity. Hence, the public administrators in the contemporary society need to meet a dual challenge to address, which could be granted in any inviolable context and in ultimatum.

\section{Threats to Justice and Social Equity: Less Courageous}

In this structure, we derive two strands that they are shaped. First, as Frederickson mentioned, the public administration put any more strains and emphasis on the implementation of policy rather than the creation of them (Frederickson, G., 2005). Of course, they may develop their career later as a law maker or could serve more effectively. However, the policy implementation or the concept of law in action would be unique to be exclusively reserved for the group. His argument on the poverty and increasing inequality between the haves and have-nots are imminent for the public administrators to respond with (2005). His message is straightforward and reflexive since the antigovernmentalism is largely impractical at this point of time. His attribution about the basic propensity of American citizen, as philosophical conservatives and pragmatic liberals, seems to be generally universal in my surmise of global public (2005). Of course, still in contention can it be argued in the first prong, hence, we may go to ask what we like to conserve or make it inviolable. In any notable interplay or in general complacency about the demise of ideology, that question would often be dealt in a secondary profile or impossible to be resolved in any mutual agreements. Then the second prong would be operable to impose a duty or moral leadership to be subservient about. In this backdrop, the justice and social ethics would be defined to level their playing field on professionalism. It would be honorable objectives and the group has to be persistent and continued to mend it, not to end it. It perhaps would be the idealistic smacks of bureaucracy who should not tolerate sinful inequalities. The phenomenon, in Frederickson's assessment, is serious so that it is important to ask for whom the policy or social program was addressed in any identifiable policy consequence (Frederickson, G., 2008). It is insufficient to point to the shape, codal language in mandate, structure of policy, often expressed in the form of statute and acts whether the social injustice was properly prescribed. Hence, the public administrators need to think about the three faculties as classed of knowledge, courage, and a quick wit. Often incompleteness or shortcomings are caused by 
the lack of courage which is a major challenge in improving the current state of social ethics in the American society.

\section{Some Examples of Justice and Social Equity}

In consideration of the gaps on this point, and as illustrated in the street level bureaucrats, both concepts may be made distinct in epistemology, epithet, and in intellectual ways to develop the logic and metaphor (2008). As seen generally, both concepts could be used interchangeably, and trigger the same destination practically. The concept of justice, at the beginning point, bears two dimensions, which incorporate the individual and social strands. For the individual justice, the notion would often be posited in the respective condition and behavior of agent, which is processed in his inner mind about the moral issues having to do with goods or property. It may be questioned to probe its verity or ethics, however, as often deferred to be vested in that particular agent. Consider a father to kidnap his early child and abandons her in the deep mountain. Does he act on the terms and requirements of justice? We would not attack his act on its face that his act would contravene the moral or just requirement. He may suffer a worse poverty which drove him to have no way but to discard the early life. Other individual context of background may force him to choose or act. The concept of distributive justice may get closer to that of social justice, but the proposition employs an extent of historical, economic, philosophical, judicial, and political as well as experiential scholarship in flavor (SEP : Distributive Justice, 2013). The concept of social justice is a matter of societal concern and based on the science and statistics, which could be more tangible and beyond the idealistic posture or status. Hence, it anticipates an implementation as its companioned concept, social equity. The individual justice and social one may be independently set, but the marginal example can be convivial in the ancient sage of China, Mencius. Consider, in perversion from the first case, the adult pedestrian who found an early child who are about to be drowned in the river. Is it ethical or does it conform to the justice as Plato traveled in his book Republic? Mencius answered negatively unlike the former case and the courage is required as a moral agent. Mencius was a pro-goodness moral adherent while Xun zi would churn on the evil strand of humanity at its very bottom. Transpose, in hypothesis, the agent to be a father of drowning child. The moral requirement may shift across the society, and offers the source to be discussed intensely in the jurisprudence. We, therefore, can borrow the ideas in understanding the diverse viewpoints in bridging the justice, ethics and morality (Meyer, M., 2008). The Good Samaritan law also would be one example. As the justice entails this individual domain, it can operate as a useful concept to view the phenomenon and social mechanism. For example, the individual justice cannot be assumed if the agent is incompetent or minor. They, in a cogency and assumption, could not be deemed to make an ethical or moral decision. The criminal and civil laws recognize this understanding to institute a law in the case and statutory form. Social equity, as hinted, can possess an applied and phenomenological focus to make us possible on the grand picture of society. This light of dualism may be ascertained in the long practice of Court of Chancellery, what we often call an equity court. The common law court is often ascribed to defend the justice, which would be technical, detailed, party-specific, and inquisitive or probing. The Court of Chancellery would serve the will of sovereign to redress the injustice in a grand and fundamental stage. It may entertain the finality privilege from its character, but the modern court is structured and operates in the idea of division of labor. The social equity could be reinforced to correspond with the advent of democratic society, which would be owed to the development of modern science. For example, Comte's positivism affected the 
intellectual minds of society in any revolutionary influence, and enlightened new waves of thinking based on the objective science.

\section{A Relationship of Both Concepts}

The concept of justice would be useful to penetrate the politics, public administration, and law. It encompasses squarely the ambit of individual, social and administrative domain (SEP: Justice as a Virtue, 2013). In the public administration, both concepts would be combined to reflect. In reverting to the Frederickson's point, the gap actually is problematic that the levels of administrators need to heed on precaution. As a policy implementer, the executives are one organ in assumption to penetrate the line authority in the destination to share the uniform concept of justice. The same context was posed in the theory of criminal justice system in Korea. Each prosecution officer is deemed in terms of its capacity and legal qualification as same in the uniform fashion about respective cases. They are responsible to the higher ranks in the sphere of public administration, but not in the level of quasi-judicial role. Their quasi-judicial role also manifests to deliver a specific justice so that I consider it to be received in any extent to awaken the less courageous bureaucrats or street level ones who could be biased or manipulative. In dealing with the cases, a junior prosecutor is same as the head of prosecution office. In remedying the social inequity and carrying their official power, they would do as same as the president or higher ranks. The concept of justice intrinsically is related with the basic attributes of humanity, and hence individual (SEP : Justice as a Virtue, 2013). As Cicero stated, it enshrines in the quality of ruler, whom the levels of policy administrators can be integrated into one ethics and moral direction despite a different mask. That said, we can understand the theory of vicarious liability where the court centralizes if the officer's tort is perpetrated in the color of governmental function.

Therefore, a scientific inquiry and policy implementation to secure the social equity can be tightened toward a justice. Both concepts swerve through the myriad of bureaucrats and moral administration, which may be leveled from the bottom, mid-ranks and top officers. In some cases, the kind of different institutions, as in the example of Court of Chancellery, may serve the cause of justice and based on the equity concept. As the science develops, their wisdom may respond with the shift in the public value and good. I may state that justice is more specific, individual, on the human-element science, universal, but dominantly national, and through all the ranks of administration while the social equity is grand, collective, often on the quantitative science, grouped, but both national and international, and often urged on the mid-ranks work force.

\section{Reference}

Frederickson, G. (2008). Social equity in the twenty-first century: An essay in memory of Philip J. Rutledge. Journal of Public Affairs Education, 14(1), 1-8.

Frederickson, G. (2005). The state of social equity in American public administration. National Civic Review, 94(4), 3138.

Korean Bar Association (1998), The Human Rights Report No. 14, Seoul, South Korea.

Meyer, M. (2008). Revue Internationale de Philisophie - Volume 62 Number 246 - No 4 2008 (Aesthetics). Presse Universitaires de France. Paris. 
Stanford Encyclopedia of Philosophy: Justice as a Virtue. Retrieved Nov. 8, 2013 from http://plato.stanford.edu/entries/justice-virtue

Stanford Encyclopedia of Philosophy: Distributive Justice. Retrieved Nov. 8, 2013 from http://plato.stanford.edu/entries/justice-distributive/.

\section{Globalization and Workplace}

\section{Dimensions and Lives of Public employees}

In dealing with the ethics and justice within the workplace, I consider two assumptions as important to be reified. The professionals would penetrate the ethics of workplace into its projected scale of policy outcome for the addressees and society. Then they share to be consistent to create a public good and value which the public administration ultimately pursues to realize. In the course of weighing and deliberation, the subtleties in distinction could be touched on. For example, the public administration can be made into an independent slot that a neutrality should be in primacy other than public policy making, a peer concept in this field. As Frederickson articulated, the segmented equality may variegate the terms and conditions of equity to be specific, cultural and pluralistic as well as even esoteric that would hardly be generalized (Frederickson, G., 1990). Therefore, equity to equities and equality to equalities are expected and even desirable to increase a fit of distributive justice in response with the sectors and societal progress or diversity. One thing may evolve into many things as challenges and opportunities for the public administrators. We may ascribe three elements for the administrators to tackle with, i.e., value preferences, organizational design preferences, management style preferences (1990). For example, the social equity would be intense as involved in the last one. However, we need to ask in fundament, "Do we steal popular sovereignty?"

I revert to say that this does not necessarily require that the two dimensions, workplace and policy object in span, have to be severed for breeding them into dual minds and attitudes. Still are the elements to converge, and they integrate the workplace and exterior object as a policy addressee from the projected ethics. Basics, rules and principles can well stay universal and inviolable that they have to ultimately respect (Sandel, M. J., 2010). The smacks of bureaucratic professionalism, henceforth, often are habituated with the same tone, manner, errand and mission to be a cult in both planes. Often the public would be outrageous if the public enterprises, particularly high ranks of justice institution, commit to speak of verbal abuse against the females or a racially minority group. That would differ in sensibility and expectations of conscientious citizen if any other entities of private nature have been engaged. Once President Obama expressed a concern and regret about the unlawful killing of minor black boy, who was sacrificed from the prejudice and recklessness by the police on public duty. Consider if the American society stands on the public value, such as equality and liberty as signified in the Statue of Hudson River. I believe that this concept needs to be consistently upheld through the public commitment even in view of a personal imagery or impression as well as knowledge, skills, conscience and courage. The White House speech may be misimpressed how the black president can make an affirmative statement for the same race. I consider it pivotal to make the public emphatic on the American commitment to 
the liberty and equality. This kind of consistent multifacetism, what may be seen a respectful catch-all professionalism through the personal lives, workplace justice, and a policy making or administration for the community, could make it improved and appealing, and diminish a public distrust or potential criticism of showcase administration.

It would be idealistic if the public employees could be a living legacy to be constantly diligent for the commitment of public service. It then can make himself, organization and his followers identical and armed with the public values they pursue.

\section{Globalization as the Workplace Environment, and Public Governance}

In rethinking the workplace justice, the neo-liberalization in some combined influence with the globalization may directly or indirectly affect the shape of organizational ethics and justice paradigm or practice. As seen in the message of Mittelman, public governance could have any more potential and possesses a diverse spectrum to give an answer to the global restructuring and counteractive response (Mittelman, J. H., 2002). The states had been contested in the absolute logic of economy, so that it brought about two points of ill consequence. In the first, economically deprived or uncompetitive entities could no longer survive. In other, the national politics are to be enslaved into the global logic of capitalism, which increased a prestige of capitalists or conceptually leading states, being done in tradeoffs of the wane side of Asian or Latin American leadership (2002). As the driving force to an economic interest would be any more powerful than other social factors and on grassroots from an universal motive, it can gainsay any other competing alternatives. His prediction about the important role of public governance could be received in parallel with his suggestion, say, organic intellectuals. A tension and context would be inextricable given the stalemate and some of inefficiencies within the free market system or market failure. I agree on his point about the stellar mediating roles from the organic intellectuals and enhanced concept of public governance (2002).

In this understanding, we would not become a fool attempting to rewrite a globalization script. The new paradigm of public governance would not tolerate a courtesan role within which the sleeping states would have passively reacted. It would be based on the constructive friendship to discuss, share and implement on consensus. One ambitious scheme may be found in the Labyrinthine Tobin's tax, which may face with tough challenges from the local reaction. It may be idealistic as in the neo-liberal experimentalism, but rather abstract or principled with lacking a quality of public governance and enforceability. His proposition would be received as same as the concept of glocalization, but his thesis has persuasively maturated a picture of that experiment. He enabled us to have a histography about the application of neo-liberal tenet, particularly based on the experiences and exposure to such vulnerable region. The nations, for example, South Korea, Malaysia, Russia, Mexico, Brazil, and others, were studied in view of its wake of financial crisis (2002). He considered it some way to discipline those in the scheme to adjust for a new structure of neo-liberal market economy. IMF conditionalities and currency speculation would be two examples to be remarked in impression. A power deflation, in his view, is coupled with the overwhelming economic cause about its hardship, which even dismantles some of area on the embedded commitment by the national policy makers or public administrators. Erstwhile public functions could be discouraged or offset to remedy the dystopia of free market institution (2002). Therefore, the tension between the haves and have-nots has stood out within the 
course of evolution over the decades. The contemporary dealings enable to witness the possibility of global public governance, as we see in Davos forum and many rounds of summitry, i.e., G8 or G15. His suggestion, while I also consider as workable and practical, for new understanding of public governance in the present context employs three strands, to say, organic intellectuals, self-determination or autonomy, and cooperation or pluralism of financial affairs.

\section{Japanese Students and Workers in South Korea}

For the example of workplace justice, I may think about Japanese students in Chosun University. Japan is an adjacent country, and both countries developed mutually a rich history in commerce, war, and imperialistic rule during early half of the past century, as well as new constructive partnership in some of mixed national sensibilities on antipathy and cooperation. This example would be helpful in reflection with the above promenade in the ethics of administration and globalization. The diasporadic cluster of Japanese community in Korea recently flourished in many localities of Korea. This would be owed to the globalization and enhanced mobility of labor force. Hence, how we perceive and govern this group of people would raise a serious aspect of public governance, which may be keenly related with the kind of segmented equality in the Frederickson frame. It could bring a diversity in the workforce, and the basic commitment on social equity and equality of liberty also are entangled with (Cropanzano, R., 2000). As they are workers of Japanese origin and may work in a different nature of organization, the equity into equities or segmented concept of justice can be embraced for the managers. The generic source of contention also deserves our review across the multiculturalism and effective or more efficient management or leadership. A justice could be prescribed which depends on the Korean authority, and organic intellectualism or autonomy within the globalized arrangement may intervene for the proper shape of workplace justice. In this light, the sociological, psychological or cultural studies about the Japanese community in Korea could offer a useful reference to make a specific justice for this group.

\section{Societal Expectations from the Cooper's and Some Solutions}

As we learn, Cooper framed a useful paradigm which could lead to a responsible conduct for ethical governance. It covers four elements to interact for shaping a responsible conduct, which are multiple to affect and dimensional as classed into the individual attributes, organizational culture, organizational structure and societal expectations. By waiving other elements, I intend to parcel out the last slot to address the ethical challenges and work place justice. The last slot, societal expectations, would possess the quality as universal and for all scope of organizations although the Japanese workers involve an esoteric nature of bilateral interplay within the national passion or emotion, political and historical resentment, and cultural differences. Other three elements could make it distinct the process of forming an ethical decision and responsible conduct in varying with the purpose of their stay in Korea and organizational culture or structure. In the updated statistics, the Japanese community within Korea has grown, and most of Japanese residents are reported to engage in any quality job, such as research, teaching, technical assistance, professional work, and so (Lim, Y.E. \& Huh, S.T., 2012). The purpose of stay would fall in comparison between the male and female workers as shown in the chart below. 
(Figure)

\begin{tabular}{|l|l|l|l|l|l|l|l|l|}
\hline $\begin{array}{l}\text { Natio } \\
\mathrm{n}\end{array}$ & Sex & $\begin{array}{l}\text { Trade and } \\
\text { Managemen } \\
\mathrm{t}\end{array}$ & $\begin{array}{l}\text { Universit } \\
\mathrm{y} \\
\text { professor }\end{array}$ & $\begin{array}{l}\text { Japanese } \\
\text { instructo } \\
\mathrm{r}\end{array}$ & $\begin{array}{l}\text { Researc } \\
\mathrm{h}\end{array}$ & $\begin{array}{l}\text { Technical } \\
\text { counselin } \\
\mathrm{g}\end{array}$ & $\begin{array}{l}\text { Professiona } \\
1 \text { work }\end{array}$ & $\begin{array}{l}\text { Entertainmen } \\
\mathrm{t} \text { and arts }\end{array}$ \\
\hline Japan & Male & 59 & 147 & 104 & 335 & 5 & 5 & 24 \\
\cline { 2 - 9 } & $\begin{array}{l}\text { Femal } \\
\mathrm{e}\end{array}$ & 0 & 77 & 258 & 11 & 0 & 0 & 8 \\
\hline
\end{tabular}

How to address the workplace justice and create any specific ethical decision, as we confirm, highly depends on the types of organization and its mission or work frames, as well as its culture and structure. It requires, however, of proper response to the societal expectations. As the workplace is educational and pursues a philanthropic errand to teach, breed, and research, the equal treatment, social equity and non-discrimination would be cherished and should be shaped in response with the societal expectations. The public administrators, in this aspect, need to heed on the segmented strands which could possibly counteract that important public value, i.e., the workplace equality on aliens.

First, the antipathy among two nationals may distort their due status which could threaten a fair treatment. From the qualitative research on an in-depth interview, the Japanese residents, of course including the students in Korea, would suffer a fear and apprehension from some less friendly attitude of Koreans. As Cohen and Safran elicited, the history is a primary source to offer the personal trauma of diaspora, particularly originated from the kindred-ship, national identity and trauma to disperse. In the interview, one aged Japanese male lamented, "some Koreans are friendly and benevolent, but a large number of them are not sympathetic or alienating perhaps because of sad imperial history" (2012).

Second, the worse factors to affect an equitable treatment also are related with the false understanding of history and a chronic contention of real issues, such as high school history textbooks, comfort women, and territorial claims of Dokdo, as also noted Takeshima in Japanese. This aspect must be a focal point in education and in the purpose of increasing a mutual awareness (2012). It also would be the strategic subject to create a harmonious ethos among workers and students, as well as a peace in the work place. It could be a precursor to induce the discriminatory consequence against the Japanese students or workers, which has to be tactically responded with. An education and informal fraternity could work for the congruent workplace in justice and effective multiculturalism.

\section{Reference}

Cropanzano, R. (2000). Justice in the Workplace: From theory To Practice, Volume 2 (Applied Psychology Series), Mahwha NJ: Psychology Press.

Frederickson, G. (1990). Public administration and social equity.Public Administration Review, 50(2), p228 (10p). 
Lim, Y.E. \& Huh, S.T. (2012), The Diasporadic Cluster of Japanese in South Korea, and its Cultural Identities, The Journal of Northeast Asia Research, Vol. 27. No. 2, Gwang-ju, ROK : Chosun University Press.

Mittelman, J. H. (2002). Making globalization work for the have nots. International Journal on World Peace, 19(2), 1-23.

Sandel, M. J. (2010). Justice: What's the Right Thing to Do? New York, NY: Farrar, Straus and Giroux.

\section{The Responsible Administration, Ethics and Justice: Two Illustrations from South Korea and Some Reflections about the Public Administration Studies}

\section{The National Assembly of Korea and Nature of Organization}

I chose the National Assembly of South Korea (NASK) for the purpose of final assignment, and shall apply the hypothesis as well as typology of ethical analysis on philosophies and corners of ethical virtues. This work would include the ethical challenges seriously debated in the near past and present days of NASK. As a public policy student, I intend to frame recommendations to produce a better picture to resolve the conflict of ethics, and explore factors to affect an implementation (Hicks, D., 2013). I finally draw upon the outcome of suggestions. While linking the two cases with the philosophies and theories to ground an intelligent basis of public administrators, I will discuss two implications about the ethics and responsible administration within the collegiate body as well as new orientation of academic response to the changing world politics, economics and society

NASK has long been an indispensable organ incorporated within the Korean constitution since 1948, and the practice or institutional tradition can be shared as same with the universal context. Even if the parliamentary system of government may be discarded by the constitutional drafters as in Korean cases, the assembly body, mutas mutandis, the Congress or Parliament would sustain for a public governance. This tradition would perhaps be more strong as in the Socialist states in Duma or National People's Congress of People's Republic of China. In a suggestion later drawn to bridge the Orient and West or Socialist to Liberal by focusing on the ethics of ruler and ruling class or social justice, it bears a perceptive implication that NASK operates as a collegiate body (Laureate Education Inc. a, 2013). This implies that the collegiate body, as structured within the constitutions, is indispensable and centralized in public administration. NASK can well be viewed to mostly share the universal qualities and attributes when we surf onto other global bodies in any comparative politics or constitutional study. It is chaptered in the first of government structure in the Korean constitution, comprised of the elected congressman, exclusive legislative power and supervisory role to monitor other governmental branches, privileges and immunities ascribed to the members, the fixed constitutional term on their service, restrictions in double-posting and so. 
According to the Constitution, the election will be held in four years to reshuffle a previous body and for the new term. The last election was held in 2012, and was denoted as the $19^{\text {th }}$ congress in the constitutional history of Korea. The election requires the members directly chosen by the people, but some quota basis approach was introduced to assign the members based on the total number of votes for a respective political party. Sanenouri, the ruling party of Korea, had been successful to achieve a majority status in the last election. Minjoo (democratic party in English), a major opposing party, also acquired a fair number of seats able which became able to influence their political ethos and goal. Some groups may like to explore a constitutional reform, who advocate the parliamentary system of government, but merely hover around the academics or distinct group of politicians. NASK currently operates under the 1987 Constitution based on the presidential system, and the chance to transform would largely be seen improbable in any recent years. Hence, NASK is generally considered to execute their constitutional mandate on the separation of powers principle, which only takes a part to integrate the national policy, neither a center of government unlike the parliamentary system. However, the party system often dominant in the contemporary politics would mediate the president and NASK, which also would be a case in Korea.

As the social justice and virtue of Republican democracy still largely are the factors of political contention despite the commonalities and divergences over history, the type of collegiate body would certainly be the forum where the nature and state of social justice issues in a specific national polity are to be debated (SEP : Economics and Economic Justice, 2013). This would not be an exception in Korea. While Korea has practiced the constitutional democracy since 1948, NASK often had been less powerful or usurped, in some sense, below its expected role in the Republican democracy or liberal politics. This means that it has, most of times, generally be seen a feeble institution under the kind of charismatic presidents. From his personal background, Syng-man Rhee had been strong as a national leader of independence from the Japanese imperial rule. He had a hereditary affinity with the Chosen dynasty and one of most enlightened intellectuals educated in the US. Chung-hee Park also ruled in any absolute hierarchy beyond the congressional check and balance, which had been a root basis in his militaristic might and growing quest to national industrialization and economic development. Chun Doo-hwan, who had reigned during 1981-1988 and one of his protégé, would largely be disposed in some similar fashion, who ruled the country in his personified way. The constitutional institution and system were be neglected or disregarded, and the personal network prevailed. It is, however, interesting that the theme of social justice, in his period of rule, made a debut in the Korean politics, at least in the parlance of government owing to the enhanced status of national economy (2013). The role and performance of NASK, therefore, largely depends on the constitutional system and political culture in a specific country. In this respect, NASK, who could be considered as leveled with the western counterpart in its culture and performance, has truly begun since the 1987 constitutional reform and Roh Tae-woo's administration.

\section{Two Ethical or Societal Issues}

\section{The First Case}

For the purpose of illustration, let me pick up two issues which possess a different characteristics in terms of the classic liberty and nearer concept of social rights (Universal Declaration of Human Rights, 2013; Crocker, L.H., 1980; SEP: Positive and Negative Liberty, 2013). The first example, contended in view of the ethics or social justice, aroused a 
public attention about the conflict of interest (Hicks, D., 2013). It poses the challenges, in an analogous context, concerning many issues and agendas of ethics and administration, such as Russian Mafia or Chinese trauma of corruption, although its substance involves a small ambit of national pension for the retired congressmen. Therefore, an ethical dilemma of the issue exhibits a good aspect of discussion about the liberty, equality and social justice, particularly from a perception about the ways of operation within the collegiate bodies (Cooper, T., 2012). The second example developed in the context of municipal program concerning the child subsidies. Seoul city, in the initiative to promote a political philosophy and social justice, has endeavored on the program, which now faces a difficulty from the worse national budget. The issue progressed contentiously and in any intensity of public controversy, which had both strands amenable to public criticism as well as progressive activism. It shows a fine context of political interplay, the concern of which spans over the roles and responsibilities between the national and local governments, as well as the political ideals both major parties engineer in continuance. A contention and disagreement on this issue had fueled a major debating point in the mayor election, and no candidate would be convinced of his unwavering probabilities about winning the election. This would go as same in the 2014 local election since the program also was not supported this year by the national budget.

The Pension Program for the National Assemblyman in Korea (PPNAM) was pursued around 2009, and the statute has passed in Mar. 2010. Since 2013, an implantation was secured through the 2013 national budget approved by the national assembly. The official title of statute to ground the PPNAM is the Supportive Act of Democratic Constitutional Rule in the Republic of Korea (SADCRRK, 2013). The Act provides in its pertinent article, "the National and Local Government would grant the subsidies in the purpose to meet the cost and fund which are deemed necessary to support the operation of Democratic Constitutional Association and its senior members above the age of 65 (2013). To put it simply, the goals of statute has been intended to support the former and standing congressmen, who only could enter the Association and obtain its membership. So it has the nature of seniority pension program on the condition of its membership, which at least one chance of successful candidacy and qualification as a congressman is required.

\section{The Second Case}

Other ethical issue for the National Assembly involves the Free Fostering Plan of Child (FFCP), which has led to a serious public debate about the social justice and feasibility of that plan (AECFP, 2013). There had been factors to affect an implementation, for example, excessive budget or incidental irrationalities from the unrefined system (Cooper, T., 2012). Often it was put in contrast between the opposing party, Minjoo, and conservative ruling one, Saenuori. As the local election for a Seoul mayor profiles so high in view of Korean politics, the parties most always do their best to attract the voters and persuade on their strengths of public policy. Seoul citizens often are an educated intellectual who can assess the policy issues and their consequence, who are large to account for one fourth of national populace. Seoul is also the province of contention with a half to half cut leading to any decisive margin for key national elections, such as Presidential and National Assembly. The Plan particularly gets to be problematic since Seoul also is required to be responsible for many social programs including the Free Food Program for the Middle and High Schools and because of its pressing political gravity between the two parties (Korea JoongAng Daily, 2013). I now brief 
on the feature of that programs, the issues and challenges, points of assessment as well as factors to affect an implementation of both Plans.

\section{Key Social Justice Themes}

\section{The First Case}

The ethical dilemma of this program contributes to the worse public sentiment as it is problematic in view of the public conscience and reason (Chosun Daily, 2013). The kind of program was not unique in Korea, but a scope of developed countries enacted and implemented such policy. They generally are, however, considered as designed reasonably and in the permissible fashion. US, UK, Germany and France could come within this class, and Japan has recently abolished the system. PPNAMs in these countries mandate a stern classification about an eligibility to the pension money, and the sum was not fixed unlike Korea. It maintains, however, a sliding system on the calculation method which pertains to each specificity. Let me tender an extent of its flaws and weaknesses. First, the scope of eligibility is rather comprehensive and too generous to disable a prudent assessment about the merits. The Act provides ten disqualifying causes in this end, yet to be insufficient because of its ambiguities and catch-all dealings inoperable to exclude an impertinent beneficiary. The practical consequence of this flaw would be that the assemblymen can claim a monthly alimony if to serve a short of one year only. This contradicts a prevailing concept and social justice for which the national pension system is directed. Second, the system would be vile since it did not filter the context of other pension beneficiaries. This means that they may exploit a dual receipt of pension, which doubles their retirement income and causes a social injustice in terms of public welfare. Even for the unworkable scope, e.g., a retired wage assemblyman, the pension would purport to ensure a basic level of human subsistence without the labor. The ideals would be disserved or perverted by allowing the same or more compensation for whose labor cease. This multiplicity problem is now debated around many drafts of pension programs, for example, the National Pension Plan (NPP) and Basic Subsidies Program of Aged People (BSPAP). In the case at matter, the alimony is ten times bigger than BSPAP, and NPP requires a contribution from the beneficiaries. Hence, the dual or multiple eligibility obviously comes more serious in PPNAM.

The alimony monies are rather gross in amount. According to the 2009 statistics from the National Pension Foundation, the spouses residing within Seoul are entitled to 1,100 and 1,008 dollars on a monthly basis since 2006, who contributed an installment during 219 months and 218 months respectively (Chosun Daily, 2013). This means that 18 years of contribution of statutory sum in each month could only qualify them to as less than 1,200 dollars. In comparison, an alimony for the retired congressmen, which is set at 1,200 dollars, outpaces it. One day service in the national assembly may bring a more economic benefit than the earnest and honest middle class of Korea. The NPP now undergoes a downward adjustment from the public pressure, but the alimony for them would be adjusted upward as corresponds with the price index. This leads to the challenges about the public sensibility of justice, equity and equality (SEP: Economics and Economic Justice, 2013; Cooper, T., 2012).

\section{The Second Case}


In the second case, the Plan, around Mar. 2012, was designed to promote a social reproduction if the nation was in the face of radical decline within the birth rate. It was pursued by the national government without an exception and on no discriminatory basis. The government applied a scale to increase the subsidies amount, but it has made no significant effect on the parents since it was less effected (AECFP, 2013). The parents may commit their children in some time frame to the public facilities. Besides the subsidies, however, an additional expense falls within the responsibility of parents, such as that for the education or activities. More problematic would be a serious confusion and unpredictability in the floor of public facilities, which stems from the lack of standard, rules nor ethical guideline on the subsidies system (Korea JoongAng Daily, 2013). The system is entirely on the basis of financial contribution by the direct transfer of currency amount. This serves a distortion of system in an intense competition for cash, and undermined the public value of fostering service, the kind of utilitarianism, an expansion of public infrastructure, as well as a liaison or network concept in bridging the private and public for the maximization of happiness. A particular note on the increase of the Household Fostering Service would show a floating away of public commission and trust, but it merely expedited the private enterprises to exploit as their income source. A tremendous amount of budget actually made a lesser effect since the quality of service provision and cost management were neither officially nor institutionally controlled (Reichert, E., 2011). This factor baffles a more efficient outcome. The Plan also has a critical flaw which was failing to exercise a policy survey and assessment concerning the addressee's class. This failure is a principal culprit for the abusive and imprudent vagary of clients, "file first and wait to see." On this basis, the true addresses in need of public fostering service could get in a secondary priority or excluded eventually from the benefit of service.

\section{Major Challenges and Factors to Implement}

\section{The First Case}

A problem of the first case lies in the fact that it contravenes a basic promise and frame of public pension system in that no installment was exchanged for the bargains of eligibility (Chosun Daily, 2013). This way of dealings is prevailing and basic on the kind of system, as we see in NPP, BSPAP, and National Pension System for Teachers, as well as one for governmental employees. This point comes central that most of the conscientious people expose their sentiment and get to be disgruntled. It aroused them that the social justice and equity was either in imbalance or undermined. Other problem lies in the vulnerable system of monitoring and feedback. As said, the exculpatory clause enters the scope on exemption or disqualification (SADCRRK, 2013). The causes are vast to pertain to the initial determination of eligibility. Nonetheless, the regular device to check a qualification needs to be strengthened. The chief of Association is able to ask a submission of evidence to support their continued status as a beneficiary. However, it would be needed of mandatory as a matter of law. Other more enhanced system to ensure a continued check-up for eligibility would be desired.

The controversy about this system has not been just on the public, but surfaces as a one of hyperboles within the political parties themselves (Chosun Daily, 2013). The Budget and Audit Committee of National Assembly (BACNA) prepared the white paper, which includes a reaction and resilience of the people in concern and dissatisfaction. The critical 
points in this paper would be same as briefed that the basis to pension benefit is stripped solely with the age requirement. The elements often factored as a standard in the public pension system, such as income, assets, an employment years, had been waived. That would transgress the ideals of frame instituted in other occupational pensions or National Pension. The controversy became especially serious since they are norm creators and receivers of norm. The ethical dilemma within the conflict of interest as well as prejudice on their position power and privileges enhanced a public contention and criticism (Hicks, D., 2013; Cooper, T., 2012). This aspect was geared up by the media and public press, which heralded an informed disclosure about the issue. A short service assemblyman and the criminals upon the termination of prison terms would not be excluded which could be sufficient to question its ethics and social justice (Laureate Education Inc. a, 2013). A dual or multiple receipt and too much alimony were also pointed out in the paper. One other critical flaw was illustrated that the system avoids an eye from the economic condition of national assembly man or his household.

\section{The Second Case}

We now turn to see the challenges and factors to affect an implementation of the second policy, which, amongst of all, could be encapsulated into three points of consideration.

First, the budgetary constraints distort the Plan and lead to a complex ethical or social justice dilemma. On the last day, 2011, NASK approved an increased sum of budget from the governmental proposal covering the subsidies amount for the 0-2 years children (AECFP, 2013). This social benefit was fixed in a scheme over the years whose income ranges as lower than 70 percents. A scope of social welfare programs often have been pursued in a match with the local governments, which, as a corollary, require an incidental local budget in the process (Korea JoongAng Daily, 2013). As the Plan was released on public notice, new demand increased dramatically and the required budget amount doubled. The national conference of city majors and province governors forecast an increase from the 50 percent households to the point around 70-80 percents, who commit their baby for the care of Plan facilities (2013). The local governments, largely troubled on an unsound budget and often vulnerable in the state of financial independence, have to undertake the Plan by creating a heavy debt and owing to the absence of sufficient intergovernmental coordination in advance. Jong-bum Lee, who is a chief administrator of local governments, lamented, "The subsidies for the Plan would be drawn in the form of matching funds, and usually in the half to half ways between two governments en toto, which depends on a specific condition of respective local government. NASK miscalculated the number, 30 percents households disserved in the past, and expected 3.7 million dollars to meet the demand. The new demand unexpectedly exploded that the financial burden of local governments amounted to as high as 7 million dollars" (2013; Reichert, E. 2011).

The National Planning and Financing Department and other agencies shared an expectation that the budget basis will be drained within about 10 to 17 local governments in June and July, 2012. One Seocho-gu officer said,

"Seocho-gu would be most serious. Other adjacent prescient would be supported with 60 percents share from the central government, but ours would be as less as 30 percents. This means that we will have to discontinue in this June because of the financial unfeasibility" (2013) 
One rank officer of local government also deplored,

"The residue from the last year was officially transmitted to the local government in May. However, this monies already was planned to complement the shortage of NPPAP and other public projects. Then the monies would not serve any fiscal deficit from the FFCP. Any more drastic measure only could save the current dilemma of fiscal impasse" (2013).

FFCP was designed and attempted absent any consonance and prior consultation with the local governments, and processed in the NASK. This anomaly from such unilateral initiative should be put on the shoulder of that responsible dimension, i.e., a central government.

As the FFCP began to be implemented, over new five hundred public facilities had been recorded through only two months period, Dec, 2011 and Jan. 2012. Only 35 were national and public facilities, but other 438 private ones increased in number by twelve times to the former Plan (2013). This course of multiplication also went same in 2005 and 2006 provided that a subsides amount on the basis of facilities diminished as well as that on the children basis increased. We can chart a same mode of progress that the private or a free home fostering form multiplied, that a competition to induce the children intensified, while the pursuit of commercial interest swaying as unethical. The national or public facilities got marginalized in number as less in 5.3 percents, and the private facilities predominated a provision of service. The policy goals from the Plan had a central focus on the expansion of subsidies amount, and the increase of infrastructure or facilities was on the list in policy items, but set aside because of an insufficient budget. This critical flaw virtually paralyzed the Plan, and well calls upon its halt or suspension. A focal attention from the consumers of Plan would rather sees a trust and credibility related with the quality of facilities and adequate management or supervision. Given the burden from an additional expense, the Plan's primary goal would less effectively work (Cooper, T., 2012).

A use rate of fostering facilities for the $0-2$ years children amounted to $50.5 \%$ in 2009 , which allows a third spot in the OECD statistics. This rate is too high in factors from the OECD recommendation that $30 \%$ would be adequate and the home breeding would be a better option below the age two. Korea surpassed the recommended rate four years ago. Only Holland and Sweden outranked Korea by 83 and 66 percents respectively. Their case would be distinct that 72 and 76.5 percents of parents are working while Korea shows only 29.9 percents of parents on the employment status (Korea JoongAng Daily,2013). This statistics shows that no strong reason afforded a ground for such high rate of subscription to the public fostering service in Korea. This trend principally seems to be caused from the unsavory rush of parents, which perhaps would be from the intuition of free riding and any hallucination of loss. No genuine concern seems to be posited on the committing parents. This trend is certainly inimical to the most seriously interested households, say, working mother homes. The system legally misled a consumer's classification by exclusively relying on the number of children for each facility, as well as the "first come first served" dealings. The housewife mother homes can petition earlier to frustrate a working mother. From the launch of Plan, their propensity got worse to consume the whole hours as maximum as possible and legally entitled to them (AECFP, 2013). 
It is a postulate dominantly accepted that an affinity and pathos created around the earlier years of children as 24 months is determined to form a healthy psychological ego, i.e., social attitude, personal emotion, and trust relation in later years. A stable affinity and pathos in these years also affect to develop their brain or mental capacity, and autonomy as well as maturity of an ego later years. Otherwise the children would suffer a mental dip about an aggressiveness or brutal hostility and degradation of self-confidence or sense of trust. Any best way to increase the affinity and pathos of children is a mother's hug that needs to be frequented, and some intimate contact with a biological mother. Ericson, an influential author in this area, particularly stressed the importance of early childhood and intimate relationship between the mother and child. Myoung-hee Ahn, a professor of psychology in the Seogang University, also adverted,

"The mother plays a role to bridge the world and child in his or her earlier years. The children can develop the character and intuitive power to overcome a frustrating pressure or strains. A lack of this phase in earlier years often causes a self-suspect and distrust of the exterior world. Korean tradition once would be a paradigm that the western household worshipped to follow. That now is no realities here" (2013).

A public employee, named Hye-jeong Choi, served five years to provide a fostering assistance and said,

"She is discontent with the Plan. The children committed to her care, all through the daytime, are crying for her biological mother, and the apparent context of subsidies benefit usually incurs an impulse of non-working housewife to ask for long hours of care." She now works in the Seoul Child Facilities, which operates from 7. 30 in the morning through 7.30 in the evening."

A tax abuse and additional expense burdened on the parents also pose the challenges. Some of the fostering facilities enforced a wholesale increase of incidental expenses for 3-4 years children although they focused on the five-years group. This practice urges a follow-up investigation and adequate policy response at the national scale. The government granted subsidies in sum on the basis of law, and the facilities often should neither trade off that nor even increase the cost from other justification (AECFP, 2013). This could make a policy effect by never reducing the pocket expense of parents and because of the tremendous amount of budget, i.e., 1.2 billion dollars. Their basis to increase an incidental charge is ambiguous, such as the heating cost or event expense. Nonetheless, the local governments, a principal actor to supervise the system, have not performed any research nor initiate a supervisory command to ensure the transparent administration. This status, highly irresponsible and neither fiduciary nor ethical, forecloses the initial ambition of this plan, which would practically be obvious over ten private facilities at the urban Seoul (Cooper, T., 2012).

The fostering administration often does not function in the public trust and credibility, which would likely be from the unethical and interest-driven owners. A short minute of care legally entitle them to claim the subsidies so that they often prefer a housewife children rather than those of working mother. It is highly selective that an easy access to the facilities was baffled. As the quota of children increased, the quality of service would degrade and a workload of fostering teachers gets tougher. The benefit ascribed to each party also shows 
that the policy grossly favors the fostering facilities, which, in dollar amount, 800 for the facilities, 400 for parents, and 200 for the fostering teachers (Korea JoongAng Daily, 2013).

Finally, a geographical disparity can undermine the equal justice of this policy varying with the quality of fostering teachers and their service provision. The government implements a guideline on the work frame in time, which is from 7 in the morning through 7 in the evening. If the work frame would change to extend, the paper work of fostering teachers would add making it a twelve hours cumbersome work. Their compensation might be halted in some cases, which also got worse depending on the fiscal state of each local government. The fostering teachers tend to leave a deprived region for the high income locales, which often are populated with the working mother houses. A reform alternative to improve the facilities is dispensed by the terminal officers or owners which undermines the sense of pride and personal decency. However, they do not have an effective means to raise their political voice. That is because the fostering teachers are not represented collectively unlike the owners of facilities. The unethical owners often see a headcount of children as their income source, and some fostering teachers are incompetent or uncommitted. This context could impact seriously to the disadvantage of children. For the children of $0-2$ years range, a shortage in the supply of teaching servants poses a greater challenge, particularly for the locales of province and in the agricultural area. In case of Chung-chung Province, the necessary fostering teachers would be around 7,000 from the whole quota, 600,000, while the practical force is 6,000 in number (2013). For this reason, the quota often was not satisfied from 80 percents and even lower as 6o percents in the agricultural area. Three children would be assigned to match one fostering teacher, but the context is not being implemented as schemed. One local employee of government urged, "a special policy response needs to be shaped. Otherwise, the ambitious plan may be accused of perpetrating a serious discriminatory consequence" (2013; Reichert, E., 2011). Thirteen facilities among fifteen in Young-dong failed to recruit a requisite number of fostering teachers. Some provinces enacted to reimburse a special compensation in some small sum, but likely effects less.

\section{Recommendations and Outcomes}

\section{The First Case}

BACNA reported a policy suggestion to remedy the identified problems, which is encouraging and on progress. They perceived a controversy in competing policy goals, i.e., an integrity and sanctity of congressmen as a constitutional agency and the acceptable design of system. They are required of high standard of position ethics from the Constitution, statutes and internal ethical code, but the support of senior members, who could be economically deprived, is lacking. This context was responded, as said, by an enactment of the pertinent laws across the developed countries. Korea has already entered an advanced status, which requires exploring the needs of system more seriously. It increases a point of persuasion provided that the nation has long afforded an affluent public pension for the military personnel and government employees. BACNA adopted the alternative to go with the current system as is, while simultaneously launching the task force to be responsible for a revision. The revision project would begin with a collection of ideas and opinions from the incumbents and former national assemblymen. A first priority was suggested that the administration unit of NASK reviews the merit of sliding scale as well as the linking 
possibilities with NPP (Chosun Daily, 2013). Their long term ideals would remain as same that it is required and ethically rewarding to support a financially vulnerable and aged assembly man. It comports with the requirement of social justice for their contribution and devotion to the nation. Therefore, their viewpoint on this agenda basically agreed on the fundaments of this system, but urged the need of political process for the popular support and sense of justice, as well as the equality and equity. The reform voice is not solely for BACNA, but the major political parties are active to modify the system toward a more reasonable one (Cooper, T., 2012). Three revision proposals are now pending and assigned with the responsible committee. This development would fall in a sharp contrast with the passage of Act in 2010, which was a one day process.

\section{The Second Case}

Most impending is that the policy makers have to be perspicacious in decreasing the quandary of policy abuse. How to be faithfully committed to the foster and care of children would be the way of fiduciary duty owed by public officials. A mere spending to grant and subsidize would vitiate the values on human right, liberty, as well as social justice (Laureate Education Inc. b, 2013; SEP : Positive and Negative Liberty, 2013; Universal Declaration of Human Rights, 2013). As surveyed, 0-2 years children would be more desired of home fostering, and many countries, in accordance with an OECD suggestion, institutionally support the mode of financial benefit. The Korean system, on the other, enforces a unitary scheme of public facilities, which can bring a discriminatory effect on the households. In consideration of the concerned parents and children, children over three years could be grouped for the fostering service. The national programs in this kind need to be designed carefully, which requires referring to the professional advice and adequate public forum. While we share the merit of subsidies in the cause of welfare expansion, the government will perform well if to revalue the scheme for home breeding of children below 2 years in age. The present system limited an access to the public subsidies for the second class in the government wealth classification code if the household opts for a home breeding. It has to be revised that all classes can choose without any disadvantage between the home breeding and use of public facilities. This would serve the equity interest and would comport with an OECD suggestion (Cooper, T., 2012).

A serious assessment of ill effect in the prior year was not made. Until 2011, the subsidies were dispensed exclusively to the users of public facilities. In 2012, the revision rather extended the amount of subsidies and avoided an acid criticism about the discrimination of home breeding (AECFP, 2013). A view announced from the Seoul YMCA is echoing,

"As the children under the age of two would be done better at home, and this being in accordance with the OECD guideline.... The public service would pertain to the group of three to four years, which requires the system to be transformed from the subsidies to a national child alimony" (2013)

It is fortunate that the Department of Health and Welfare (DHW) accepted this view to allow the parents of 0-2 years children an option between two ways of dealings. It would also serve the equality and convenience of system to provide the voucher system where the parents can use only in case of needs. A tax benefit needs to be afforded in the purpose to 
boost a birth as well as to meet the fostering needs of women. A tax deduction on the educational expenses also would be helpful. On other basis, it would make a public good if the policy can shift to be founded on the disparate income frame and scaling system. The national or public nature of facilities would yield a fair and impartial administration in experiences, and the workplace facilities would be urgent to improve the system. According to the Nov. 2010 report from the government, it obliged the statutory size of firms to provide the workplace fostering facilities, but four of ten would not satisfy that requirement (2013). The government keeps their names confidential to avoid the public criticism. The Civil Society on the Justice of National Economy, one of most active pressure group in Korea, claimed its public disclosure in the last June, but the response has been inattentive in any short comment, "It would jeopardize the property rights of citizen." This interaction simply shows a historic contention between the liberal and social state paradigm. In the statistics, 236 among the whole 576 classed into the scope of statute failed to meet a legal requirement, which includes a workplace with more than 500 employees at total or more than 300 female workers. In conditions as the safety issue or lack of space, they may alternatively bear the expense to foster the children or designate other exterior facilities. The above 236 firms neglect on these duties, and the aspect of penalty or disciplinary measure has to be reinforced relying on the requisite legal provisions (2013).

\section{Philosophies and Theories}

The cases described above show a typical dilemma about the classic ideas of government as well as the modern national paradigm in the pursuit of social justice or welfare. The first case can be ethically questionable if the lawmakers could enact a law to their selfinterest. In the modern ethical term, the pension plan possesses a quality of contention possibly in derogation of the right ways on the conflict of interest requirement (Hicks, D., 2013). The legislative power is expected to operate under the separation of powers principle (SPP), hence, this traditional adage of legal principles can be reminded to respect. As incorporated into the Constitution, the standard as to regulate their conduct and ethics would approach as powerful as in the cases, such as the prohibition of ex-post laws or selfincrimination. Otherwise, even the natural law theory could also mandate to conform their conduct to the inviolable concept of justice. For example, it is self-evident that nobody can enact the laws for himself in any discriminatory or specific ways to dispose. The laws need to keep on the essence of justice in general as well as in the form of abstract terms or prescriptions. A classification and way of dealings are required to be impartial and unbiased so as not to disparage the intrinsic of executive power (Kranich, N., 2007). Hence, it is strictly forbidden to enact the kind of dispositive law, but the acts should allow an interpretive leeway expected to operate within the province of executive power. That assures, as a way of inter-branch check and balance, the ideal of separation of powers principle and against any arbitrary abuse of vested powers by one branch of government. The vehicle of SPP, hence, could enable a "division and loyalty" to the popular democracy.

We often say the "divide and rule" axiom in the traditional operation of labor union and in the imperialistic ways of ruling for the subject states. The idea shares a similar attributes except that the public administrators have to be loyal to their sovereign and popular will. The public administrators are no longer placed to the role and responsibility on the successive or hereditary basis. They are elected by the people and may be appointed by the representatives of popular will. That is the only basis that they could be empowered and carry 
their constitutional or statutory power. They are, in this respect, required to owe the kind of fiduciary duty and act on trust to serve the people in any faith, professional competence and capacity. As Cicero, a Roman philosopher on the ethics of ruler and social justice, said, "Justice is a fundamental element to be ensured of the rule or governance, which is only way leading to a human solidarity" (Laureate Education Inc. a, 2013). While the pension plan can fuel a controversy in light of the liberty and SPP, it also can evoke the dated notion of social justice and ethics of public administrators. Bentham perceived the importance of new thinking about a rule, its ideals, understandings, network, system, and organization. He offers a philosophical foundation for the modern positive state on the legislation and new covenant of public administration to share the revolutionary spirit (Audard, C., 1999; Postema, G. J., 2006). His utilitarian conception and theory could contest, in tenet and ethical requirement, the right ways which NASK had to opt for. His pursuit to maximize the individual happiness would be sublime for the administrators to bear in practicing their official duty. His free rider's thesis is interesting which could well discourage this faithful public theorist.

As outlined, the pension plan led to a high likelihood of public dissatisfaction and unhappiness about its sudden protrusion, hastened progress into the act, lack of public forum, insufficiency in provisions and inadequacy of finding an eligibility, as well as the high amount of subsidies. The goals and purpose triggered by the pension plan, however, could be verified to have a plausible ground. It was planned to support the great nationals who could not afford their lives in later years (Kranich, N., 2007). A fiscal feasibility is considered well in the purview of ordinate treasury and apparently costs less a burden. Many incidents developed in the NASK over the decade, however, proves in other way that several of such self-motivated measures frustrated the citizenry. The civil monitor group in Korea thankfully charted and reported to increase a public awareness. Notably, they have long years voted to increase their compensation under the circumstances where the national economy had staggered, the unemployment of youths disrupted the society, and the citizens were pressured so much to yield the highest rate of suicide in the OECD statistics. They often showed the tendency to side their peers in the incident of justice on the arrest of person, who ccould, then, claim his constitutional privileges and immunities as a national assembly man. They are never a housebreaker or highwayman whom Bentham made a wry wit about and who could stall the ethical and minded public administrators as saddened (Audard, C., 1999; Postema, G. J. (2006). They seem a due cause to institute the plan, which complies with the comparative illustrations of developed states. The practical aspect of Plan, as suggested, could be reexamined in the end to create a supportive ethos of people.

FFPC was pursued in the social welfare sprit and in order to promote the birth rate of nation. The social justice and equity, however, would posit a serious challenge as we detailed above. It does neither involve the conflict of interest nor ethics of congressmen in any conspicuous dress, but the redistribution of resources and wealth could possibly be misdirected or in the vein of structural or implementation flaws (Hicks, D., 2013). Most problematic is the present context of progress that a true beneficiary could be discriminated in the interest of facility owners leading to an ineffective consequence and contravening the intended goal of service. The equity, most closely related with the whole scale of social justice, would not be operated as deviated from the expected trajectory of Plan. The housewives have grown in number to exploit the benefit of plan as a primary class of beneficiary so that the working mother home, a target class of the Plan, was set to be secondary since the committed care requires a more hours and work demand. From the libertarian view in clanning on the original freedom and property right, the welfare expense 
in this type would not be supported. They would entertain their ground that no legitimate basis to spend the tax income and public funds without any key public use, such as police and national defense service. The positive liberty concept, however, suggests its role more affirmatively that the working mothers can be enabled to exercise their function and liberty with the welfare assistance (Crocker, L.H., 1980; SEP : Positive and Negative Liberty, 2013). They can work thanks to the public aids, and can manifest their capabilities, talents, and economic activity in freedom. The negative liberty or equal opportunity from the least involvement or less regulation of state could not reach this dimension. The context of controversy also reveals an equality concern that the functional equality, implored by Dworkin and Sen, could be served if to be compared between the working mothers and unmarried maiden (2013).

The government made a classification to serve their policy goals in the benefit of household, which has the intended range of children, i.e., 0-3 years old. This brings the consequence of unequal treatment among the citizens, which can possibly abridge the equality of resources and opportunity. The first principle, in the Rawls proposition, can see its way to the complex equality for the aids and grants to restore a justice. The veil of ignorance in the Rawlsian understanding could be posited about the deprived and child burdened household incidental to the working mothers. They are economically vulnerable, but could contribute to the increase of birth rate and national production or economy. The idea or concept can be shared in the same strand when the developed countries boost the developing counterparts by aids and grants, which Rawls and the current structure of WTO espoused as their economic justice (SEP: Economics and Economic Justice, 2013). The context of interplay would upgrade the function of them and contribute to the material welfare of humankind as well as the increase of world economy. This scheme on social justice would be perceived as ambition-sensitive as Dworkin focused. A retreat to merely an endowmentsensitive approach of equality would lead an intolerable waste of working force and huge sojourn of human resources.

The equity or equality requirement may be highlighted by pointing to the geographical terms of nation. A fiscally deprived local governments may suffer a minimal operation of fostering facilities which marginalized the service in a specific region. This would incur a great potential to deprave the legitimacy of Plan, so that the government is required to elicit the standard and revised scheme. It could be on feedback from the initial implementation period of Plan. The supervision and monitoring process need to be enhanced and be controlled to remove the chance of owner's unethical or contradictory commitment. The nursing teachers would be a precious actor to perfect the Plan. The government should prevent an intermediary exploitation of owners or managers of facility, increase and maintain the quality and faith, and procure a requisite number of teachers to fulfill the demand.

\section{Concluding Insights}

\section{About the Ethics and Responsible Administration of Collegiate Body}

The rapid context of globalization and geographical compression may be enabled by the technological advancement in the new millennium. I believe that this factor transformed the mode of governance where the collegiate body would penetrate the differing polities on the universal basis (Cooper, T., 2012). Now the people, or global public at this time, perhaps 
would be less attracted by the political or economic theories, which have depraved the polities to their own way. The Orient and West also had long been deemed heteronomous between the western liberals and communists or feudal Orientalism. The impact of etechnology, as a most notable influence, now affords the opportunity to share and sense in any common attributes of humanity or society. Now the ethics or social justice, which is, in many subtleties, intimate, delicate, and applied beyond the established formality of western intelligence, can appeal not only in the national politics but also in the international plane (Laureate Education Inc. a, 2013). We can encounter a usual scene of summit meetings who exchange their personal value, perception and administrative ethics.

That would often not be the case when we consider the most universal body, i.e., national assembly or congress. An interchange in this domain may be in the network or liaison, but could not be leveled to the context of summit. Particularly, the way of executing their constitutional duties would be rather different as pointed out. For example, anonymity in their vote could render them even less responsible than even the executive officials. The two issues discussed above expose a very basic contrast across the self-enactment, self-interest, social welfare and justice, positive liberty, as well as the human rights to a decent condition (Donnelly, J., 2013; SEP: Human Rights, 2013; Universal Declaration of Human Rights, 2013). The first case involves a classic notion concerning the potential power abuse as coupled with the social welfare of target group. The second case deals with some most enhanced science and reasonableness of the social welfare program. Both issues actually sensitized the Korean people in a great concern and interest than any other serious economic issues. This implies that the netizenry and people in this new millennium are largely disposed to track intimately on the public administrators who long enjoyed an insulation and independent nobility. The trend may go similar in the socialist elitism of Congress or communist parties, and converge to be subject to the public monitor or critical eyes. However, the ethics of them were not dealt in any coherent manner which factors the attributes as a collegiate body. I suggest that the Cooper's model may serve an individual member of collegiate body at this point of time, and hopefully expects for further studies more suited to the ethics of collegiate body (Cooper, T., 2012). Both issues actually disclose a square aspect of ethical failure to pull down the public image of NASK. Behind the controversy and public disappointment, we regret if they might neglect on a due regard to the required ethics. This could have been ameliorated if he or she individually and seriously assessed the problem on the kind of Cooper's deliberation. The attributes and qualities of organization also seems to matter in the kind of "institutional inertia" or amok, which requires a system studies of ethics and public administration concerning the collegiate body (2012).

The ethics and social justice are one of sensitive topic for the contemporary administrators and global public. For the material conditions have improved, this theme poses an aspect of serious challenges to attract our attention. The contemporary literature in this field had been dealt mostly with some philosophical studies, practical point of public administration, and some of efforts on theorization or design approach. The outcome of this less exposure and unattended research would lead to the lack of pertinent frame to analyze more systemically and in affluent sources of reference for the different nature of public organizations. While Cooper's ethical decision making model shows some of mental stages to deliberate on the ethical dilemma and challenges, it could possibly possess a universal quality as the design of ethical decision making process (2012). However, it is highly generalized to neglect on the specific nature of public organizations. I would like to withhold 
looking into the private or for profit organizations since the theory or metaphor with the public ones would properly subdue their minimal nature of dealings. Given the Cooper's analysis and approach provides a good model in the aspect of formality and mental progress about the specific public administrators, it is also necessary to substantiate the quality of ethics or social justice issue in terms of the attributes of public organization (2012). In this standpoint of view, I intend to make a distinction between the bureaucratic nature and collegiate body of public organizations. There are a scope of public organizations in the different nature, which maintains a bureaucratic work structure, notably the executive branch of government, foundations, and high supported charity organizations, public schools, and so. There could we find the collegiate form of organizations, such as congress or national assembly, public commission or council, consortium on the public project, and etc. The quality and attributes concerning the interplay of ethics or social justice with the collegiate bodies could be clarified in several aspects against the bureaucratic types.

First, the organizational members generally would enjoy an equal status and competence that a complicated or aura of ethical issues distinctly arising from the context of command and obedience would not be present.

Second, the organizational members often undertake an important role and positional power as a decisional body, which would be to leverage their ethical requirement more stern in some cases, but more softened in other cases. Both cases discussed above could be viewed in the latter light.

Third, they would be a norm or standard giver and simultaneously a norm or standard receiver, who has to respect the ethics codified or required in any form. They could be plenary to regulate their conduct, but the tradition and social attention would monitor as coupled with their good conscience and personal quality or integrity (Maccallum, G.C., 1993). The specific context of norm formulation, for example, anonymity in the vote, could have a potential to be resilient in producing a socially desirable ethical code. In some of response, we may reinforce a stricter scheme about the name-designated enactment, open vote to be name-disclosed, and the kind of intensive hearing sessions about the sensitive social welfare program as well as a public forum indispensable with the agenda on conflict of interest, and etc.

Fourth, they perform their job responsibility on the ad hoc basis in many chances that the ethical requirements would normally be less serious nor challenging than the employees in bureaucracy. Therefore, I consider that the standing status of organization would be more a factor in distinction. For example, the panel would be a lower and ad hoc basis arrangement while the appellate body staffed with tenured judges within the standing nature would be seen otherwise in the context of WTO.

Fifth, it seems also relevant about the ways of ethical process whether the organization is governmental or entitled to the constitutional privilege. The nongovernmental organizations of public nature would share the attributes in middle status between the private and governmental branches. Given the constitutional privileges, the national assembly, for example, would face a distinct body of ethical practice on the tradition and constitutional expectation. For example, it could be a virtue for them to more readily disclose a public truth in the Floor, which is other than the ranked bureaucrats or executive 
directors. The philie buster could also be viewed not strictly unethical, although we see it undesirable in some cases. Other governmental organizations, however and across the jurisdictions, tend to be governed uniformly by the centralized statutes or decrees on the ethics and responsibility as a public officer (Laureate Education Inc. a, 2013).

\section{From the Econo-political (West) to Ethics or Justice Discourse (Orient and West)}

The two cases exhibit the typology of western thoughts between the liberal and social dualism projected over the scope of disciplines, i.e., politics, economics, sociology, law, and so (Murphy, A., 1998). The cases also exhibit typical burdens which the public administrators, over the long centuries or decades have been posed as challenges. The two cases would perhaps be irrelevant with the locus of nations, if to be west and east. For example, the spoils of victory in $19^{\text {th }}$ America would still be on vestige and ethically challenged by some of public views. The Russia Mafia or Princelings in China over the decades would also show a dilemma involving the conflict of interest in any grand scale. The social welfare policy also could be shared in the communist states, and China notably intensifies the liberalization of national economy within the socialist basics (Hunt, L., 2008). They may restructure a perfect, but minimally afforded social welfare due to the materialistic incapacity. The liberal western states also struggle with any adequate extent of social welfare policy. Hence, the two cases are prone to seriate the wake of history and hemisphere on earth, which drove us to mediate on the practical and ethical aspect of academic thinking. I consider the ethics and responsible administration studies in prongs, possibly with sharing and reaching the common breath between the West and Orient, as well as the communists and liberals. The traditional frame is dominantly western, hence, econo-political to implant. Now I consider, however, that the needs or background on this intellectual exposure could be said a tradition or basic, mere a backdrop or in the least practically not arguable. We may impeach an evil state on human rights violation, but never condemn them as they are a communist regime of national economy or so (SEP: Human rights, 2013). Notwithstanding the famous word, "demise of ideology," we now generally agree on its flip side, but some of new trends in our everyday lives.

Reverting to the cases, we suppose that the rulers in power should be on some ethics about the conflict of interest, and that the social welfare program could lead to the positive liberty or functional equality and the kind of substantive justice (Laureate Education Inc. b, 2013; SEP : Positive and Negative Liberty, 2013). Often the econo-political frames have been imposing to structure our intelligence, but the massive society or close context of public interaction on e-technology or for other many reasons, now defines the practical points of contention in other ways. While neither or only minimal improvement could be ascertained from the earlier century or decades of Congress in both issues, the public now are more interested in their ethics, manner, motives of policy, and the kind of justice attitudes. The contemporary society poses a multifaceted challenge of human condition and lives in dignity (Hunt, L., 2008). A progenemonon to the modern civilian society enabled a materialistic prosperity in our living conditions although some of awakened voice claims an aspect of fundamental wrongs from the generalization and consequent amok from the unbeknownst or intoxicated leverage of massive general base or manageable citizens. They have a concern about the unemployment rate, stalemate of economy not to satisfy the population growth, as well as their income or retirement prospect in terms of the assets or pension. The modern structure of politics and economy has settled well making them to be a merely adaptive 
personality and to focus on their chores vastly. This constant tone and ethos in the lives of dominant class would be refreshed by an occasional exposure to the international controversies or idiosyncrasy from the politics and national or international leaders or other exotic experiences. However, that would not entail a serious political or economic issue to disrupt their pleasant personal domain (Murphy, A., 1998). If we now gradually acknowledge G2 politics and the rise of Oriental power, we may be helped with some of useful insights from the standing Chinese leaders. In the hierarchy and rank order, the newspaper introduced three Chinese leaders, Xi jin Ping, Lee, and Hwang. The leaders had addressed his interest by illustrating a most influential book in his respective leadership. $\mathrm{Xi}$, as matched with his top national status, illustrated a Chinese novel titled Ordeals and New Plane and authored by the professor of Chinese Military Academy. Lee, as a second rank of leadership, was concerned about the national economy, and mentioned the book which frontiers the second industrialization on the fossil fuels toward the third of information technology (1998). Hwang shed a light on the insights and wisdom proposed by A. Tocqueville about the revolutionary social condition. China, besides his rising status in the world economy, is a most populated country. We now witness that the world becomes compressed to see a gradual congruence between the West and East or Orient for many reasons, for example, e-technology or some of decades experience of the liberal or social democracy. The civilian wake of democratic governance has trained both pans to share a common ground and openness to exchange.

Despite a continued difference or contention at some extent, I like to suggest the ethics and social justice issue could be one of governing theme which the contemporary global public implicitly receives more than any other political or economic discourse (Laureate Education Inc. b, 2013). While, in the Lee's interest, his book can bear an intellectual insight and serve to cultivate the mindset or attitude of national leaders, it may be seen to the large public as some of applied restructuring of the current structure within the global or national economy. For $X i$, the Chinese novel would offer the soil and implied value or social compassion for this long history of grand nation, but might be nationalistic well to rebut a common rationale for the global public. It would come little to influence that it perhaps lacks a quality of socialism advocacy if the book is merely a novel other than any social science or professional books. Hwang's regard to the Tocqueville's may contain a universal theory or viewpoint about the revolution and social condition. However, it could be limited to the worse political condition of China for the still lower per capita income, gradual economic disparity between the poor and rich, and their prevailing adherence with the economic equality on socialism.

If we turn our attention to the western mode of developed countries, the econopolitical framework devoted to the western industrialization perhaps would exhaust its all the genesis in stalemate. Nobody questions the precious idea of free market and financial policy to energize the national or international economy. FRB has tried their best through the decades to vibrate the national and global economy, and the IMF as well as the World Bank could gladly take a part to cooperate and collaborate. We, the global public, however, could share merely in reticence, accomplice, nodding or support, and general credence of their wisdom and theory. This attitude or intellectual perception would also be same about the modern prevailing political discourse. Now the Korean people generally do not think if any swift of governmental structure to the parliamentary system would bring any difference on the politics or their actual ways of living. They probably would be correct to know if the scheme is keenly related with the turn of modern democracy from the feudal system. The 
context would be said similarly as the second and third generation narratives in the economic transformation.

So I believe that the contemporary global public, in the mid of post modern realities and besides some of distinct groups or individuals, would be vastly concerned of the ethics, social justice or responsible administration than the insipid reiteration of the property and freedom of contract generalization. An assembly man Choi, who is a floor leader of the National Assembly from Sanouri said, "Korea is now on excessive democracy than its lacking or insufficiency, in response with the street demonstration of opposing party." This comment suggests some of truths that Korean public would detest a stereotype of political narrative on the democracy and freedom, demand a professional ethics, and is more sensitive to the social justice, and pays a due regard to the responsibility of public administrators. Lee Kuan Yew, a respected charisma of Singapore, impressively addressed the Oriental virtues as distinct and precious through the long history (Postema, G. J., 2006). Eo-ryung Lee, a distinguished professor from the Ewha Woman's University in South Korea, also emphasized thorough his brilliant academic career the Korea and Oriental philosophy, the strengths of Oriental values, and predicted a new cultural primacy of Orient in the new millennium. He commented, "The first millennium had been an era of Oriental dominance in the material prosperity and cultural superiority." The second thousand years had been led by the Western power to embed the democracy and idea of free market in the world. The new millennium would be wheeled ahead by the Oriental influence where the ethics and values in the esoteric nature could be shared and expand into the universalized respect and followership (2006). For the importance of China, I like to revisit an above illustration pointing out that they imply their social minds except as basically variegated with their urgent needs to administer their state developmental paradigm. Among the aspects of principle, I assess that they sacrifice the liberty interest in trade-offs with the equality adherence. The social justice and conception of human rights would compete, but would probably find a point of compromise with the western concept given the near future on any sufficient material conditions (Donnelly, J., 2013). It also complies with their state foundation recently conformed (SEP: Human rights, 2013).

That briefed, I suppose that the future academics would deserve a new enhanced focus on the studies of ethics, social justice and responsibility of public administrators than any other times. 


\section{Reference}

A Harsh Response from the Citizenry Against the Passage of Alimony Act (2013, Jan. 6) Chosun Daily, Seoul, South Korea

Act on Early Childhood Fostering Program (AECFP), Korea Stat 12068 (2013).

Audard, C. (1999). Anthologie historique et critique de l'utilitarisme, tome 1 : Bentham et ses précurseurs (1711-1832). Paris: Presses Universitaires de France - PUF.

Cooper, T. (2012). The Responsible Administrator. San Francisco, CA: John Wiley \& Sons.

Crocker, L.H. (1980). Positive Liberty: An Essay in Normative Political Philosophy (Melbourne International Philosophy Series), New York, NY: Springer.

Donnelly, J. (2013). Universal Human Rights in Theory and Practice, Ithaca, NY: Cornell University Press.

Hicks, D. (2013). Dignity: Its Essential Role in Resolving Conflict, New Haven, CT: Yale University Press.

Hunt, L. (2008). Inventing Human Rights : A History, New York/London :W.W. Norton \& Company.

Kranich, N. (2007). Equality and equity of access: What's the difference? Retrieved July 10, 2008 from the American Library Association Web site:

Laureate Education Inc. a, (2013). Ethics and Social Justice "Equality and Equity: Applications" with Amanda Baker (approximately 6 minutes)

Laureate Education Inc. b (2013). Ethics and Social Justice "Liberty: Applications" with Amanda Baker (approximately 7 minutes).

Local Governments on the National Child Fostering Program (2013. June 19), Korea JoongAng Daily, Seoul, South Korea.

Maccallum, G.C. (1993). Legislative Intent/Essays, Madison. WI: University of Wisconsin Press.

Murphy, A. (1998). Reason, Reality, and Speculative Philosophy. Madison WI: University of Wisconsin Press (1996).

Postema, G. J. (2006). Interests, universal and particular: Bentham's utilitarian theory of value. Utilitas, 18(2), 109-133.

Reichert, E. (2011). Social Work and Human Rights: A Foundation for Policy and Practice, New York, NY: Columbia University Press.

Stanford Encyclopedia of Philosophy : Economics and Economic Justice, Retrieved Nov. 2. 2013 from http://plato.stanford.edu/archives/sum2008/entries/economic-justice/. 
Stanford Encyclopedia of Philosophy: Human Rights, Retrieved Nov. 2, 2013 from http://plato.stanford.edu/entries/rights-human/.

Stanford Encyclopedia of Philosophy : Positive and Negative liberty, Retrieved Oct. 25, 2013 from http://plato.stanford.edu/entries/rights-human/.

Supportive Act of Democratic Constitutional Rule in the Republic of Korea (SADCRRK). Korea Stat 12068 (2013).

Universal Declaration of Human Rights, Retrieved Oct. 3, 2013 from http://www.ohchr.org/EN/UDHR/Documents/UDHR_Translations/eng.pdf. 


\section{Ethics of Workplace and Entrepreneurship}

\section{The Current State of Ethics within the Workplace}

Nobody would disagree if the contemporary society is on the basis of professionalism and organizational lives (Ethics Resource Center, 2013)). Most of postmodern citizens, probably on the mid-income status, would be amok of the smacks of bureaucracy and their occupational activities. This group often constitutes the prevailing ethos of society and vertebrate of citizenry. They often are ascribed, in most of paradigm, as sovereign people and pillar of national politics or economy, who are the center of contest that the national morals and conscience would reflex and abound around. They are any standard of political or economic issues with which the political leaders have to interact. Their predominant disposition would be embedded on the organizational lives. I consider that three of simple principles would govern their professional course of dealings and commitment, which are ethics, political responsiveness, and merit (Yeager, S. J., Hildreth, W. B., Miller, G. J., \& Rabin, J., 2007). These elements are actually overwhelming and powerful on which the leaders and followers could rely.

The elements could be on a varying extent in response with the types, size, structure and culture of organizations. For example, the political branch would require more of political responsiveness than an ethics while the private organizations often consider it more important a merit than the former two. The quality of each element also could not be the same where the international organizations often are based on the more universal and loose, but grand principle of ethics than the national ones. The latter could be more enriched in substance and comes in an intense interplay with the leaders and organizational members. In many cases, a condensed, definite-to- pursue, disciplinary and integral, but even nasty on the chances of corruption or static pleasure as in the kind of bureaucratic mazes would the ethics of national organizations be. We often are less experienced of the corruption from the officers of international government. A former IMF chair person, S. Kahn, would come as one example, but we generally do not see it any serious ethical violation. The national aspect would go otherwise if we would consume some time on the news paper articles or reports. The current state of ethics in the workplace, therefore, would hardly be simplified in any single paradigm of assessment, but requires a case by case investigation by the supervisors and researchers (Ethics Resource Center, 2013).

It is, however, obvious that the three elements would fairly assist in gauging the current state of workplace ethics. The diversity could come as a fourth factor leading to define the ethics state of workplace, and related with the multiculturalism in leading and managing. This triadic would, of course, need to be substantiated from the inculcation of public value, organizational mission and goals, as well as the political or societal virtues. It would be dissimilar of ethics, no matter if it may be societal and even organizational, between the socialists and liberalists, although it can be sublimated, particularly within this rapidly advanced and compressed global village, into any congruence or sharing of basic human attributes.

Conceptually, three elements are independent to lead our organizational lives, but the ethics could be comprehensive to define and matter with other two. The merit, which would be ultimate in any utilitarian perspectives, can plainly impact the shape of ethics. Consider if 
the bottom line of meritless employees or organizational policy would generally be deemed unethical or unacceptable. The political responsiveness is one criterion to influence the ways of response to some specific challenges. It could be virtuous in some circumstances, and may, in other context, fail of organizational or employee's reputation or right ways that the organization are obliged to do (Yeager, S. J. et al., 2007). The whistle blowing may simply reveals this aspect of ethical conduct. This type of employees'conduct can well raise a serious debate about the ethics. Hence, the ethics could conceptually be extensive to cover all the three, and the issues have to be what scope of due play needs to be ensured in a specific organization about three different factors.

\section{A KPO Issue about the Organizational Ethics}

\section{A Development of KPO Issue}

Recently, Seok-yeoll Yoon, a branch head of prosecution office in Korea (KPO), was assigned an important duty to investigate a grave political criminal case involving the central intelligence agency (KCIA). His skills and expertise were bought by the chief of KPO, and called upon to work in the special team of investigation. He was committed and faithful officer to emphasize a neutrality and sanctity within the national exercise of criminal authority. A sinister officer, in his view, has to be punished in proportion with his culpable conduct, no matter who they are. That is principled and authoritative in the prescription of supreme law of nation, and must have fairly been cautioned by himself about any exterior influence. He, in ranks and team structure, is responsible to Yeong-gon,Cho, who is his senior prosecutor and may assume a mediating role between the investigation and higher ranks of political propensity. The case entails a sensitive issue about the legitimacy of last presidential election, and was disputed about an allegedly impermissible engagement to draw the support for the candidate of ruling party. During the course of his professional activities, he might not obtain a favor from Y.G., Cho about his suggestion to tackle more extensively into the core of a nasty or undue influence from KCIA. Not clear in public relations, the context might be led to drop a positive alternative, and eventually exploded with a sudden public announcement of S.Y. Yoon about the unethical command or implied oppression to frustrate the ambition of this junior prosecutor. They were called upon the investigatory hearing held in the national assembly, and a serious inquiry or defense had been exchanged among the congressmen and two prosecutors. The opposing party, Minjoo, likely saw the incident challenging and opportunistic to strip off the ethics of Sanouri and current administration. Y.G. Cho, as a supervisor of special investigation team would be a right person to encourage his subsidiaries as suggested by Yeager, S.J. (2007). He seems to abandon his role to ensure the criminal justice of nation, and merely said,"I alleged him to be neutral or reticent, but in no intention to influence the key investigators in responsibility." For its social impact and worse public sensibilities, the department of justice (DOJ) began to exercise a supervision authority to impugn and discipline if any misconduct would be confirmed. About two weeks ago, S.K. Yoon was rendered to divest of his official power and status, and Y.G. Cho shortly thereafter announced his resignation.

\section{Reflections}

The episode briefed above brings a point of reflections on the current state of ethics in KPO, and concerning the general aspect of organizational essences, job satisfaction, ethical 
perspectives, external and internal ethics pressure, likelihood of changing jobs, and so on. The context is esoteric involving the twilight strands of organization, say, quasi-judicial and intra-executive qualities. The criminal justice system on this concern would get diverse, but the Korean system may be generic or dominant. In some of national system, notably in France, the prosecution offices operate within the judicial preserve, and they need to officially report to the court with regard to the administration and supervision. In the socialist states, the prosecution authority is considered to execute the will of people collectively, hence, sees less chances to be reflexive about the individual or professional conscience and theory of humanly justice. The political primacy is absolute which profiles ahead of traditional concept concerning the proportionality principle or perhaps a common understanding of western concept of distributive justice (Laureate Education Inc., 2008). KPO would possess dual qualities so that the administration were integrated into the executive, but shielded from the political influence by affording an independent statutory term of KPO's chief officer. It also is severed from the command line, i.e., head of DOJ, for the specifics of criminal investigation. It is wiser since the resources are fairly required to meet such great number of criminal cases in personnel and apparatus. The executive, as we are aware, are the sources to administer the public policy with a vaster resource than the legislature or judiciary. The quasi-judicial nature of criminal investigation also requires an independent ground from the executive, which offers the ground to create the current system on the national statute and decrees. For the special matters of politics or other sensitive cases, the statute also provides an independent counsel to be appointed by and responsible to the congress, who is not a fulltime public prosecutor, but lawyers, who often are experienced in rich career or retired rank officers. The independent counsel supplements to ensure the sanctity of criminal justice, and the system followed the American model as we see in the Star case for the former president, Clinton, as well as for the Watergate investigation.

As the nature of society is highly professional and based on the experts from years of study and apprentice, the ethics in KPO expected to exercise often would not diverge, but be coherent in the same tone or manner of response (Frederickson, H. G., 1999). That, however, would not always the case as we also expect. This kind of sensitive issues particularly could be suspected of whether it would be disposed in comport with the public sense of justice and the ideals of criminal justice system. The case was fairly exciting to impress some quandary of ranked officers, and the research from Yeager S.J. could be applied in terms of importance we can find in the supervision role (Yeager, S. J. et al., 2007). The encouragement of supervisor, C.K. Cho in this case, could have a high potential to increase, even forefront the ethical perspectives of S.Y. Yoon. It would be an easier case for him technically, but entails a delicate aspect of national politics. Hence, a senior supervisor's role seems determinative, but could be escalated by discussion, consultation, and intimate collaboration. The kind of interplay between the external and internal ethics pressure could come fancied that the former would, in high probabilities, be enormous and demanding. Of course, the young society of public prosecutors in Korea, like the judiciary, had been active and is committed to advocate the professional ethics as central. But the bureaucratic maze in KPO can effectively screen its influence or unacceptable suggestion. They have been a source of intra-organization flak on the public criticism and misconduct of the KPO higher ranks. But it would often be postincident voice in the remedial recourse and in the end to restore their pride or public relations. Therefore, the external ethics pressure other than the young society must have been rather pounding so that supervisor's role seems essential to shield and encourage. An unidentified miscarriage within the team or confidential interplay seems to have increased the ethics stress 
for S.Y. Yoon, who eventually behaved like a whistle blower (2007). Someone may accuse him of committing the kind of vagary and others perceive him as conscientious or loyal to his job demands. We can confirm that the communication is really a critical factor working to maintain an organizational integrity and uniform fashion to proceed. We may well reserve other elements, say, job satisfaction or employee job attitudes since, in this case, they have eventually been depraved on their professional path. They would feel hard pains, and even the likelihood of changing jobs should not be excluded (2007). This incident has to be borne seriously in the mindset of or ethical guides for the posterity generation of prosecutors. I mean that the feedback should be adequate to teach and learn about how much the supervisor's role would be important for the reputation and credibility of public organizations.

\section{The Ethical Management and Entrepreneurship}

In this discussion, I like to survey the corporations of Korea about its ethical management, its current status within the Korean context, as well as one of great illustrations in view of the management ethics and its social impact. How do we connote the concept of ethical management. In the dictionary, it is defined that the enterprises are required to be responsible to the social expectations beyond the management and legal accountability. The concept demands the increase of moral quality and profile of enterprises and encompasses a set of moral conducts and anti-corruptive deals between the employees and counterparts in trade, bribery in trade, as well as support of cultural or social events, givings and charity activities in the contribution to the society as a whole.

The theme of ethical management was supported by an increasing number of enterprises according to the statistics of Korean Management Association (KMA) in 2005 (Ethics Resource Center, 2013). Over ninety percents of largest businesses in Korea have adopted an ethics charter. These enterprises also enacted a scope of ethics programs and action plans to be implemented in their work place. To illustrate some, $K T F$ daily aired the ethics education drama through its intra-firm network since Mar. 2005. Shinsekae developed the ethics index to address the challenges. Posco also began to implement the reward system for the reporting of an unethical conduct. YK had obliterated some nasty strands of salary which were designated as marriage, funeral and public relations expense. LG electronics has continued to offer an ethics education program since Feb. 1994, the year of ethics declaration.

KMA conducted a public survey addressed to the member companies and KOSDAQ firms, which are five hundred and completed in 2004. The positive response about the need of ethical management ranged at 38 percents. Same survey conducted in 1999 was as low as 6.8 percents. In the 1992 survey, the reason for ethical management was reported to lie in the social responsibility of enterprises, which accounted for 92.2 percents (Frederickson, H. G., 1999). This rate declined to the point of 60 percents in 2004. This indicates that the increasing profile of ethical management could arise in the concern of profitability other than social responsibility or public opinion.

\section{The Ethical Commitment of Yuhan-Kimberly and Its Impact on the Entrepreneurship \& Social Change}

Yuhan-Kimberly is one of corporations which produces the consumer goods for home use (Sung, S.Y. \& Choi, J.N., 2010). It attained an international acclaim which made a 
top ten list in the survey of Asian Wall Street Journal in 2003. The survey ranked 900 Asian companies in terms of worker-friendly firm environment. The market share and recognition of YK products were superior than any other firms, which would well be benchmarked as a world class quality. The national economy these years were staggering. The unemployed youths amount to 500,000 in number and the red credit poor also radically increased to the number of 4,000,000. The domestic market has been in deep stalemate. Under these crises, one enterprise, named YK, has a remarked success in 4 times of sales increase as well as 17 times of net profit between 1991 and 2005. All of its eight sectors of business have entertained a top share in the market. This company was created in the partnership with Kimberly Clark, a US corporation and YuhanLtd., a Korean corporation in 1970 (2010).

The Korean public were pleased to witness its success. It fairly deserves a public attention since the IMF crisis in the late 1990's and economic diminution afterwards had made no factors without any layoffs nor radical rationalization of business. In the survey conducted 2003, it was ranked sixth by being highly rated in the job satisfaction, trust of employees on management, and social change factors. Then what strands enabled YK to continue on its prosperity? Is this a guaranteed bank note to be applicable for many other businesses? Is it easier to benchmark the success story to implant its modality in other firms? We may ascribe its esoteric nature of corporate culture to its splendor of success. I consider it one of successful paragon in any glocalizedculturalism.

First, the top management pursued in continuance and conviction that the employment realtions will make better to be stuck on the Korean mode of livings, i.e., four days weekly for personal pleasure and leisure (2010). It is certainly ethical to increase the merit of employees in the workplace. It is contrary to the general theme about management, say, as possible as low pay and much extent of work hours. It would be paradoxical and eventually proved effective in eliminating the low rate of factory operation, increase of inventory, and disgruntled labor union. Its strategic, but ethical aspect of decision can be epitomized in two prongs, i.e., four frames of work turn and lifetime learning. The workers in the production line are divided into four turns. In this frame, they work four days and get off the duty also for four days. The free days will be consumed to develop a personal amenities and learning for self-improvement. This way to deal can effect on the increase of productivity for the employer and job stability for the employees. This management strategy is ethical to bring a merit, social justice, and positive liberty of employees. It also contributed to the social change in the corporate culture of Korea, and serves the national economy as a paradigm of Korean entrepreneurship (2010). It is impounding to make the turn toward a congruence, harmony and coexistence, human value and pain sharing of worse economic conditions. YK actually offered the model in the end to increase the trust, reliability and consensus among the family, individual workers, and company. The understanding was serious in holding a human value and its employment status, and they preferred a sharing on employment other than layoffs.

Second, YK management also advanced to propel a competition of ideas from the employees and friendly interchange between them and labor (2010). This requires that the management should be committed ethically to interact and cooperate, and also based on the social attitudes distinct in the Korean culture. This organizational culture and structure could give a lesson to other enterprises, and eventually led to the social change of Korean entrepreneurship. It could not come into any reality unless the management assumes toils and 
sacrifice in conviction and authentic commitment on the trust of human resources and potential. That is because it requires an investment and mutual trust without a tangible short turn. The mindset is, therefore, the kind of social, humanistic, progressive which involves a courage, knowledge, as well as moralities on the side of management beyond a mere myopic management priority. This could build up the trust leading to the ethical management in their industrial and social commitment. The ethical perspective would turn as desirable while the external and internal ethical pressure could be moderated (Yeager, S. J., Hildreth, W. B., Miller, G. J., \& Rabin, J. , 2007). The ethics stress would more be easily resolved because they were humanly interacted and based on the mutual trust. It is needless to speak of job satisfaction of YK employees and their chance of changing jobs (2007). The firm actually purported to convert the kind of physical workers into some intelligible ones, which made a profound effect on the social ethos of Korea. Kook-hyunMun, a CEO of this firm, termed this paradigm shift as a "knowledge management," which requires to learn as well as to be creative (2010). It should be a critical lesson for the society and Korea, and the progress within YK is notable with so high rate of participation in the learning program. YL offers a compensation for the participants, and programs were neither limited to the occupation skills nor work-related. The humanity subjects and social science were offered to foster the personhood of workers as a democratic citizen.

His management philosophy had not rested within a small scale of firm itself, but projected into the neighborhood. The environmental campaign, designed and pursued in his initiative, had impacted on the Korean society, in the least, the basic understanding of Korean citizens about that issue. He seriously perceived an interactive nature between the corporate and society in the whole. The internal turf to oppose his vision of environmental preservation arose since his plan requires a sum of budget. However, it had shortly been proved that the environmental and ethical concept of management could bring a positive consequence about the social change as well as the corporate interest.

\section{Reference}

Yeager, S. J., Hildreth, W. B., Miller, G. J., \& Rabin, J. (2007). The relative effects of a supervisory emphasis on ethical behavior versus political responsiveness.Public Integrity, 9(3), 265-283.

Frederickson, H. G. (1999). Ethics and the new managerialism. Public Administration and Management: An Interactive Journal 4(2), 299-324.

Ethics Resource Center (ERC), Organizational Ethics Articles http://www.ethics.org/resource/organizational-ethics

Sung, S.Y. \& Choi, J.N. (2010), The Leadership of Mun, K.H.; Myth and Success of YuhanKimberly, Seoul, ROK: HANSMEDIA.

Hunt, L. (2008). Inventing Human Rights : A History, New York/London :W.W. Norton \& Company.

Laureate Education Inc. (20o8).Ethics and social justice. "Philosophical Roots" with Amanda Baker (approximately 11 minutes) 
Maccallum, G.C. (1993). Legislative Intent/Essays, Madison. WI: University of Wisconsin Press.

Reichert, E. (2011). Social Work and Human Rights: A Foundation for Policy and Practice, New York, NY: Columbia University Press.

Stanford Encyclopedia of Philosophy: Human Rights, Retrieved Sep. 27, 2013 from http://plato.stanford.edu/entries/rights-human/ 


\section{A Repository of Socratic Conversation}

Kiyoung Kim

Posted Date:

September 5, 2013 4:38 AM

\section{Hi. Domaneneicka.}

The organization would play an important role to nurture the boys and girls of America. It obviously would take the form of national system in branches and collaboration. Ethics in this case may involve a difficult educational issue on the conscience or spiritual cultivation of youths. The state of Alabama is notorious even to Koreans in the context of civil disobedience and other civilized concepts in disagreement or contention. You said the bond of youths with the grown-ups and aristocracies in the local community. How do you handle a possibly undesirable influence from the unverified indoctrination or ensure a sound system of youths to grow and learn? Thanks for your introducing a great organization, and I suppose that the organization may have a twin system globally. Regards.Kiyoung.

\section{Kiyoung Kim}

Posted Date:

September 5, 2013 4:12 AM

\section{Hi. Derek.}

Thank you for the posting. Your organization seems interesting that the conflict of interest likely is self-adjusted. The board members, are payers and beneficiaries from the operation of company. It is likely a mixed nature of organization between public and private in terms of its commission and budgetary system. I guess that the income may be accumulated to the benefit of owners since it is a private company. Is the organization responsible to the shareholders? Do the board members work on a paid basis? What ethics, if any would be involved in deciding an issue of income distribution? Respectfully.

Posted Date:

Kiyoung Kim

September 5, 2013 2:31 AM

Edited Date:

September 5, 2013 3:45 AM

Hi Amin.

Thank you for reading my post. The cause for and calculus from the troublesome sanction or war in other frame, never seems simple nor straightforward. As we share, Syria is a most persistent and acrimonious regime, and the international source reported its relentless continuance on massacre and persecution. Actually we know the middle Asian nations are religiously orthodox and in no probabilities being submissive or repentant if on the Koran. One factor is that they are culturally or religiously incurable to persuade. The other is that we can see some of imperialistic remnants to make them incongruent and less easily 
defined. The branches or ramification in the society and their political interaction apparently confuse a point for some of constructive dismantlement or regime change. Despite their regime of theology, we can surmise a new wave of democratic group to reconcile with or reform the religious nature of absolute rule. These complicacies, as coupled with a Russian share with this country, perhaps led to a restrictive scenario of war engagement in the last announcement. In this nature of cases, we often consider a state sovereignty, international laws and coercive action based on the UN resolution, collective concept of self-defense, and so. In many cases involving the Middle east Asian states, however, the practical aspect in controversy and armed conflict seems not to be a sovereignty concept on the state, but likely stronger on religious sovereignty. Their pride for the Grand Islam or absolutism on Great Mahomet would not be misperceived if we have their contribution to the world civilization in medieval times. This historical heritage and political dominance at those times, as well as their aspiration to rise seemingly have aggravated their untamed violence problematic in the eyes of western intelligence.

This is the case, therefore, typically deserving our attention between the morality or ethics and responsibility. Reason and social custom generally are a principal source of moral standard. One scholar also illustrated that a passion or intuition is another powerful source for embedding the morality within an individual mind. Their moral argument would not be dropped if they may lawfully kill the enemy of Great Mahomet. That is in contrast with Christian teachings, "Love your enemy." Most eclectic perception was institutionalized into the modern penal laws in a proportionality principle and reasonable sanction or penalty. I consider the Syrian authority may argue their moral loyalty, but I am dubious if their process is ethically or by ways of reason and law, tolerable. It biologically fails the global community and produced a mass of victims in cruel and inhumane ways. Ethics possesses the quality of system, institution, co-existence and humanly subsistence, interdependency, and organizational dynamism through the global community. Law might share a vast of these elements, and come closer to the requirement of ethics. Most of legal scholars consider the positivist law of extremist nature as illegitimate as in the case of Nazis' dictatorship. And the quasi-religious nature of socialist laws also is subject to the criticism and international resilience from the western legal society. The context of present days contention involving Syria, in delicacies and flavor, emanates the confrontation between the West and Quasi-East in strands. They would not be a communist regime that they are Quasi-East. Their perception about the morality and political virtue are idealistic and absolute, but cruel and relentless, and likely disparage the balanced concept or proportionality element in human understanding. I suppose they are not identical in religion, but the tone or atmosphere overlap in impression.

I consider the cause seems mature to ground a sanction, and some of practical points should follow in calculus. For example, one commentator saw the sanction is necessary to give a lesson to North Korea. The chances about some of possibly tragic military confrontation with Russia or China would also come into play. The capability on preemptive measure seems very encouraging on the side of US military. The consequence, however, may bring an eruption of retaliatory action in other region. We may agree on a little subtlety in difference from other cases in this region. I consider the positive factors outweigh a retraction alternative if Syria continues to miscarry the ethics of global society in their morality ground. Thank you for sharing.

RE: Wk2Disc1KHedgepeth-main post 
Author:

Posted Date:

Kiyoung Kim

September 12, 2013 4:22 AM

\title{
Hi. Kristina.
}

I agree that you seem very penetrating the ethics and morality. It seems applicable that the ethics often is required in the settings of workplace and so. It is precisely true that the extramarital affairs seem to fail both of work ethics and morality. That is in comparison with the moral demand involving a before marriage sex. Those also would be an example in irony between the passive dictate and affirmative one. Not always though, the morality often appears to be given in some of passive dictate than the ethics. For example, we may construct some of work ethics to convert his religion from Christian to Muslim in the end that facilitates the multinational corporation operating in the Arab states. If not to respect the work command to convert, she may lawfully be dismissed without any violation of fair employment statute. How do you assess this powerful influence of work ethics to intervene a sacred domain of personality? The other context in quite opposite may be illustrated with the case of forceful coercion to foot on the Cross. Of course, this way would be an effective measure for the soldiers to distinguish from the Christian people on hostility, particularly in the war time. The job ethics of dominant military on the conquered land may not see it seriously problematic, but we would see this conduct immoral. I consider those cases show the adaptive or circumstantial nature of work ethics than the morality itself. In any case, we often do not say "work morality" although we talk about "work ethics." I agree on your view. Respectfully.

Author:

\section{RE: Ethics and Morality}

\author{
Kiyoung Kim \\ Posted Date: \\ September 12, 2013 2:45 AM
}

Hi. Pamela.

Thanks for the posting. I agree that the ethics and morality are a form of building good human character. They likely enable humans on consistency and pleasure to keep on their integrity. The breach of code of conduct contrary to the prevailing force of society would certainly disrupt a self or ego. This means a failure of self in a myopic implication and public education in the larger scale. Conscience is one strand between the two, but highly individualistic and might be a modern equivalent of contient from the Aristotle's version. Aristotle said contientis not friendly with a virtuous agent or ethical administrators and governor. Hence the notion, conscience, seems more affiliated with morality than ethics, but could be occasionally not shared even in the name of morality. Then, the concept would be nearer to the religious dimension as we see the controversy of conscientious objector against the war. I like to know your thought among the three strands if the state could interrupt the person, say, a conscience objector, on the libertarian beliefs. If his belief is absolute and not swayed, is it permissible to abridge his or her libertarian way to build his character? How do 
you perceive if only the state has a definite say on morality? Any point in distinction in dealing with the issue between the liberalism and libertarianism? Respectfully.

\title{
RE: Ethics and Morals: Kathy J Shelton
}

Author:

\author{
Kiyoung Kim \\ Posted Date: \\ September 12, 2013 4:55 AM
}

Hi! Kathy. Thank you for the posting. Next time I will make it sure to be seen a sufficient font size in any untroubled vision. You seem to do very good on your nursing job and cumbersome issues faced daily within your job responsibility. I entirely agree that the ethics are presumed on some of knowledge and intent dimension, and get variable on the circumstances. You may retire that your business ethics may become vitiated, but the morality still stands at even the aged years. So the ethics discourse, as you stated, would be "....on the accord that your upbringing, schooling, and practice are congruent with what is ethically reasonable to deliver the healthcare." Then we may have some sense if we juxtapose those, "Professional Code of Conduct," "Code of Conduct for the Multinational Corporations," and etc, which are against a non-denominated, "Code of Conduct. The latter would perhaps be a (human) Code of Conduct to define a morality. Given this perception, the ethics would be an enhanced concept, but be contested still from the morality. As you illustrated, the right to die in comfort and peace for the extremely painful patients would rise. I also favor a virtuous agent, like the doctor, Jack Kevokian, but unfortunately their practice seems excessively controlled by the government. Do you see the current rule of judiciary should be sustained between the medical ethics and human morality? Respectfully.

Author: Kiyoung Kim

Posted Date: September 13, 2013 10:46 AM

Hi! RAE.

Great post! I have enjoyed reading. We read that the state or political community in the Aristotle's exists a priori from an individual citizen. This context of collective supremacy or presage of communal being is also found in his teachers, say, Socrates and Plato. For example, Socrates, in his dialogue with a friend at the imminence of death, had a high tone of preaching about the rightfulness to thank one's parents and society. An individual can only be an esteemed being since he is bred and educated by the parents and society. He, therefore, objects to debase the legitimacy of death penalty, and thought to be honored if he were to respect the state order. This classic assumption, as basic in our dealings, would also be shared in the Confucianism of Orient. They conceived the loyalty and faith to their parents and state as a most ultimate beauty or fineness, hence, ethical and moral as inviolable from other social or individual needs. However, I consider this does not endorse a communism, monarchy or the type of totalitarian form of government. A dictatorship on the staticism, such as fascism, corporate or social nationalism, would also come defaulted as historically contested and proven. For another example, the former Soviet constitution set forth the duty of children to foster their aged parents as a public matter. However, I am dubious if that provision could 
yield any more effect than the lasses faire system about a faith to their parents. The constitution also prescribed the duty of denizen to serve the community in their highest of talent and capabilities. This virtue to view the community or politics supreme and not tempered actually has been dangerous on the historical lessons. Regarding the final sentence of posting, I agree that the libertarians may, in some cases, be penalized in accordance with the state law. However, it should be scrupulous as a matter of criminal policy. For example, anarcho-communism may be subject to the higher standard from the clear and present danger rule if we consider its possible evils on the sedition and insurgency. Hippie, one expression of libertarian idea, should have been considered in view of the constitutional right of privacy on one hand, and its harm against the society on the other. I rather, in this sense, advocate the delicacies and eclectic view between the state and one or agent. The balance test was rejected that the 1970 and 80's Korea punished them for some days of imprisonment or treated as a petit offense. This is now critiqued by concerned intellectuals in Korea, who argued on its infringement on the privacy right. You also said that a possession of firearms is sanctioned in the State of Virginia. However, I am increasingly has some differing view that we may be prudent if we regulate more tightly for the public peace and against a high rate of killings from this context. Your thought?Respectfully.

Author: Kiyoung Kim

Posted Date: September 13, 2013 9:42 AM

Hi! Amata.

Thank you for the posting. I found your final sentence touching on the Korean context in 1950; "it would be unethical not to flourish nor fight for the pursuit of liberty and happiness." Sixteen liberating nations, in due cause, willingly engaged to fight against the aggression of northern communists in Korea. They certainly were virtuous agents or countries gladly assuming the massive risk of sacrifices and casualties in the Korean war. Hence, the friendship between South Korea and US has been strong and continues as President Obama stressed in the previous speech of Arlington Memorial. I regret, however, that the northern regime accused South Korea and US as a parasite or an object to be stricken off. They do not merely say "unethical" or immoral, but they go further to define the relations in the plot of US imperialism or saw South Korea as the kind of watch dog to ensure the US interests in this region. It is paradoxical, however, that they are a worst of human right record, but mentioned a bit the kind of center-periphery theory. They are highly scientific, and, of course, critiquing on the capitalist economy between South Korea and US. But they persecute for their political objectives and actually is one of world least economies in the statistics. They stress on a state sovereignty, but sustain a generations of dictatorship. I consider the points of ethics differ in our case. I like to ask how we could reconcile the conflict of ethics if we borrow the Aristotle's idea. If in a Korean case, how could we see the difference between a friendship of two countries and northern accusation about the state sovereignty? Respectfully.

\section{RE: Bravo!}

Author: Kiyoung Kim

Posted Date: 
Thank you for Kathy. Your question is stimulating to see the nature of policy or administration expertise. Most of policy decisions, particularly in the federal system of United States, would involve a wealth redistribution or social justice issue. A scope of policy tools, say, programs, projects, action plans, contracts or partnership would have an impact to lead the society in some intended direction and often underlie an issue of economic assessment. While many competing interests or factors are considered, they often come secondary as any final point of deliberation. The federal government is grossly a provisional nature of state than regulatory one in the US. Hence, this aspect generally intensifies than the unitary form of government, such as Korea and Thailand. A dual sovereignty between the state and federal governments requires the public administrators more sensitive about the policy effect from their funding or granting to the state entities or other linked system between the funds and their obligations. Therefore, I consider the economic aspect approaches seriously as we see in the contention around 1930's about the role and scope of public intervention within two types of sphere. This point of consideration, as you know, also matters with the political issues between the Republicans and Democrats. For example, the environmental policy may incur a different extent of federal measure, and reshapes the division of responsibility between the federal and state governments. Given the role and nature of public administration on this focus, this week's topic dealing with the liberalism and libertarianism is thought very useful to see a philosophical foundation about the humanity, social justice, and economic arrangement. Also interesting is that we have a political party named and represented for the libertarian virtue in US.

The controversy and departure seem to originate as centers on the politics, liberty and economy or property right. The Three Estates and their feudal interest fell to be contested in $18^{\text {th }}$ France, and the politics fluctuated although the revolutionary spirit of liberty and property right could keep sacred throughout. In my research, I can confirm that the libertarian school of thoughts or ideas obtained a practical feature in the turmoil of French revolution and Napoleon's rule. Libertie is a French word to glorify the liberation of Napoleon perhaps against the prevailing hostility on Ancien Regime. A libertarianism seems rather radical than the liberalism with a principal point of identification between the justification of rule and liberty. Hence, the theme is fundamental in "politics vs. individual liberty" while the liberalism would come more squarely and in diverse aspects of humanity. In the course of history and varying politics of localities, the libertarian idea developed in different forms. More extreme is the anarchism, which may be shared by both capitalist libertarians and communist ones. Once I read the article about one of greater teachers in 1930's US, who spent their later life in devotion to writings and growing plants in their garden zoned on their own. I could not tell his name instantly, but he, one of eminent socialist leader at that time, shows the pattern of their livings. In the historical progress on this ideal, Pierre Pourdon's perception about the true nature of property and economy was articulated into the tenet of mutualism in the economic relations. The theoretical work of Peter Kropotkin also represents one ramification from the libertarian ideas, as read in his Conquete du Pain. He enlightened an anarcho-communism, which succeeded the tradition of liberty and personal autonomy. They, then, tend to develop a distrust on the mainstream politics and dominant frame of market economy. Their concept on property may be shown typically by their proposition of "personal property" rather than "private property." They farm for their own needs and may get the products mostly handmade. They may, if necessary, meet to exchange their products, 
but not for the commercial interests but on the mutualism to be lived in the liberty and against the hyper-structure of rule or governance. That might be similar with our discussion work in an analogy or feel if the context is non-commercial and mutual. Shabby, but intrinsic, and posed by some hyper pressure with any of grand topic or theory, but finally becomes liberated if to write and present.

As a public administrator, the libertarian theory or tenet would likely lead us to some fundamental point of rethinking about the system, humanity, society and routine intoxication from the practices or series of policy decision. A most factor in reflection is that the public administrators are a trusted class to determine on serious materialistic issue and any desired outcome. They are also required to respect the popular will of society and act in the line authority or hierarchy in command and responsibility. Then the theory or tenet would go merely intelligible or indirect on their public responsibility. However, some points can also be raised in view of the bureaucratic ethics and their consistency or track unaffected by the switch of government or new directors. The libertarianism may, nonetheless, go dubious how much it could practically works on the policy makers or administrators. The Mondrean concept of market or Green peace group in Europe may be viewed in the libertarian ethos, and the environmentalism may profile in assessing the libertarian thought. But its influence would not be clear since it actually is a minor party or less organized group unlike the Republicans or Democrats. I hope this to answer your question. Respectfully.

Author: Kiyoung Kim

Posted Date:

September 12, 2013 1:27 AM

\section{Hi. Susan.}

I agree that the consistency and integrity are important to behave as an ethical administrator. The design approach, in the Cooper's proposition, may help the way that the administrators may figure out what to do, and to find a right fit to address the difficult ethical dilemmas. This serves standardizing the ethical practice in an amalgam as a professional agent, as leveled distinctively from the lay persons and based on the general requirements through a respective trait posed by each issue. The practice would likely be an operating manual against ad hoc basis judgment, and facilitates an unbiased and neutral administration about the ethical dilemma. Without the inconsistency and integrity, I believe that any unbiased or neutral administration would be impossible. Respecfully.

Author:

Posted Date:

Kiyoung Kim

September 20, 2013 10:56 AM

Hi. Freda.

I have enjoyed reading your thoughtful post. I agree that the external goods, such as power, money, and status, should be finely matched with the prospective officers, who possess a quality, character, enthusiasm and so. Galton once said that the respected leadership 
has some of hereditary attributes. The version now may take some of differing concepts over the interplay between the internal goods and external goods. In the times of democratic rule, the educated citizens come to be eligible to practice their vision and conception of public values. That would be harder or inconceivable if we live in the Ancien Regime. You had been raised in Newark, which is your loved hometown. I believe that your attachment or enthusiasm as a public planner would not be questioned. It underscores that you also have a good temper with and respect for the standard ethics from the American Society of Public Administration.

You made a point between the public administrators and elected officials. That generally is true as we learnt. For example, it would be same as Korea that the public administrators often times are convoluted from the lengthy approval contingencies. The red tape practice also would incur bureaucratic inefficiencies. However, the career experiences as a public administrator, later likely provide some of background to win the public election in Korea. The status would make a good career path toward an elected official, so that the values or principles may be shared, as you pointed, "political economy, social order, and popular sovereignty." I am dubious, however, how much the elected officials value the concept of efficiency. Your thought? As Caroline Whitbeck stated, I consider the practical aspect seems important, and the administrators may be helped if to figure out what to do about the ethical problems. In his view, the kind of concept, say, defining a problem and generation of alternative solutions, gathering information would certainly be a working ethical process as we also learn in the Cooper's model. The bureaucratic practice, then, could be a distinct preserve of wisdom precedent, at least, in each of administrator's domain, and may serve a frontier-reshaping by the faithful and self-cultivating public servants. How much do you agree if the ethical issue is not merely a simple nature of judgment? Thank you for the great post.

Author:

\section{RE: Wk3DiscKHedgepeth-main post}

Posted Date:

Kiyoung Kim

September 20, 2013 9:44 AM

\section{Hi. Christina.}

The example would be best when we consider an ethical issue. Often the police is viewed a top ranked institution as a matter of public credibility. The police make a high impression on justice and their loyalty for the public, and they are a useful source of cinema and novel stories. Some gangsters or rascals would menace the community, and a detective or special unit counters to finally capture a culprit or eliminate the rascals. To become a police officer had been taken highly honorable in Korea since it serves a social cause, relatively high income from the tradition of underdeveloped country, and seniority system or national pension benefit. A high share of my students aspires for the job, and devotes much time to prepare for the National Police Exam. The income context decreased since Korea is now one of developed countries. They could not be said as of highly paid now, but the decades of economic recession and the job stability of police would still be attractive as a good career alternative. These points are for the Korean police officers, and I wonder how the US context operates. We generally consider the level of pay rendered for the public employees weigh 
about the probability of bribery, theft, embezzlement and so. You may agree if one way to respond with the depraved or unethical behavior might be to encourage their public impression and their value for the community? Also your statement about a hardship of Chief can be shared equally with a Korean case. The police officers generally are firmly tied in spirit and morale that they may go unethically further to hide their subsidiaries or fellows. I agree that the best way to find a fit in the ethical decision making model seems a proportionality principle between the culpability and disciplinary measure. The issue still problematic would be how to educate the petit offenders, the small theft, since their propensity would be same as the large theft regardless of their theft amount in dollars. Hence, the sanctity of organizations is still possibly to be tarnished unless they are removed or cultivated to be reborn as a good officer. Your thought? Thank you for this excellent post.

\title{
RE: Domaneneicka McDaniel: Discussion - Week 4
}

Author:

Kiyoung Kim

Posted Date:

September 27, 2013 11:56 AM

\section{Hi. Domaneneicka.}

Thank you for your interesting post-modern prose or narrative on this stiff topic. It actually gets leading to the point convivially. Kindly allow to ask several questions. I wonder what the "political human rights" actually imply. Is it the same notion about a "political justice" that the human rights critique employs to satire a judicial policy on the emergent national needs, such as in the Guantanamo camp or others. You juxtaposed the political, party-political, and communal rights with the human rights. I got the point, but actually what does the communal rights mean? If you mean the political rights are the kind of suffrage right or participation to the government, those would likely be a classic human right. You perhaps indicate "power" than right? Then it should be placed in dissimilarities as you said, since both, say, the politics and human rights, had struggled. I also like to know if you think it better to exclude the social rights since they are "peculiar" from the modernization lawful value. Your thought?Respectfully.

Author:

\author{
Kiyoung Kim \\ Posted Date: \\ September 27, 2013 11:16 AM
}

\section{Hi. Amin.}

Thanks for your Great Post, and I enjoyed reading it very much. Your point that the human rights are a political progeny than any superstitious ways on sanctity would fairly enable to see the realities and need of human strife to watch the progress. Your view would also corroborate with the kind of legal positivism from Austin or Heart to pursue any ground for the validity of laws. They saw the sovereign command only could ground the source of laws. Suppose, however, that the natural rights concept and American legal realism marched forward its way through the world history. I am afraid if you agree that there would be a sphere which a mere political majority could not take a control over. A legal positivism from 
the German tradition also rather finds the validity and effect of law from the social custom or legal fundamentalism, as slightly different from Austin or Hart and your version of political rights. For example, we would like a freedom of expression and, of course, champion the right to know in the context of pursuit of happiness. Suppose that the majority congress shut down any opportunities about the books. How do you tolerate if you are an avid reader to know, or publication mania? Consider if the property rights are not ensured on easy confiscation and condemnation from the Eminent Domain without just compensation, how do you tolerate your loss of long works and efforts to the brand new house and necessities? In the normal situation, a sovereign command, social custom or legal fundamentalism would not do those vagaries unreasonably, but who bet from that, perhaps a least possibilities. There are also the case of extremities in the two World Wars, and Syria now undergoes a contentious conflict. The international constitutionalism, as seen in the context of UN, was pushed forward initially from this conflict of politics and reflection to restore.

The concept, on the natural rights and inviolability of human rights do not negate the public reason to regulate the society. I am also not definite on the truths of natural rights, nor sure to rebut the legal positivism. My intent is to see the good or bad aspect of those assumptions. In any case, the social rights seem more accurately fall within the kind of political process argument. The death penalty issue or right to abortion, on the other, would rather feel more friendly with the kind of natural law tenet. The practical test would be if the Eighth Amendment about the cruel and unusual punishment could be abolished based on the political consensus. Some group of extreme natural law theorists would not endorse an effect of such constitutional amendment on the ground that it would transgress the inviolable or inalienable strand of human rights. The right to same sex marriage or that of homosexuals are not a social right within the prevailing concept of classification, but a liberty interest or civil right about the personhood or privacy. They could be argued for a legal protection in the courtroom when the state power infringes upon those rights. They may seek a legal remedy to invalidate the heterosexual public record of marriage or imposition of fines on the homosexual relationship. Respectfully.

Author:

Posted Date:

$$
\text { Kiyoung Kim }
$$

September 27, 2013 10:06 AM

\section{Hi. Derek, Amin and Eric.}

Your illustration about the recent stride within South Arabia and Somalia can signify the working concept of human rights. The right to participation in the government is a threshold to ensure a democracy. The implications would much be doubled if the women were afforded that right. It needs to be noted that the universal suffrage was achieved as late in early $20^{\text {th }}$ century, which included a woman. Both are critical to ensure an inalienable right to an equal freedom between the different sexes. We welcome the recent context of South Arabian achievement in this respect. Amin's comment is also helpful to see the nature of theocracy in Middle East states. I wonder, however, how the religion in that region would merely suit a King's control. As far as I know, the women in the Koran states can be honorably retreated from the western mode of livings. I rather fear if the enactment of participation right would go mere into any ornament or sham provision. The problem to ensure a genuine surge of 
women within the government would lie in the affirmative action of government and society at large. I consider Eric's point would be a prevailing view that the social rights would be seen a mere prescription or state goals other than right. They generally lack the quality to a concrete cause of action in the courtroom. They otherwise would operate in the public street to petition for a better law and desired congressional action. However, I also agree that they could be a right in some limited scope of social rights, for example, the right to social benefit in the context of ex post laws argument and loss incurred therefrom. As the society intensifies in communication and interplay, the right to education or free food program for the middle or high school students in Korea virtually approaches some kind of anticipatory right although not inherited from the God. So the distinction may blur in that perception as you said. Thanks for the post, and I have enjoyed reading it. Respectfully.

Author:

$$
\begin{aligned}
& \text { Kiyoung Kim } \\
& \text { Posted Date: } \\
& \text { October 4, } 2013 \text { 8:44 AM }
\end{aligned}
$$

Hi Nicholas.

Thank you for the interesting post. The context of military administration would likely be considered out of the normal constitutional ambit perhaps because it has the nature of special relations in the purpose of organizational commission and structure. I am dubious if the same extent of freedom or liberty interest would be assured of the military personnel, students of public schools, and government employees. The scope of these people would be assumed to waive, to some extent as required to ensure the organizational commission and purpose, their constitutional rights. This theory of distinctive treatment against the normal civilians has been respected as a matter of law in Germany, France, Japan and Korea. This legal principle has increasingly merged into a unitary yardstick for both groups with some exceptions still based on the organizational goals and special needs. So the chances to censure a freedom of expression in the military are greater, yet to be deemed permissible. The court, if faced with the claims for the damages, corrective measure or invalidation of dismissal and other disciplinary actions, would, in many probabilities, apply a different standard in assessing the argument on the constitutional freedom.

However, I consider, as Kathy and Dr. T viewed, that the commander had been seriously prejudicial about the freedom of expression and equal protection of laws. The comment of drill sergeant may be received as the kind of hate speech against the homosexuals, including himself. This personal anxiety would drive Sergeant Monk to make a countering statement as a "discrimination." The commander might see it a prejudice against the minority group, say, homosexuals, who would be legalized in some state jurisdictions. These points would favor his version on this event, but the manner and final disposition, given its severity and arbitrariness, seemingly could not stand as Kathy and Dr T. perceived. Sergeant Monk may well claim to remedy his grievances from being relieved from his position and banned from the unit. Respectfully.

$\underline{\text { RE: Discussion - Week 5. Main post Rachel Morrison }}$

Author:

Kiyoung Kim 
Posted Date:

October 4, 2013 5:37 AM

Hi Rachael.

Your view is fairly ambitious and encouraging, and the dealings you implemented as a supervisor proactively for perhaps a discrete religious employee are thought to be sustained. The dominant practices, however, are not mandatory unlike a maternity leave or child breeding vacation. They possess an economic quality, so that could be exchanged in the labor market. I suppose it no less meaningful, however, if we review or explore to apply the possibilities of a Bentham's concept on the public value within the workplace we serve, say, subsistence, abundance, equality and so. I may not be wrong if the religious need is any more important to each personhood. I doubt if any subsistence or abundance, in this highly affluent contemporary society other than Bentham's' era, can be perfected without a religious, cultural or social strand. Do you have the authority, in any case, to shape a constant and organized command in this respect? Respectfully.

Author:

Posted Date:

Kiyoung Kim

October 4, 2013 5:15 AM

\section{Hi, Cornelius.}

I agree on your point about a due treatment of aged prisoners. The criminal justice system may serve several goals from the prevailing viewpoint, such as a retribution, prevention, correction and so. The dilemma comes in a similar context where Bentham sighed about the tension or incongruence between the public utility or value and sinister actors. Do you consider if a due pain for the criminals serve a human solidarity. It is a basic propensity and humanity strand to impose an extent of retribution against the culpable criminals. One day, I came across a newspaper article that the parent of Dodgers fan deplored on the sudden death of his son after a baseball game. He was struck on his head with the stool by other spectator, and the shock caused him to death. The perpetrator of that violence had been capture and investigated by the police, but acquitted instantly since the police found a self defense claim valid. The parents likely lost their sense of human solidarity, and actually that point was highlighted in the article. Of course, there certainly would be points of legal issues which lay persons could not apprehend. Based on the short introduction, however, I may get as same to the frustrated parent. Without a justice, the human solidarity seems hardly achieved. How much do you believe if the goal of retribution in the national penal system would explain for our justice concept? Is it a stronger point than other correctional or educational paradigm of criminals? How do you consider it better serving if the privatization of prison facility would be expanded? Respecfully.

Author:

Kiyoung Kim

Posted Date:

October 11, 2013 3:30 AM 


\title{
Hi. Cornelius and Dr. T.
}

The issue of same sex marriage recently rose in Korea, and according to the similar context of US. One male held a marriage ceremony in the public forum and in the gatherings for media coverage. After the ceremony, he announced to dispute about the current system of heterogeneous marriage only. As Korea adopted a recordation element with the public record as a requirement of legally valid marriage, they would be frustrated even if they completed a ceremony. Hence, they would have a valid ground to question the constitutionality of recordation system and lacking of system to support their case. As Dr. T said, the incorporation clause can enforce a respective state to abide by the liberty or equality requirement within the Federal constitution. The court perhaps would not be expansive in viewing the class of liberty subject to this clause. Perhaps only a fundamental freedom merits to require the state to be bound, such as the right to free travel. It is also a matter of discretion, and in limits from the constitutional empowering, so it is dubious if the Fed would advance to regulate the marriage affairs. If the controversy invokes an equality, and often the ways to be dealt, the $14^{\text {th }}$ Amendment can be applied. However, I suppose that the court would be less positive to condemn the system of respective state on this matter. Korea is a unitary state on the same ethnic background, but that is not the case of US. This would lead to respect each state authority in this kind of subtle privacy issue. I am not sure if the matter is any kind of federal nature or necessary and proper to advance the federal interest. Hence, the Fed, in high chances for the near future, is expected to stay reticent or indirect about this matter.

Respectfully.

\section{$\underline{\text { RE: Discussion } 1 \text { - Gender and Equality in the Workplace }}$}

Author:

\author{
Kiyoung Kim \\ Posted Date: \\ October 11, 2013 2:57 AM
}

Hello, Pamela.

I agree that the gender equality has to be given a due respect in ensuring the workplace democracy. I consider that the pay equality and equal opportunity to promotion would be concerned most seriously. In the recent context, it is interesting that Korean congress women organized an ad hoc monitoring team by themselves against the male abuse of sexes within their House. In the past, one male congressman played on the demeaning statement in the informal meeting, which defamed a woman media worker. He was captured under the public criticism, and faced the challenges to be disqualified. In other case, a congressman subscribed to pornography in the official session of the House. The female team made an official statement to denounce such unethical conduct, and urged a proper response. As the society develops, the equality seems to develop in any extended complexity and diversity in fashion. Respectfully.

Author:

Kiyoung Kim

Posted Date:

October 11, 2013 12:25 AM 
Hello Dr. T.

The policy makers often deliberate on the point of what standard would be proper to design or implement their policy frame and goals. As Phoenix showed, the earlier thinkers would face the dilemma among the democracy, equal quest from a radical emancipation, as well as public rationale. They even detested a pure democratic form of government on an extent of fear and distrust. The $14^{\text {th }}$ Amendment, as you said, could give a standard that the bureaucrats have to refer to administer the complex nature of public policy, say, efficiency, fairness and creation of public value. In the course of public policy process, it is notable that the $14^{\text {th }}$ Amendment even allows a different standard of review, say, strict scrutiny, intermediary one, and reasonable test. The suspect classification centers on this theory developed by the courts. In the paraplegic case, I consider it to fall within the last standard so that the policy makers entertain an ample scope of discretion. On the other hand, a policy measure to deal with the suspect classification, such as race, aliens, and other some, requires a more prudence on behalf of the congressional or executive officers. It would also compose a bureaucratic ethic and the responsible administrator shall mind to review. One interesting point would be the "business judgment rule" which relaxes the responsibility of corporate directors and officers. Their personal responsibility would diminish on this rule even if they fail to meet the strict standard of care and harm his corporation. This rule then could effect to encourage an ambitious decision and in reflection of often unforeseeable business environment. I doubt, however, this perspective can apply to the context of government if the damages may be awarded from the wrong measure of government. Korean jurisdiction strictly limits a personal responsibility of governmental employees on very exceptional cases. The business decision rule may go toward the same point of concern about the personal responsibility of public administrator, which, in conception, includes both sphere. If the business judgment rule is enforced strictly, both can converge in the extent of fining a personal responsibility, but still the government employees are entitled to the virtually free context of policy framing work. I am a little skeptical that the mid rank officials, who are principally responsible to shape a specific policy, likely enjoy the immunity, which is similar to the President, Judges or Congressmen. The business judgment rule was invented, in contrary force, for the directors of private organization, but can offer some lesson for the governmental context. My regards.

Author:

$$
\begin{aligned}
& \text { Kiyoung Kim } \\
& \text { Posted Date: } \\
& \text { October 12, } 2013 \text { 9:45 AM }
\end{aligned}
$$

\section{Hi Cornelius.}

I agree on your point that an equal access to the court proceeding would say very much to ensure the justice and human rights. Indigent litigants may be afforded a special assistance about the court fees and other context. That seems particularly pivotal if the case incurs a serious criminal violation and potentially high punishment. You also suggest that the higher education and social or economic privileges can well lead to the different status of people. The court would once deal with the former context, but it is in their limit that cannot say positively to enact or implement. They would say only to rule on the challenged and extant institution. We often regret of no mandatory order to provide a free education or welfare program in the courtroom, but the kind of dealings should be around the politics or public 
ideals. I like to know if any special treatment for the indigents, such as a free counsel or court-appointed attorney in the criminal jurisdiction or waiver of court fees in the small claims are afforded in South Africa. Your answer? By the way, please disregard the post mistakenly uploaded in the name of Derek. Respectfully.

Author:

Kiyoung Kim

Posted Date:

October 12, 2013 9:13 AM

Hello Nicholas.

It is not unexpected that Michigan people favor a fair competition based on the learning abilities, scholastic aptitude and achievement on the basis of application. It is also problematic as you suggest if the students consider it as a usual course of dealing for the favorable quota. Korea also is very contentious if any unfair, of course meant in the merit based justice, factors affect the admission policy of university. Particularly, most of us have the notion that the academics have to worship of merit and intellectual growth. The counter thesis may look, besides the points on the "affirmative action" from any positive minds and "reversed discrimination" from the negative eyes, to the academic freedom of university and autonomy about the school administration. How do you consider if the school administrators see it serve a bright line of goals and can administer on a reasonable ground? Could they claim their academic freedom to select their student on their own scale and assessment elements? How do you see any difference between the public and private universities? Respectfully.

Author:

Posted Date:

$$
\text { Kiyoung Kim }
$$

October 12, 2013 8:52 AM

Hi Eric.

Thanks for your interesting post. Your illustration about the disease and health service seems to allow us in a good comparison. One would voluntarily assume the risk if to be harmed from the tobacco use. Another person may be economically deprived that could not afford to defray their health expense. In terms of the equal justice to social welfare, the second case could be remedied if controversial in extent as in the Obama care. In view of libertarian concept of equality, the second case would be disputed seriously if to establish a prima facie case against the tobacco company, which claim the tort damages. How do you consider if the tobacco company claims their right to the original freedom on property and business operation? Do you see the argument plausible if the tobacco company has to be responsible since they stand on a developed footing about the technology and key information about the harms. In factors about a gross disparity in the economic power between the individual consumer and big tobacco company, does it comport with the social justice to compensate for the death of tobacco patrons? Respectfully. 
Author:

Posted Date:

Kiyoung Kim

October 12, 2013 8:46 AM

\section{Hi Derek.}

Thanks for your interesting post. Your illustration about the disease and health service seems to allow us in a good comparison. One would voluntarily assume the risk if to be harmed from the tobacco use. Another person may be economically deprived that could not afford to defray their health expense. In terms of the equal justice to social welfare, the second case could be remedied if controversial in extent as in the Obama care. In view of libertarian concept of equality, the second case would be disputed seriously if to establish a prima facie case against the tobacco company, which claim the tort damages. How do you consider if the tobacco company claims their right to the original freedom on property and business operation? Do you see the argument plausible if the tobacco company has to be responsible since they stand on a developed footing about the technology and key information about the harms. In factors about a gross disparity in the economic power between the individual consumer and big tobacco company, does it comport with the social justice to compensate for the death of tobacco patrons? Respectfully.

Author:

Kiyoung Kim

Posted Date:

October 10, 2013 9:44 AM

Author:

Kiyoung Kim

Posted Date:

October 18, 2013 10:13 PM

Hi. Cecilia.

I agree that the girls would be one source for the national income. They work on the house chores, but I am dubious if their work value is to be converted into the statistics of GNP or that in per capita. We may have some of conversion chart, but is it dealt so? I also agree on the serious challenge you mentioned about the male crime rate at his earlier years. Is there any tangible measure from the policy makers besides the adverts or oral encouragements? If it were to be so, what extent of probabilities do you consider that the law or regulations in challenge would be brought to the courtroom. Respectfully.

Author:

Kiyoung Kim

Posted Date:

October 18, 2013 9:53 PM

Hi. Ahmed. 
Thanks for the interesting post. The context can be applied at the global practices of bureaucracy and training scheme. We, however, would not have any definite sensibility in agreements. Korea once had the Sam-cheong Training Camp to refresh at an emergence of the militaristic rule in 1980. A socially esteemed people had to undertake a severe training in the group of criminals and innocent suspects arrested in the street. Korean bureaucrats often have a personal perception that his career path may be disadvantaged if to be committed to the educational institutions. This apprehension might not be shared with the US and other developed countries if they favor and see the life-time learning good to develop their career. In those countries, it may be one way to enrich their skills and expertise in the alternative for the long years track service in the key post. I am about Michel Foucalt on his churning of prison history. One other peer could be the idea of Pan-opticon of Bentham drawn to idealize a perfect prison structure. This way of approach seems to be required of public administrators. The educational institutions, often managed by key branches of administration, might be compatible with the prison setting, but I also see the tightened bureaucrats on his track also be seen as same. Is there any promotional discrimination if the Nigerian police officers with the experience to be posted into the School. Respectfully.

Author:

\author{
Kiyoung Kim \\ Posted Date: \\ October 18, 2013 9:17 PM
}

Hi. Nicholas.

I agree that the LAUSD's initiative on IPad idea concerning the redistributive welfarism could encounter any public criticism. I suppose if the food program would not be universalized through the public high schools. IPad is an expensive equipment that even adults may not use it due to his short pocket expense in Korea. I am also at odds if the IPads are dominantly for the learning distraction purposes, although you mentioned that there would be some points of concern about the ESL. As we know, the state government has long exhibited a fiscal pressure over the years. Is there any independent basis to collect tax on behalf of the Unified School District? What purposes other than the redistributive welfare would underlie the IPad idea? Given Sen's functional concept of equality or ambitionsensitive from Dworkin, equal access to the use of IPads may be agreed. However, I am not sure if the students were to be essentialized on the device in any ways about the learning or other educational activities. I consider if the poverty or homeless people should be in any urgent policy priority? Respectfully.

Author:

Posted Date:

Kiyoung Kim

October 26, 2013 9:19 AM

Hi Ahmed.

Thanks for the interesting post. Actually it would be a sad story that the girl was deported to Kosovo and allowed to be imported into France. As you said, the negative liberty is real and the positive liberty is the kind of power or capability as Sen noted. It has been really 
ambitious to integrate the Europe, and place it under some of uniform public administration. The labor or social welfare policy could be shared in some extent, and its expansion may increase the positive liberty of European citizens. They now progress on the same currency of Euro, common recognition and transfer of academic credits, and many of common policies to facilitate the basis of individual freedom. In this context, the liberty must be positive other than negative. Hence, the level playing field may be assured in any uniform fashion, likely the evolution of US democracy and federalism, which enables an individual to be free to something. The privileges to interstate travel in the US may be applied to France and Kosovo, and the ambit of individual freedom would expand beyond the mere absence of obstacles. In other sense, it may be seen a negative liberty if we take a more universal notion about the human freedom to travel. Therefore, it seems relative in concept and direction. The practical issues in the European integration, I suppose, would trigger a wisdom of public policy and political consensus. It actually poses the challenges as we charted in the decades, including the financial crisis, popular dissention about the common welfare policy and disapproval of European constitution, and so. Given their integration, we agree that the ability to do something on behalf of Europeans would enlarge. However, the wealthier Europeans would be highly reluctant to endorse the European constitution in order to defend their property right and to keep the external constraints to be minimal, which would likely be as the kind of conservatives or libertarians are presumed. It is surely imposing if the positive liberty would encroach upon the public administrators. We could be aware of the dilemma and trouble if European leaders struggle with their tough policy agenda. Respectfully.

Author:

$$
\begin{aligned}
& \text { Kiyoung Kim } \\
& \text { Posted Date: } \\
& \text { October 25, } 2013 \text { 10:41 PM }
\end{aligned}
$$

\section{Hi Cornelius.}

The subjective journalism also once practiced in Korea during 1970's and 1980's. In their view, the wisest man can select the information useful or not harmful to the society. His or her ideal or vision perhaps would be paramount, and generally negates the competition of ideas in the market. The basic premise on the free expression and first amendment right could be undue until some of leader's pursuit is completed. Hence, the normal apprehension about the liberty and equality can dispense way which presumes an understanding "born equal under the God." Galton's way of approach about the leadership quality or Joseph de Maistre's belief would be more powerful in their case. In Korea, the context of 1970's 1980's government is still in dispute and feud about the identity, ethics, and political ideals of Korea as well as its legitimacy among the historians, which hovers around the industrialism and democratic fashion of rule, such as the free press and expression. The vision of economically developed countries can deserve a first priority for some of radical critique as in the case of Bismarck. As Koreans lack the phase in history on the absolute power and national industrialization, say, Queen Victoria in Great Britain around the mid of 19 century or the State Premier Wismark in Germany under the Wilhelm administration, they generally see it inextricable that President Park and other militaristic groups may reign to lead the country in their ambit and vision. Other camp, often democratic adherents, perceived it critical on a dominant ethos of democracy. How do you consider your native country in this frame of analytical lens? Respectfully. 
Author:

Posted Date:

Kiyoung Kim

October 25, 2013 10:03 PM

Hello Nicholas.

Thanks for the interesting post. If people would often be staunch on their religious beliefs, it might go controversial. You just narrated the fact, and I see little basis to provoke any peer. It would be obvious that cutting hands is any cruel and unusual punishment. Stoning to death the women would also be intolerable for the eyes of normal humans, who committed an adultery. On the other hand, as the religious piety often shapes a dominant part of human subsistence as we believe in Jesus Christ, I also suppose it might be plausible for the Muslims in the course of justice administration to impose such a cruel punishment. The point likely underlies in the Eighth Amendment of US Constitution where the punishment should be humanly. We are surprised to see over 200 years of democratic history since 1789 Constitution has been gone as irrelevant with the Muslim states. Hence, their regime would be classed in more proper terms as theocracy other than democracy. In mere a shape of punishment, the Orient feudal history also exposes an inquisitive nature of criminal process, torture and cruel punishment. Hence, we also are skeptical if the "rule of man" could seriate the kind of Muslim, monarchy and communism. We also suspect what nature of human elements is governing or determines the dominant dimension of human as explored by German psychologist G. Freud. Some might be honest if the woman deserves a death who committed an adultery. That might saturate our intuition or the kind of id instantly. That might be most strong depending on an individual or even universally. In this case, the dimension of ego or in some cases super ego, which usually requires a reason and complex notion of phenomenon may get left secondary for them. In Korea, there has long been a debate about the abolition of death penalty. Often the voice of recognition had prevailed and the abolitionists failed to achieve a popular support. A logic and metaphor of advocates on the death penalty rely on the injustice between the perpetrator and victims as well as honest pathos of humanity about the rightfulness of retribution. Hence it involves points of concern covering the criminal policy and justice system, legal pluralism, the tension between the natural laws and positivism, and so. In any case, we may be wiser not to intervene a domestic jurisdiction or internal affairs of nation. The problem may likely be developed into the breach of public peace or harms against the international community. The notions may not be easily defined, however. Nonetheless we may know some course or pattern in the last half century. I also agree on your bright comment about Turkey. It is a bigger country which probably possesses the quality to take a leading role in the advancement of region. In my native country, the saying is "if it is small, it would more likely be cruel." Respectfully.

Author:

Kiyoung Kim

Posted Date:

November 2, 2013 4:17 AM

Hi! Rae. 
You pointed to a serious issue that the e-communication or business could create. I also share the fear and human indignity which the abusive or unconcerned management decision can bring about. While the ethical standard could not be strictly required of private organizations, the ethics and responsibility of business manager likely are only recourse the public could rely on. Along with the invasion of privacy issue, the e-business grossly is not amenable to public controls so that the business entities often are not in the corporate form, but largely limited liability corporate. A notion or value from the concept of fiduciary duty and other traditional ethics embedded on the partnership could easily dispense away. A tax evasion or other aspect of unethical management including the privacy issue actually is challenging. How do you consider any effective way to remedy this phenomenon? How much the education and training program about the entrepreneurship could save this predicament if it were to be mandatory? Respetfully.

Author:

\section{Kiyoung Kim \\ Posted Date: \\ November 2, 2013 3:48 AM}

\section{Hi! Phoenix.}

Great post to see our reality. The tendency of employers on the incentive or bonus system is really awakening if the positive controls often could be acceptable. Some of firms in Korea, often on an advanced footing, also follow the kind of US employer's practice. It seems to permeate to develop delicate grievances about the liberty and equality within the workplace. As the private management largely could go in his own judgment, it might discriminate the smokers or other nonconforming workers to the organizational policy. The employers in the US, concerning the labor relations, would be the kind of beneficiaries who are often unregulated or less intervened by the government. You hinted that the policy would be motivated by the cost benefit calculation. It may work to preserve the workforce in quality standard. However, there could be some of socialization issue if it could discriminate or infringes directly or indirectly with the liberty of person. Some may think that smoking is one way to pursue the happiness as critically related with the freedom of lifestyle. It could be patently offensive if his peer is afforded a large bonus. He may feel alienated or even punished if the workplace is any whole of his life context as often we conceive. In a disappointment, he may head around to rely on the lebens philosophie or murmur why we live. The subjective philosophy of vitalism or importance in the immediacy of experience, as held by Bergson, may have supported his long years of work life, but eventually proves devalued objectively by the managers. Managers would be a strong rationalist to support the organizational policy, but the employee's personal dimension was affected. In any case, we often take it as granted that smoking is worst in the society. And this view likely is prevailing. As a smoker, I also would not recommend others to smoke. How do you consider why the public insurance has yet to be mandated to compensate the victims of smoking and how the incentive scheme could expand in the near future. Is it to be planned on the public enterprises or governmental branches?

Respectfully. 


\author{
Kiyoung Kim \\ Posted Date: \\ November 1, 2013 10:30 PM
}

Hi. Trudy.

Thank you for your practical points in the posting. The federal government, especially the court, seems to impose a rather strong policy in the purpose for some uniform fashion of FELA in the civil proceedings. While the civil procedure would dominantly be a creature of respective state and Erie doctrine were to be in a higher profile, the concept of federal common law seems to be on track about the labor dispute. I am concerned of what you actually mean about "At Will" concerning the state government. Often we have a notion on the Federal Supremacy between the state and Federal governments. How much were it to be variegated if the issue underlies the employment relationships other than the traditional scope of human rights? Is it really true that the state government entertains so ample a discretion or autonomy to manage the labor issues on their own? The employment at will doctrine, in my surmise, could be restricted to the private nature of contract. Your thoughts?

Respectfully.

Author:

Kiyoung Kim

Posted Date:

November 9, 2013 3:53 AM

\title{
Hi. Eric.
}

Your quote of Slotes seems to fairly lead us to any bright line of conceptions about the principle. They would be pivotal to sustain the ethics of public administration, say, equality of liberties, difference principle as well as public value for the maximum advantages of all. We would be bereft of human resources if we end at this point. Hence, the ideals or ultimate principles seemingly could be played out only by ethical leaders. The aspect of ethics would likely be viewed as a litmus test making it distinct from the pure theory of political power. In this context, your illustration of mayor's failure on the ethical standard would be an ingredient in this area of concern. Often the argument or perception seems so persuasive so that we generally are empathetic on the role of capital or businesses and government. They are key engineers and actors to address the status and vision of society. Hence the leadership or entrepreneurship discourse would flourish, and new technologies have advanced the paradigm of business enabling the individuals to form a small or solo business than any other times. Some of small enterprises based on the electronic creativity now could earn a tremendous amount of dollars just on a few work in the internet paradigm. Now the ethics lecturers could attain a social popularity, manage their consulting service, and make a profit. Therefore, the ethics of public administration needs to be approached beyond the traditional form or narrative. For example, e-ethics can be discussed. However, still the check and monitoring context of civil society seems to come into play despite the diversity or pluralistic trend of ethics. A biological environment of industrialism concerns an imbalance in power between the big and small businesses. The monster businesses in Korea, which are small in number and what are called chaebol, could well be compared to the government in terms of 
influence and social prestige. I consider two alternatives can be said about the ways to check and monitor the ethics of administrators, i.e., national and international. Some cases may do good on the popular recall system of elected officials. The civil pressure and the role of press can also function leading the government and enterprises to see a right way. An enactment of ethical code or law would be an immediate way to address the issues as in the international code of ethics required of multinational corporations and the anti-corruption laws as nationally and internationally pursued. With regards to this problem, OECD guidelines would be useful, but the progress seems not to be remarked in each national context. A bad aspect of international approach would be less practical to penetrate the issue to some root basis. Is your case one time incident or over long time? How would the local system operate with or without the popular recall? Is it the country which does not have an anti-corruption statute unlike the US? How much is it serious within the national criminal policy? Recently many beloved entertainers were seriously condemned in Korea who had a shot of propople, the kind of cocaine. Respectfully.

Author:

Posted Date:

Kiyoung Kim

November 9, 2013 3:41 AM

\section{Hi Pamela.}

I agree that the criminal justice system is another battle ground for the social justice besides an econo-political contention. Stand your ground laws had also been debated, and the attributes of each nation would lead to a different design in some area of criminal policy. Given the sparse populace and diversity in demography, it might be wiser to expand the legitimacy and more space for self-defense. That could differ in Korea concerning those factors, as well as particularly on the right to bear arms. The culture and passion then would also distort the criminal justice in a variegated form. As much an extent of similarity with the model penal code could be one alternative to respond with the criticism. That could, however, face the challenges from an independent state ground. Hence I suppose it fairly difficult to assuage for social justice. In Korea, the criminal issue provoking the social injustice would be a burden of attorney fees. In sayings, "The richer being acquitted, the poorer should be found guilty." It might be seen as some of Voltaire-like prose in some dereliction of $18^{\text {th }}$ century common law court on its delay, barrier from the nobility, masked judges of self-interest or social sections. A recent trauma would be the group of Korean superrich who was alleged to commit a fraudulent accounting and embezzlement. Unlike an Enron case, they often have not been delivered a serious sentence which disrupts the public sense of justice. One example to be welcomed, however, was a heightened frame of criminal penalty against the bribed government officers. It was achieved by the amendment of statutes. In the Korean context, the legislature has seldom been criticized because of the wrong or unreasonable criminal policy. The judicial branch had been otherwise. How is it in the state of Florida? Respectfully.

\section{RE: Wk10DiscKHedgepeth-main post}

Author:

Kiyoung Kim

Posted Date:

November 9, 2013 3:33 AM 
Status:

Published

Hi Kristina.

Thanks for the interesting post. I also consider we often face with the challenge between one's fair share and strict egalitarianism. Actually how we perceive or comprehend one's fair share entails a tack of points entangled with the social ethos and system, individual virtue, culture, national moralities, and history. As the state governments in US are debted across the nation, it might trouble if not successful to pass the bills. They perhaps could no longer collect more money from the tax payers. How do you consider if the bill would be proposed in the next time? If in some greatest materialistic affluence or worst level, it seems that a strict egalitarian argumentation may prevail or serve as in decadence or communism. However, the concept of justice and one's fair share could not be automated to sustain any level or quality of welfare provision. The kind of ethics dialogue may be similarly required, beyond the moral administration, of the deprived group or individuals if we are a part of capitalistic industrialism. In this line of thought, I suppose that the moral capitalism and bureaucratic ethics from M. Weber could make some of insight. Respectfully.

Author: Kiyoung Kim

Posted Date:

November 16, 2013 3:54 AM

\section{Hi. Gerald,}

I agree on the point that the employers are actually a prime authority to manage the scope of issues on his business. It bears a proposition of modern human rights about the property and economic freedom. However, I am dubious if the employers are so afforded both with a tax benefit or other governmental incentives and their autonomy of decision still intact.

Phoenix's view rather seems practical that the equitable quota may increase a mutual interest in the society. Some aspect in your viewpoint may imply some of policy failure in effecting the desired ends. The public may prefer a more prudent policy design which depends on the nature of business and some of mandatory trade between the incentives and hiring quota. The vets may not be inferior in certain jobs or businesses. Those may be targeted in primacy and as mandatory. Simultaneously, the policy design in other area of jobs may take its scheme as experimental and relatively expanded as well as in the option to choose between the incentives and hiring. I mean that a pursuit to the end consequence needs to be ensured, and that it seems not even economically meritorious to dump all the cards to the employers. Your thoughts? Thank you for the thought provoking post. Respectfully.

Author: Kiyoung Kim

Posted Date:

November 16, 2013 3:49 AM

Hi. Eric,

I agree on your point that the public education is sacred and deserves a due regard on its autonomy, faith and commitment. The unethical behaviors of teachers are really surprising, 
particularly because they are educators as responsible to breed their students in any exactly opposite way. A cheating is unethical which would neither be controverted nor granted an excuse not varying with the organizational culture or societal expectations. I may add some more about a cheating in the exam context. In Korea, the TOEFL test regularly has long been administered, and some occasion suffer a post-measure null due to a cheating or impermissible conduct of the Korean test takers. A small allegation for the misconduct of other Asian countries also offer a basis to null the whole context of test. Other innocent test takers in this case may feel or ascertain they performed well, but has to obey the ETS decree of invalidation. That may comply with the requirement of justice since the test must have been stained in the whole. However, it may be compared with the Atlanta incident that the TOEFL case failed to deliver a justice specifically unlike that suited for the unethical and cheating teachers. This organizational policy of ETS was not questioned expressly by public or the group of test takers, but often creates an unidentified stigma for the foreign English students or test takers. The test takers could well be disposed that they are collectively distrusted or prejudiced from the ETS' discrete dealings than the normal justice administration. I am not sure if they are refunded of the test fee. However, it would be obvious that the innocent test takers incur other costs or loss of time, effort and opportunity. The organizational culture of ETS may come reasonable as differed if it involves the international context of administration. I also suppose if it may be one example of segmented equity Frederickson presented. However, I verify that the universal quest for any more refined distributive justice comparable to the domestic nature is fairly strong in Korea or perhaps other countries. A discipline or sanction should be for the unethical or cheating test takers, not for the innocent others. Your thoughts? Respectfully.

Author:

Kiyoung Kim

Posted Date:

November 16, 2013 3:00 AM

\section{Hi. Susan.}

Thanks for raising a sensitive issue. A pay rise or public insurance is certainly the point of primary concern the wage workers attend with. As you agree, the response from Phoenix seems realistic and plausibly addresses our current status. A unionization would serve the social justice and equity, which, however, should be economically inefficient and often felt the kind of feasant to merely reproduce. I would be a middle income earner in Korea, and pays much of taxes and public insurance in draining my gross amount to 70 percents in net. I am doubtful if any richer class will pay more than me. The social injustice or inequity is actually squeezing and one of power games in the society. I am merely strolled around several points as instantly inspired. First, the core concept of "competitiveness" has to be questioned. This concept thrills the capital, and they tend to accumulate their income or revenue for the future risk or some more profitable alternatives, and so on. That could distort a more desired status of social reproduction and can marginalize the worse class. We often rest on the idea as quai-religious, "natural selection or survival of fittest," but I may suppose that the tendency on the capital is never a matter of nature, rather a mere superstitious interplay on the mutual distrust among the capitals and competitiveness enslavement. I consider a social consensus could be negotiated or turned into any reality. Second, we can have an idea that the earlier capital was absolutely subjected to the Royal control. The Royal 
charter has been only a ground that they perform the commercial activities as we see in history. Now the logic and hierarchy were overturned that the narrative of economic freedom overwhelms ( $i$ ) intellectually the concept of sovereignty, (ii) practically political power and (iii) ethically public virtue. A worse aspect of monopoly and dominance in the earlier charter enterprises now remains, but the state control or fundament has likely suffered a disrepute or been neglected by the economic power. Third, we would be wise to retrospect a potential of corruptive practices, which may be embroiled between the political power and capitalists. Of course, an enhanced ethics of public administrators across the global jurisdiction may get those incidents rare, but still the kind of transparency is one point of contention that the global enterprises often see as a barrier. I am interesting to know how Wal-Mart, the kind of largest and famed business in the world would run without the public insurance for their employees. In any case, I may feel not incorrect if to see the problem between the physics and humanity or society. In some level of inertia on the capitalistic wake of development, it seems to turn not economic or materialistic, but physical. It is paradoxical as if the fortune global businesses might be on a fetishism with the kind of public highlight, to see their art concept of product, show girls besides the brand new car, journal ranks of business size, business story or ads, but possibly in the sacrifice of employee's basics. My regards.

Author:

Posted Date:

Kiyoung Kim

November 22, 2013 8:50 AM

Hi. Rae.

I agree on your point that the ethics could make it different between life and death. We have bad cases in Korea that the basic rule of corporation, for example, a strict requirement about the division of ownership and management, were disrespected. Owner managers have to be ethical on that point, but some of them had, in many occasions, were criminally punished because of the embezzlement of corporate funds. The ethics issue would be one of popular corner in the news section about the bribery, sexual misconduct, embezzlement, and so. The current state of ethics in the workplace perhaps had never improved over time. The internet or new mode of livings also seems to foster a growth of ethics inertia or callousness. Today, we were reported that some video game was developed to depict a killing spree in the public school. It was restrained to distribute from the public reason. The kind of video games may do good for a leisure time, increase of active brain or so. However, it seems also ill on many of human or mental aspects, and particularly concerning an ethical strand. I consider, in the alternative, that a practice of meditation, such as seen on the Buddhists, could help to develop the mental or psychological status of youths and employees. I also share some of incurable realities, in regret as Pamela hinted, that some unethical actors or employees would grin in the hidden side of organizations. I believe, as you implied, that the successful leadership most always would be a triumphant about the ethics issue of organization. Thanks for the interesting post. Respectfully.

Author:

$\underline{\text { RE: Workplace Ethical and Unethical }}$

Posted Date:

Kiyoung Kim 
November 22, 2013 8:43 AM

Hi. Pamela.

Thank you for the current state of ethics in Florida. We, Koreans, have a same story about the dress attire, but in some different concern. The government regulation was enacted about years ago that the employees could work in no tie and short pants during the mid of summer time. That personal appearance or workplace scene may militate against a decent or loyal impression of public employees, hence, could make them less friendly with the public or clients. Of course, some opposing views sustain its informal or soft imagery as acceptable. In any case, it was considered to bring an advantage that the government can reduce a power consumption during the peak season. It also was viewed to increase a personal autonomy of public employees. I have been surprised to know that Korea is fairly short of power supplies, and the price will be adjusted upwardly for the industrial use of power. The ethics of workplace often would be thought in view of the social accountability, but could be malleable by a combination of external or internal conditions. The ethics code could be creative to double the public value depending on a specific leadership role, which leads to "one stone, two birds" as in the Korean case, i.e., the good public relations and economization of cost. By the way, how does Florida regulate the dress attire in their ethics code? Respectfully.

Author:

\author{
Kiyoung Kim \\ Posted Date: \\ November 23, 2013 4:15 AM
}

Hi Rachel.

Thank you for the insightful post. I agree on your view that the policy decision making, often reshaping the social attention with a funding and allocation of resources, would draw a new direction or public good, and hence social change. I consider the environment and national health would be two of most intense focus or contention in the allocation of national resources in US. It's most advanced profile would perhaps be pioneering, and would later be contaminated into the second group of countries, such as Korea, China, and other new developed economies. The concept may penetrate a terminal of enterprises or firms as we see in the enhanced standard of environmental regulations, for example, Green Mark or others. Korea, under the lady president of administration, now champions the concept of creative economy. It is the kind of puzzle for the policy makers and concerned intellectuals how this leadership focus would bring a social change in Korea. I suppose that the policy makers or leaders would be more competent or ethical if to have a level of awareness about the nature of product, consumerism, decency of human subsistence, and others. For example, there is some doubt if we were to be too generous on the GMO products. The health care system would reflect on the national ethos and possesses the general nature of public good. How we could accommodate it in view of the economic terms would be serious and contentious. I may ask how the policy would progress in the prospect. Is there any chance that the Obama care would be revised? Respectfully. Author:

\title{
RE: Domaneneicka McDaniel: Discussion 2 - Week 12
}




\author{
Kiyoung Kim \\ Posted Date: \\ November 23, 2013 4:12 AM
}

\title{
Hi. Domaneneicka,
}

Your post, on a prose-tone, has to be praised to epitomize a cynic, but veritable essences which we acquired in this term. Your mention, "the vicissitudes trade and industry and national globalization, environment fluctuations and the inflexible antagonism for advertises, deteriorating accepted capitals in the appearance of increasing inhabitants, and developing difficulties of transformation" echoes, and frontiers a long term reflexes on the mind of public administrations. As we consider, the Annalesschoolfrom F. Braudelor other perspectives, for example, Kontratief cycle from Russia allows some time to repose and recourse. Of course, we may see some of lament or criticism from the transnational ideology adherents, notably E. Hobsbawm, against the Annales school and so. I consider, however, that a long projected mindset, as practical and curtailed from the pure ideology, may work in some of persuasion and verity. As you said, the vicissitudes have to be charted seriously to unearth a public value and rethink the points of philosophical reflection. I consider OECD, UN and other science organizations would contribute much in this aspect. For example, the suicide rate compiled by OECD reveals Korea is a worst country. That would certainly be not the case in decades ago. What that long term trend on the suicide rate imply for the policy makers and administrators? Ideology, advertises, transformation may constitute the part of engines or dynamic factors for the policy makers, and could be a precursor to common alteration as you said. In other side, we can see a static, the kind of structural, long term science or assessment to make us on new plane or refurbish. In the progress, I consider the ethics or social change would be ensured a more focus under the circumstances where the econo-political narrative must certainly forge and require. Thank you for the interesting post. Respectfully.

\section{Reference}

Kim, Kiyoung, Fiscal Administration and Public Sector (March 22, 2015). Available at SSRN: http://ssrn.com/abstract=2586039 or http://dx.doi.org/10.2139/ssrn.2586039

Kim, Kiyoung, The Relationship between the Law and Public Policy: Is it a Chi-Square or Normative Shape for the Policy Makers? (September 10, 2014). Social Sciences. Vol. 3, No. 4, 2014, pp. 137-143. doi: 10.11648/j.ss.20140304.15. . Available at SSRN: $\underline{\mathrm{http}: / / \mathrm{ssrn} . \mathrm{com} / \mathrm{abstract}=2577832}$

Kim, Kiyoung, The Leadership of Korean Universities: A Case Study Concerning the Chosun University (March 30, 2014). Science Journal of Business and Management. Vol. 2, No. 2, 2014, pp. 50-66. doi: 10.11648/j.sjbm.20140202.12 . Available at SSRN: http://ssrn.com/abstract $=2577828$

Kim, Kiyoung, A Promenade on the Ethics and Ethical Decision Making: Should Chae be Botched from the Korean Public? (October 1, 2014). International Journal of Advanced 
Research (2014), Volume 2 Issue 10, 15-23.. Available at SSRN:

http://ssrn.com/abstract=2577806

Kim, Kiyoung, A Reform Agenda of WTO Revisited: The Elements of Public Administration and International Organization (December 1, 2013). International Journal of Advanced Research (2013), Volume 1, Issue 10, 634-648.. Available at SSRN:

http://ssrn.com/abstract $=2577787$

Kim, Kiyoung, Amidst the Temper Across the Equality, Equity, Ethics and Responsibility: A Stymied or Pondering Administrator? - A Little Highlight on the Concept of Equality (September 1, 2014). Management and Administrative Sciences Review. 3(6). 909921.. Available at SSRN: http://ssrn.com/abstract=2574739

Kim, Kiyoung, The Strategic Planning: Some Dangling for the Socio-Historical and Organic Lives (September 1, 2014). Management and Administrative Sciences Review, 3(6) 845-857.. Available at SSRN: http://ssrn.com/abstract=2574732

Kim, Kiyoung, The Constitution and Tripartite System of Government: From the Mutiny for the Limited Government Through the Interbranch Subtlety. (September 1, 2014). International Journal of Advanced Research (2014), Volume 2, Issue 9, 392-401. Available at SSRN: $\underline{\text { http://ssrn.com/abstract=2574711 }}$

Kim, Kiyoung, The Separation of Powers Principle: Is it a Lynchpin or Pushpin for the Voyage of American Public? (August 1, 2014). International Journal of Advanced Research (2014), Volume 2, Issue 8, 887-895. Available at SSRN: http://ssrn.com/abstract $=2573560$

Kim, Kiyoung, Theories and Tenets: An Impalpable Troll for the Policy Makers, Research Officers and Administrators? (March 4, 2015). International Journal of Interdisciplinary and Multidisciplinary Studies (IJIMS), 2014, Vol 1, No. 8, 30-50.. Available at SSRN: http://ssrn.com/abstract=2573526

Kim, Kiyoung, Human Rights: Are They Just a Tweak for the Policy Makers or Administrators? (March 3, 2015). European Academic Research, Vol. II, Issue 6, September 2014. Available at SSRN: http://ssrn.com/abstract=2572951

Kim, Kiyoung, A Case Study Concerning the Strategic Plan: V2020 of Chosun University (.October 20, 2013). Science Journal of Business and Management. Vol. 1, No. 4, 2013, pp. 43-57. doi: 10.11648/j.sjbm.20130104.11. Available at SSRN: http://ssrn.com/abstract $=2572943$

Kim, Kiyoung, Two Illustrations from South Korea and Some Reflections About the Public Administration Studies: Are We Granted to Pillory the Ethics or Social Justice? (September 2, 2014). International Journal of Philosophy 2014; 2(4): $48-59$ doi: 10.11648/j.ijp.20140204.11. Available at SSRN: http://ssrn.com/abstract=2571903 
